\title{
From morphology to molecules: a combined source approach to untangle the taxonomy of Clessinia (Gastropoda, Odontostomidae), endemic land snails from the Dry Chaco ecoregion
}

\author{
Maria Gabriela Cuezzo ${ }^{\text {Corresp., }}{ }^{1}$, Maria Jose Miranda ${ }^{1}$, Roberto Eugenio Vogler ${ }^{2}$, Ariel Anibal Beltramino ${ }^{\text {Corresp. }}{ }^{2}$ \\ ${ }^{1}$ Facultad de Ciencias Naturales, Instituto de Biodiversidad Neotropical (IBN), Consejo Nacional de Investigaciones Científicas y Técnicas - Universidad \\ Nacional de Tucumán, San Miguel de Tucumán, Tucumán, Argentina \\ 2 Facultad de Ciencias Exactas, Químicas y Naturales, Instituto de Biología Subtropical (IBS), Consejo Nacional de Investigaciones Científicas y Técnicas - \\ Universidad Nacional de Misiones, Posadas, Misiones, Argentina
}

Corresponding Authors: Maria Gabriela Cuezzo, Ariel Anibal Beltramino

Email address: gcuezzo@webmail.unt.edu.ar, beltraminoariel@hotmail.com

\section{ABSTRACT}

Background. Land gastropods of the Dry Chaco merit special attention because they comprise a highly diverse but barely studied group. Clessinia Doering, 1875 are typical inhabitants of this ecoregion. The inclusion of their distribution areas into Spixia range, their shell shape similarities, and a former molecular study raised doubts on the monophyly of this genus. The present study review the species of Clessinia, under a morphological, geometric morphometrics and molecular combined approach.

Methods. Adults were collected, photographed, measured, and dissected for anatomical studies. Shell ultrastructure was studied with scanning electron microscope. Geometric morphometric analyses on shells were performed testing if they gave complementary information to anatomy. Two mitochondrial genes, and a nuclear region were studied. Phylogenetic reconstructions to explore the relationships of DNA sequences here obtained to those of Clessinia and Spixia species from GenBank were performed. Results. Species description on shell, periostracal ornamentation and anatomy is provided. We raised former Clessinia cordovana striata to species rank, naming it as Clessinia tulumbensis sp. nov. The periostracum, consisting of hairs and lamellae, has taxonomic importance for species identification. Shell morphometric analyses, inner sculpture of penis and proportion of the epiphallus and penis, were useful tools to species identification. Nuclear markers do not exhibit enough genetic variation to determine species relationships. Based on the mitochondrial markers, genetic distances among Clessinia species were greater than $10 \%$, and while C. cordovana, C. nattkemperi, and C. pagoda were recognized as distinct evolutionary genetic species, the distinction between $C$. stelzneri and $C$. tulumbensis sp. nov. was not evident. Clessinia and Spixia were paraphyletic in the molecular phylogenetic analyses. Species of Clessinia here treated have narrow distributional areas and are endemic to the Chaco Serrano subecoregion, restricted to small patches within the Dry Chaco. Clessinia and Spixia are synonymous, and the valid name of the taxon should be Clessinia Doering, 1875 which has priority over Spixia Pilsbry \& Vanatta, 1894. Discussion. Our results support the composition of $C$. cordovana complex by three species, $C$. cordovana, $C$. stelzneri and $C$. tulumbensis sp. nov. The low genetic divergence between $C$. stelzneri and $C$. tulumbensis sp. nov. suggests that they have evolved relatively recently. The former Spixia and Clessinia are externally distinguished because Clessinia has a detached aperture from the body whorl forming a cornet, periostracal micro sculpture extended over dorsal portion of the peristome, five inner teeth on the shell aperture instead of three-four found in Spixia. Morphological similarities exists between both genera in shell shape, type of periostracum microsculpture, reproductive anatomy, 
besides the overlap in geographic ranges. 


\section{COVER PAGE}

2

3 From morphology to molecules: a combined source approach to untangle the taxonomy of

4 Clessinia (Gastropoda, Odontostomidae), endemic land snails from the Dry Chaco ecoregion 5

6 María Gabriela Cuezzo ${ }^{1, *}$, María José Miranda ${ }^{1}$, Roberto Eugenio Vogler ${ }^{2}$ and Ariel Aníbal

7 Beltramino $^{2 *}$

91 Instituto de Biodiversidad Neotropical (IBN), Consejo Nacional de Investigaciones Cientificas y

10 Técnicas - Universidad Nacional de Tucumán, Facultad de Ciencias Naturales, Miguel Lillo 205,

114000 San Miguel de Tucumán, Tucumán, Argentina

122 Instituto de Biología Subtropical (IBS), Consejo Nacional de Investigaciones Científicas y Técnicas

13 - Universidad Nacional de Misiones, Facultad de Ciencias Exactas, Químicas y Naturales, Rivadavia

14 2370, N3300LDX Posadas, Misiones, Argentina

15

16 *Corresponding authors:

17 María Gabriela Cuezzo

18 Universidad Nacional de Tucumán, Facultad de Ciencias Naturales, Miguel Lillo 205, 4000,

19 Tucumán, Argentina

20 Email address: gcuezzo@webmail.unt.edu.ar

21

22 Ariel A. Beltramino

23 Departamento de Biología, Facultad de Ciencias Exactas, Químicas y Naturales, Universidad Nacional 24 de Misiones, Rivadavia 2370, N3300LDX, Posadas, Misiones, Argentina

25 Email address: beltraminoariel@hotmail.com 


\section{ABSTRACT}

30 Background. Land gastropods of the Dry Chaco merit special attention because they comprise a 31 highly diverse but barely studied group. Clessinia Doering, 1875 are typical inhabitants of this ecoregion. The inclusion of their distribution areas into Spixia range, their shell shape similarities, and a former molecular study raised doubts on the monophyly of this genus. The present study review the species of Clessinia, under a morphological, geometric morphometrics and molecular combined approach. Methods. Adults were collected, photographed, measured, and dissected for anatomical studies. Shell ultrastructure was studied with scanning electron microscope. Geometric morphometric analyses on shells were performed testing if they gave complementary information to anatomy. Two mitochondrial genes, and a nuclear region were studied. Phylogenetic reconstructions to explore the relationships of DNA sequences here obtained to those of Clessinia and Spixia species from GenBank were performed. Results. Species description on shell, periostracal ornamentation and anatomy is provided. We raised former Clessinia cordovana striata to species rank, naming it as Clessinia tulumbensis sp. nov. The periostracum, consisting of hairs and lamellae, has taxonomic importance for species identification. Shell morphometric analyses, inner sculpture of penis and proportion of the epiphallus and penis, were useful tools to species identification. Nuclear markers do not exhibit enough genetic variation to determine species relationships. Based on the mitochondrial markers, genetic distances among Clessinia species were greater than $10 \%$, and while C. cordovana, C. nattkemperi, and C. pagoda were recognized as distinct evolutionary genetic species, the distinction between $C$. stelzneri and $C$. tulumbensis sp. nov. was not evident. Clessinia and Spixia were paraphyletic in the molecular phylogenetic analyses. Species of Clessinia here treated have narrow distributional areas and are endemic to the Chaco Serrano sub-ecoregion, restricted to small patches within the Dry Chaco. Clessinia and Spixia are synonymous, and the valid name of the taxon should be Clessinia Doering, 1875 which has priority over Spixia Pilsbry \& Vanatta, 1894. Discussion. Our results support the composition of $C$. cordovana complex by three species, C. cordovana, C. stelzneri and C. tulumbensis sp. nov. The low genetic divergence between $C$. stelzneri and C. tulumbensis sp. nov. suggests that they have evolved relatively recently. The former Spixia and Clessinia are externally distinguished because Clessinia has a detached aperture from the body whorl forming a cornet, periostracal micro sculpture extended over dorsal portion of the peristome, five inner teeth on the 
60 shell aperture instead of three-four found in Spixia. Morphological similarities exists between

61 both genera in shell shape, type of periostracum microsculpture, reproductive anatomy, besides

62 the overlap in geographic ranges.

63

64

65

66

67

68

69

70

71

72

\section{INTRODUCTION}

Taxonomy is a crucial discipline in biology if practiced within an evolutionary framework (Dubois, 2017). The taxonomic and biodiversity crisis requires a strong acceleration of the work of exploration, study, description and naming of the species of the globe (Wheeler, Raven \& Wilson, 2004; Dubois, 2007; Dubois, 2010). However, there is a tendency towards a strong decrease in morphological and anatomical studies while 'replacing' them with molecular analyses which are unable, if are used alone, to provide the wealth of diverse information on organisms which morphology, anatomy and other biological studies offer (Dubois, 2017). Species are hypotheses, and as such it is required that they make predictions (that more data of approximately the same quality will support such groupings) and are thereby testable (that more data of approximately the same quality do not suggest alternative groupings) (Wheeler, 2004; Valdecasas, Williams \& Wheeler, 2008). Then, identification of species utilized in a study impacts all subsequent comparisons or any further studies on species-specific traits or attributes.

The combination of morphological and ecological information with different molecular markers can be a good method of species identification, because it can provide an accurate perspective on evolutionary history of an organism and its taxonomic relationships (Davison, Blackie \& Scothern, 2009). In this way, new methods do not replace, but complement the traditional, tested methods and procedures (Wheeler, Raven \& Wilson, 2004). Geometric morphometrics is a useful tool to accurately analyze shell variability decomposing shell form into size and shape in each species (Carvajal-Rodriguez, Conde-Padin \& Rolan-Alvarez, 2005; Cruz, Pante \& Rohlf, 2012; Greve et al., 2012). When multiple sources are used for analyzing a taxonomic problem, agreement among them is expected, but differences between them can also be rich revealing different aspects of a same problem and contributing to interpretation of the evolutionary patterns. Conflicts between different analyses can stimulate a new more detailed investigation of the characters and taxa involved. 
89

90

The purpose and framework of our work is to study and identify endemic species of the Dry Chaco ecoregion in Argentina (sensu Olson et al., 2001) as a first step to reevaluate its taxonomic information and conservation status. The Dry Chaco is an ecoregion that merits special attention from biodiversity studies because it represents the largest continuous dry forest remnant in South America. In the past decades it ranked second in terms of deforestation after the Amazonian rainforest, mostly due to the expansion of soybean crops and planted pastures (Gasparri \& Grau, 2009). Although this area is suspected to host a rich gastropod fauna, there are no current formal studies focusing on the diversity of molluscan taxa in the area.

Odontostomidae is a species-rich family of pulmonate snails distributed in South America, southern to the Amazonia. This charismatic group is generally diagnosed by the presence of teeth and lamellae obstructing the shell aperture (Pilsbry, 1901-1902), but this diagnosis falls short because species of some odontostomid genera as Anctus von Martens, 1860 and some Cyclodontina Beck, 1837 have no apertural teeth. Odontostomidae is understudied, most of the genera shows a lack of clear-cut diagnostic characters, and the species composition of each genus is still a matter of controversy. The last revised family nomenclator (Bouchet et al., 2017) classified Odontostomidae with family category. However, it was hypothesized as a paraphyletic group by molecular studies (Breure, Groenenberg \& Schilthuizen, 2010). Published phylogenetic hypotheses based on morphological characters are lacking for Odontostomidae.

The genus Clessinia was created by Doering in 1875 and is composed of endemic rare species from central Argentina in the Dry Chaco ecoregion. Although some other species from Brazil, such as Bulimus costatus Pfeiffer 1848, has been recently classified within the genus Clessinia (Simone, 2006; Breure \& Ablett, 2012), we believe that their taxonomic assignment are not correct and should be carefully reviewed under new information. The distribution area of Clessinia overlaps largely that of Spixia Pilsbry \& Vanatta, 1898, and to a lesser degree with that of Plagiodontes Doering, 1877 and Epiphragmophora Doering, 1874. The inclusion of Clessinia's distribution area into Spixia range, their similarities in general shell shape, and a former molecular analysis (Breure \& Romero, 2012) raised doubt on the monophyly of this genus. This situation was exacerbated by the fact that morphological, anatomical and molecular studies on both genera, Clessinia and Spixia, are scarce. Moreover, most of the material kept in malacological collections generally consists in old, abraded dry shells lacking periostracum and 
119 even, when soft portions of the body are available, they are mostly not suitable for anatomical or 120 molecular studies.

121 The objective of the present study was to revise the species of the genus Clessinia, under a

122 morphological, geometric morphometrics and molecular combined approach. One of the main

123 questions we would like to answer is how many species composed the Clessinia cordovana

124 complex, and how they are defined. For this, we first hypothesized that the ultrastructure of the

125 shell periostracum will provide new taxonomic characters useful for species identification.

126 Second, the detailed study on the genitalia of specimens from different localities over the total

127 area of distribution will result as strong evidence for species identification. And third, that a

128 geometric morphometric analysis, differentiating shell shape from size, will enable species

129 separation in Clessinia. Finally, we also want to provide new molecular evidence of the species

130 included in this work and test the validity of the genus Clessinia due to the hypothesis of

131 paraphyly raised by Breure \& Romero (2012).

132

\section{MATERIALS \& METHODS}

134 Study site

135 The area where the study was focused is the Dry Chaco on which the majority of species of

136 Odontostomidae are in part or completely distributed. Extending over north-central Argentina, 137 western Paraguay, and Southeastern Bolivia, the Dry Chaco (15\% of Argentina surface) is one of

138 the largest remaining patches of forest/savanna ecosystems in Latin America (Grau et al., 2015).

139 The Dry Chaco $\left(225,468 \mathrm{~km}^{2}\right)$ is dominated by deciduous forests over extensive lowland plains

140 and mountains (below 1,600 m) with arid and semi-arid climates (less than $900 \mathrm{~mm}$ of annual

141 rainfall) (Izquierdo \& Grau, 2009). This ecoregion is subdivided into three sub-ecoregions: the

142 Arid Chaco, the Semiarid Chaco, and the Chaco Serrano (Morello et al., 2012). The Semiarid

143 Chaco extends in the middle of the Dry Chaco area and is characterized by a vegetation of semi-

144 deciduous forest with shrubs and grassland that extend from the highlands to the plains. The

145 Chaco Serrano has an open xerophytic forest with shrubs and granitic and sedimentary rocks. It

146 extends from north to central south of Argentina in a narrow strip, subdivided into several

147 patches in the southern part, embedded in the Arid Chaco sub-ecoregion. The Chaco Serrano

148 form a transition zone between humid to more xeric forests. The Arid Chaco is composed by a 
149 xeric forest with close canopy. It occupies a wide area that limits with the Monte and the Espinal

150 ecoregions (Morello et al., 2012).

151

\section{Distribution}

153 Species distribution is based on point records (geographical coordinates) of species occurrences

154 obtained through field work in the Córdoba and Catamarca provinces, Argentina between 2006

155 and 2017. All specimens collected were deposited in the Instituto de Biodiversidad Neotropical

156 (IBN), Instituto-Fundación Miguel Lillo (IFML-MOLL), Tucumán, Argentina and the

157 malacological collection at the Instituto de Biología Subtropical, Misiones, Argentina (IBS-Ma).

158 Additionally, we examined other specimens and obtained records from the following collections:

159 IBN; IFML-Moll; MACN-In, Museo Argentino de Ciencias Naturales "Bernardino Rivadavia”,

160 Buenos Aires, Argentina (Table S1). This information was used to digitize geographical range

161 maps and depict the extent of occurrence of each species by using QGis 2.18

162 (http://qgis.osgeo.org). Shapefiles layers corresponding to administrative areas of Argentina were

163 obtained from DIVA resources (http://www.diva-gis.org/gdata) and Instituto Geográfico

164 Nacional (IGN, http://www.ign.gob.ar/sig). Classification of Argentinean ecoregions follows

165 Olson et al. (2001), but ecoregions and sub-ecoregions shapefiles were obtained from ProYungas

166 Fundation (http://siga.proyungas.org.ar/recursos).

167

\section{Collecting and Preservation}

169 Hand collection of live adult specimens and dry shells of Clessinia were carried out on rocky outcrop in xerophytic areas of Córdoba and Catamarca provinces, Argentina. Specimens collected were photographed alive, then drawn in water for relaxation previous to fixation in 96\% ethanol, body preservation was done using 75\% ethanol. Several specimens were fixed

173 directly in absolute ethanol, without relaxation in water, for molecular studies. Special attention

174 was paid to the shells to preserve the periostracum structures. Shells were cleaned in an

175 ultrasonic cleaner, air dried, and then photographed in ventral, dorsal and lateral positions, and

176 kept in plastic boxes separated from the bodies. Photographs were taken using a Zeiss Stemi 508

177 with ActionCam, and measured using the software ImageJ 1.49 (Schneider, Rasband \& Eliceiri,

178 2012; Figs. 1A-D). Voucher specimens for the anatomical study performed were deposited at the

179 IBN collection: IBN 886, C. cordovana (Pfeiffer, 1855); IBN 882, C. stelzneri (Doering, 1875); 
180 IBN 883, C. tulumbensis sp. nov.; IBN 890, C. pagoda Hylton Scott, 1967 and IBN 878, C.

181 nattkemperi (Parodiz, 1944). Voucher specimens for genetic studies were: IBN 530, Spixia

182 minor (d'Orbigny, 1837); IBN 878, C. nattkemperi; IBN 880, Spixia cuezzoae Salas Oroño,

183 2010; IBN 881, Spixia holmbergi (Parodiz, 1941); IBN 882, C. stelzneri; IBN 883, C.

184 tulumbensis sp. nov.; IBN 885, Plagiodontes daedaleus (Deshayes, 1851); IBN 886, C.

185 cordovana; IBN 890, C. pagoda.

186

187 Morphological studies

188 The different zones in which the shell aperture is divided: basal, palatal (divided in upper and

189 lower zones for internal teeth) and parietal, are the same as used by Solem (1966). Differences in

190 terminology between a tooth and a lamella follow Cuezzo (2003). Anatomical information was

191 obtained by dissecting 10 adult specimens per species under a Leica MZ6 stereoscope; dissected

192 parts were illustrated with the aid of a camera lucida. Terminology for anatomical descriptions

193 follows Tompa (1984). Terms proximal and distal refers to the position of an organ or part of an

194 organ in relation to the gamete flow from ovotestis (proximal) to genital pore (distal), as in

195 previous works (Cuezzo, 1997; Cuezzo, 2006). The limit between epiphallus and penis is based

196 on the sculpture of their inner wall. Radula, jaw and shell were observed and photographed with

197 a SEM Zeiss Supra 55VP at the Integral Center of Electron Microscopy (CIME) of the National

198 University of Tucumán, Argentina. The terms Diagnosis and Definition for the species

199 description are used as established in the glossary of the International Code of Zoological

200 Nomenclature (http://www.iczn.org).

201

202 Morphometrics

203 Traditional linear shell measurements were taken from specimens of each species according to

204 availability (Fig. 1). The number of whorls was calculated following Kerney \& Cameron (1979).

205 Descriptors of measurements and proportions (mean, standard deviation, and range) were also

206 calculated in each case. Measurements of type material of each species is recorded in the species

207 description with the following arrange: maximum-minimum (mean) of each measurement.

208

209 Geometric morphometrics 
210 This study was performed to quantitatively analyze the relationship between shape and size of

211 the species of Clessinia, testing if they gave complementary information to our anatomical

212 observations or differed from them. On these grounds, the geometric morphometric analysis was

213 performed with 15 to 61 specimens per species according to their availability, totalizing 144

214 specimens used (Table 1). Specimens were taken from different populations ranging the whole

215 species distribution area. Images of shell in ventral view of adult specimens were converted to

216 TPS format with TpsUtil 1.68 (Rohlf, 2016a). Shell landmarks, discrete anatomical loci that are

217 homologous in all individuals in the analysis, expressed by coordinates, were chosen in each

218 case. Landmarks were located on the same shell whorl number so that comparisons among them

219 were possible, even when shells have different whorl numbers. Fourteen landmarks from ventral

220 view were digitized by means of the TpsDig2 2.26 program (Rohlf, 2016b; Figs. 1E-F).

221 Landmarks selected in ventral view represent the general shell shape features such as body

222 whorl, spire and aperture. A second analysis was performed using only those species of the

223 cordovana-group from nine geographic localities to enhance the possible differences among

224 them. Finally, another morphometric analysis was performed using six landmarks in lateral shell

225 side (Fig. 1F) to test if the degree of detach of the aperture was significative for species

226 delimitation. The morphometrics analyses were performed with MorphoJ 1.06d (Klingenberg,

227 2011). The shape symmetric components associated with position, rotation, translation and size

228 were removed using the Procrustes fit. A multivariate regression of the Procrustes coordinates

229 against logarithm of centroid size, defined as square root of the sum of the squared distances of

230 each landmark to the centroid of the landmark configuration (Bookstein, 1991), was performed

231 to asses allometric effects (i.e., if shell shape variation is correlated with size). A permutation test

232 was also performed with 10,000 rounds to evaluate the independence among the variables.

233 Variation in the shell shape was examined using Canonical Variate Analysis (CVA).

234

235

DNA extraction, polymerase chain reaction (PCR) amplification, and DNA sequencing

Total DNA was extracted from $3 \mathrm{~mm}^{3}$ samples of foot muscle of ethanol-preserved specimens

237 by means of a cetyltrimethylammonium bromide (CTAB) protocol (Beltramino et al., 2018). We

238 selected 16 samples belonging to Clessinia and Spixia species and the outgroup species

239 Plagiodontes daedaleus. Collection information and GenBank accession numbers for the

240 samples analyzed are presented in Table 2. Partial sequences of the mitochondrial $16 S-r R N A$ and 
241 the cytochrome oxidase subunit I (COI) genes, and a nuclear region including the 3 ' end of the

$2425.8 S-r R N A$ gene, the complete ITS-2 region, and the $5^{\prime}$ end of $28 S-r R N A$ gene (hereafter referred

243 to as ITS-2) were amplified by means of the primers 16SF-104 (5' - GAC TGT GCT AAG GTA

244 GCA TAA T-3') and 16SR-472 (5'- TCG TAG TCC AAC ATC GAG GTC A-3') for 16S-rRNA

245 (Ramírez \& Ramírez, 2010), LCO1490 (5'-GGT CAA CAA ATC ATA AAG ATA TTG G-3')

246 and HCO2198 (5'-TAA ACT TCA GGG TGA CCA AAA AAT CA-3') for COI (Folmer et al.,

247 1994), and LSU-1 (5'-CTA GCT GCG AGA ATT AAT GTG A-3') and LSU-3 (5'-ACT TTC

248 CCT CAC GGT ACT TG-3') for the ITS-2 (Wade \& Mordan, 2000). The amplification of the

$24916 S-r R N A$ gene was performed as in Rumi, Vogler \& Beltramino (2017) in a T21 thermocycler

250 (Ivema Desarrollos). The amplification of the COI gene was conducted following Vogler et al.

251 (2014) and run on a T18 thermocycler (Ivema Desarrollos). The amplification of the ITS-2

252 region was performed in a total volume of 50 $\mu$ l containing 30-50 ng of template DNA, each

253 primer at $0.25 \mu \mathrm{M}, 1 \mathrm{X}$ reaction buffer, $0.2 \mathrm{mM} \mathrm{dNTPs}, 2.5 \mathrm{mM} \mathrm{MgCl} 2$ and $2 \mathrm{U}$ Taq Pegasus

254 DNA polymerase (Productos Bio-Lógicos, Argentina). The amplification was conducted in a

255 T18 thermocycler as follows: after an initial denaturing for $3 \mathrm{~min}$ at $94{ }^{\circ} \mathrm{C} ; 35$ cycles of $1 \mathrm{~min}$ at

$25694^{\circ} \mathrm{C}, 1 \mathrm{~min}$ at $50{ }^{\circ} \mathrm{C}, 1 \mathrm{~min}$ at $72{ }^{\circ} \mathrm{C}$ were performed; followed by a final extension at $72{ }^{\circ} \mathrm{C}$ for

$2575 \mathrm{~min}$. The success of PCR reactions was verified by agarose gel electrophoresis. The PCR

258 products were purified by means of an AccuPrep PCR Purification Kit (Bioneer, Korea).

259 Following purification, both DNA strands for each gene were then directly cycle-sequenced

260 (Macrogen Inc., Seoul, South Korea). The resulting sequences were trimmed to remove the

261 primers, and the consensus sequences between forward and reverse sequencing were obtained by

262 means of the BioEdit 7.2.5 software (Hall, 1999). For Spixia minor, the repeated attempts to

263 amplify the COI and ITS-2 regions were unsuccessful, and for this species only the $16 S-r R N A$

264 was included in further analyses.

265

266 Sequence data, phylogenetic analyses, and molecular species delimitation

267 The sequence alignment of the $16 S-r R N A$ gene was performed with MATFF 7 via the

268 MATFF web-server (https://mafft.cbrc.jp/alignment/server/; Katoh, Rozewicki \& Yamada,

269 2017); the COI and ITS-2 alignments were performed with Clustal X 2.1 (Larkin et al., 2007).

270 Genetic distances among the Clessinia and Spixia species were investigated in MEGA X

271 software (Kumar et al., 2018) using the number of differences $(p)$ and the Kimura's two- 
272 parameter (K2P) substitution model. Phylogenetic analyses were performed using Maximum

273 Likelihood (ML), and Bayesian inference (BI). For both analyses, the COI and I6S-rRNA

274 datasets were concatenated to improve the resolution of phylogenetic reconstructions. The total

275 length of the analyzed matrix was $992 \mathrm{bp}$. In addition, COI-based phylogenetic reconstructions

276 were performed to explore the phylogenetic relationships of the DNA sequences here obtained to

277 those of other Clessinia and Spixia species from various locations available in GenBank (Table

278 2). The total length of this matrix was $655 \mathrm{bp}$. We also obtained phylogenetic trees for the

279 nuclear region as an independent marker based on an $832 \mathrm{bp}$ matrix. In all phylogenetic

280 reconstructions, Plagiodontes daedaleus was used as outgroup species, with Cerion incanum

281 (Leidy, 1851) used as an additional outgroup for the mitochondrial DNA sequence data.

282 Sequences of $C$. incanum were extracted from the complete mitochondrial genome for the

283 species (KM365085; González et al., 2016).

284 The ML analysis was conducted with PhyML 3.0 (Guindon et al., 2010) available via the

285 ATGC bioinformatics platform (http://www.atgc-montpellier.fr/) with the Nearest-Neighbor

286 Interchange (NNI) branch swapping algorithm. Substitution models were selected using the SMS

287 program (Lefort, Longueville \& Gascuel, 2017) according to Akaike Information Criterion

288 (AIC): GTR $+\mathrm{I}+\mathrm{G}$ model for the concatenated dataset and the $\mathrm{COI}$ alignment that included

289 GenBank sequences, and GTR $+\mathrm{G}$ for the ITS-2 sequences. Nodal support values were computed

290 by bootstrapping with 1,000 replicates (Felsenstein, 1985). The BI was conducted in MrBayes

291 3.2.6 (Ronquist et al., 2012) with the same substitution models used in the ML analyses, as

292 identified in jModelTest 2.1.7 (Darriba et al., 2012) by means of the corrected Akaike

293 Information Criterion (AICc). Two runs were performed simultaneously with four Markov

294 chains for 2 million generations, sampling every 200 generations. The first 1,001 samples of

295 each run were discarded as burn-in, and the remaining 18,000 trees were used to estimate

296 posterior probabilities.

297 The Automatic Barcode Gap Discovery (ABGD) method, which clusters sequences in

298 putative species based on differences between intraspecific and interspecific distance variation

299 (Puillandre et al., 2012) was used to explore species boundaries in the concatenated dataset, and

300 the larger $C O I$ dataset including sequences from GenBank. These aligned datasets (excluding the

301 outgroups) were analyzed via the ABGD web-server (http://wwwabi.snv.jussieu.fr/public/abgd/)

302 using the K2P model (Vogler et al., 2016). The minimum relative gap width was set to 0.5, and 
303 the default range of prior values for maximum divergence of intraspecific diversity $(\mathrm{P})$ from

3040.001 to 0.1 was used. In addition, the $K / \theta$ method was used to assess the status of Clessinia

305 species under the Evolutionary Genetic Species Concept (EGSC) (Birky et al., 2010; Birky

306 2013). This method is based on basic coalescent theory and requires a phylogenetic tree as well

307 as distance matrices to estimate the mean genetic differences within $(\theta)$ and between clades $(K)$,

308 in order to identify clades that are diverged enough to be considered separate species (Birky

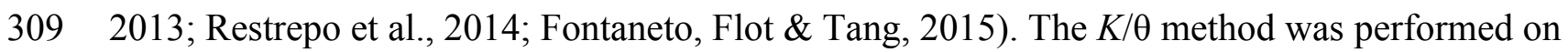

310 the concatenated dataset following Schön et al. (2012) and Birky (2013). Those clades with $K / \theta$

311 ratios $\geq 4$ were considered to represent sequences that come from different evolutionary species

312 with probability $\geq 0.95$ (Birky 2013 and references therein). Mean pairwise differences between

313 clades were estimated in MEGA X.

314

315 Nomenclatural acts. The electronic version of this article in Portable Document Format

316 (PDF) will represent a published work according to the International Commission on Zoological

317 Nomenclature (ICZN), and hence the new names contained in the electronic version are

318 effectively published under that Code from the electronic edition alone. This published work and

319 the nomenclatural acts it contains have been registered in ZooBank, the online registration

320 system for the ICZN. The ZooBank LSIDs (Life Science Identifiers) can be resolved and the

321 associated information viewed through any standard web browser by appending the LSID to the

322 prefix http://zoobank.org/. The LSID for this publication is:

323 urn:lsid:zoobank.org:pub:8DB0CC34-AE26-44BA-B7F8-A5F17254BD13. The online version

324 of this work is archived and available from the following digital repositories: PeerJ, PubMed

325 Central and CLOCKSS.

326

327 RESULTS

328 Morphology

329 Periostracal ornamentation

330 Periostracal structures are particularly well developed in Clessinia, consisting in hairs of 331 different lengths and densities, spines and rounded to quadrate lamellae. These structures were

332 useful tools for species recognition. Both, C. cordovana and C. stelzneri show periostracal hairs

333 on the teleoconch surface, being notably longer among C. cordovana specimens, with more 
334 prominent hairs in specimens from Sierra de Pocho area in Córdoba. Periostracal hairs are

335 shorter and more densely arranged in C. stelzneri. Teleoconch surface is traversed by periostracal

336 spiral rows in the three species of the cordovana-group, with a greater number of minor spiral

337 rows between the major hair bearing rows in C. stelzneri. In C. tulumbensis sp. nov. the

338 periostracal hairs are absent and the spiral rows are more scatter. In Clessinia pagoda

339 periostracal structures consist of spiral rows bearing rounded to quadrate lamellae slightly

340 imposed over each other. In Clessinia nattkemperi lamellae are spine-shaped with wider bases

341 almost as a triangle. All Clessinia species have an interesting pattern of periostracal

342 microsculpture in the space between spiral rows which is traversed by axial irregular micro folds

343 cut by spiral or diagonal micro ribs forming an irregular net.

Anatomy

346 Anatomical information obtained on the pallial, digestive and reproductive systems of each

347 species is described in the taxonomic section.

348

349

Morphometrics

350 We extracted meaningful measurement differences among taxa and present these in a summary

351 table (Table 1). In the geometric morphometric analysis performed to evaluate shell shape

352 differences in ventral view among all Clessinia species (Fig. 2A), allometric relationships

353 between shape and size was registered $(4.94 \%$ of the total amount of shape variation; $p<0.001)$.

354 The shell shape variation among the five taxa considered was successfully discriminated using

355 CVA of the residuals from the regression of shape on centroid size. On the canonical axis 1

356 (CV1) (captures $74.41 \%$ of the total shell shape variation), the main changes in shell shape are

357 associated with the expansion of the base of spire and body whorl. Specimens of C. cordovana

358 with high scores on CV1 have thinner whorls, whereas specimens of C. nattkemperi and $C$.

359 pagoda with low scores, have both spire and body whorl more expanded. It also indicates that

360 when shells are thinner they are also taller while shells more expanded are less tall. On CV2 axis

361 (captures $11.56 \%$ of the total shell shape variation) the main shell shape variation referred to the

362 shape of the aperture and the degree of inclination of the suture before the aperture (landmarks 6

363 and 10, Fig. 1E). High scores in specimens of C. nattkemperi indicate a marked expansion in the

364 central portion of the aperture. Specimens of C. pagoda showing low scores exhibit an oval 
365 shaped aperture, while C. tulumbensis sp. nov., C. stelzneri and C. cordovana have intermediate

366 forms of aperture between C. pagoda and C. nattkemperi with a higher inclination of the suture.

367 A second analysis was performed to evaluate shell shape differences in ventral view using

368 specimens of the cordovana species-group alone (Fig. 2B). As a result, allometric relationships

369 between shape and size was registered (12.64\% of the total amount of shape variation; $p<$

370 0.0001). Residuals from the regression of shape on centroid size were used in the analysis. On

371 the canonical axis 1 (CV1) (captures $57.49 \%$ of the total shell shape variation), the main changes

372 in shell shape are associated with the expansion of the base of spire and body whorl. Specimens

373 of C. cordovana from Cerro de la Cruz and the area surrounding San Marcos Sierra, plus

374 specimens of C. tulumbensis sp. nov. from Virgen de Fatima, Route 16 and Cerro Colorado have

375 high scores on CV1, showing thinner whorls. Specimens of C. stelzneri from Cerro San Vicente,

376 C. tulumbensis sp. nov. from route between Dean Funes and Tulumba, Tulumba and San Jose de

377 la Dormida and specimens of C. cordovana from Sierra de Pocho have low scores, showing

378 whorls of the spire and body whorl more expanded. On CV2 axis (captures $23.66 \%$ of the total

379 shell shape variation) the main shell shape variation is related with the shape of the aperture and

380 the expansion of the first whorl of the shell. High scores in specimens of C. tulumbensis sp. nov.

381 from all localities considered, except Cerro Colorado, indicate wider first whorls of the shell and

382 a thinner aperture. Specimens of C. stelzneri and C. cordovana, with low scores, exhibit thinner

383 fist whorl of the shell and more expanded central portion of the aperture. C. tulumbensis sp. nov.

384 from Cerro Colorado have intermediate forms between both previous described groups. Analysis

385 using landmarks in shell lateral views did not show significative differences among the species

386 (Fig. S1).

387

388 Molecular analyses

389 Sequence data, phylogenetic analyses, and molecular species delimitation

390 We successfully amplified both mitochondrial loci and the nuclear region in the majority of

391 Clessinia and Spixia specimens, except for Spixia minor in which amplification of the COI and

392 ITS-2 markers was not possible. Partial 16S-rRNA sequences ranged between 287-295 bp, COI

393 sequences consisted of $655 \mathrm{bp}$, and ITS-2 sequences were of $822 \mathrm{bp}$ in length for all individuals.

394 The ITS-2 region showed no sequence variation within each species and exhibited little genetic

395 differentiation among species (Tables 3 and 4). Phylogenetic reconstructions obtained with the 
396 nuclear marker were unresolved (Fig. S2). For the mitochondrial markers, ML and BI results

397 revealed congruent topologies; consequently, we reported only the BI tree. From the analyses of

398 the concatenated dataset, Clessinia stelzneri clustered with C. tulumbensis sp. nov.; similarly,

399 Spixia cuezzoae clustered with specimens of Clessinia pagoda, and this group clustered with

400 Spixia holmbergi. C. cordovana clustered with the group formed by these three species (Fig. 3).

401 Therefore, these trees did not support the monophyly of Clessinia (Fig. 3). The phylogenetic

402 trees inferred from the larger $C O I$ dataset including sequences from GenBank congruently

403 identify roughly the same major groups, with both genera being paraphyletic due to association

404 of Clessinia and Spixia specimens in well-supported arrangements, as shown by the relationships

405 between C. nattkemperi and Spixia tucumanensis (Parodiz, 1941) or S. cuezzoae and C. pagoda

406 (Fig. 4). Sequence divergence for the mitochondrial loci amongst the species are presented in

407 Tables 5 and 6.

408 By using the concatenated dataset, the ABGD approach recovered six candidate species based

409 on the distribution of the pairwise genetic distances with a maximum prior of intraspecific

410 divergence of 0.035938 (Fig. 3). The same as the ABGD, the $K / \theta$ method provided support for

411 six of the morphospecies to be considered different evolutionary genetic species (Table 7),

412 except for C. stelzneri and C. tulumbensis sp. nov. which were not supported as distinct genetic

413 species by either method. Based on the COI dataset, the ABGD analysis clustered sequences into

41410 stable putative species based on the distribution of the pairwise genetic distances with a

415 maximum prior of intraspecific divergence of 0.035938 . The species C. stelzneri, C. tulumbensis

416 sp. nov., and Spixia popana (Doering 1877a) were clustered within the same group. All the

417 remaining species, i.e., C. nattkemperi, S. tucumanensis, S. cuezzoae, C. pagoda, S. philippii

418 (Doering, 1875), S. holmbergi, S. pervarians (Haas, 1936), C. cordovana, and C. gracilis Hylton

419 Scott, 1966 were assigned to different candidate species (Fig. 4).

420

421

422

As a result of the anatomical studies performed, shell periostracum observations, shell geometric morphometrics and genetic analyses, and based on previous findings (Breure \& 423 Romero, 2012), we here synonymized the genus Clessinia and Spixia and according to the 424 principle of priority (ICZN Code, Art.23.1) the valid name of the taxon should be Clessinia 425 Doering, 1875 which has priority over Spixia Pilsbry \& Vanatta, 1894. In the following, we 426 provide the taxonomic description and new systematic arrangement of the treated species. 


\section{Taxonomic descriptions}

429 Superfamily Orthalicoidea Martens, 1860

430 Family Odontostomidae Pilsbry \& Vanatta, 1898

431 Genus Clessinia (Doering, 1875)

432

433 Bulimus “Clessinia” Doering, (1874 [1875]): 201.

434 Bulimus “Macrodontes”-Doering, 1875 [1877a]: 331; -Doering, 1875 [1877b]: 250.

435 Scalarinella Doering -in Dohrn, 1875: 202.

436 Odontostomus (Scalarinella) -Pilsbry, 1901 [1901-1902]: 66; -Parodiz, 1939: 731.

437 Cyclodontina (Clessinia)-Parodiz, 1944; -Hylton Scott, 1966: 30.

438 Clessinia Doering -Hylton Scott, 1967: 103;-Fernández, 1973: 142;-Breure, 1974: 110;-

439 Cuezzo, Miranda \& Ovando, 2013.

440 Odontostomus (Spixia) Pilsbry \& Vanatta, 1898: 57 [new synonymy]

441

442 Type species. Clessinia stelzneri (Doering, 1875).

443 Definition. Shell fusiform to turritelliform. Protoconch with delicate axial ribs and spiral bands 444 delimited by thin grooves. Shell with periostracal complex structures consisting on spiral rows 445 bearing "hairs" or triangular, rectangular to quadrate lamellae. Few species lacking periostracal 446 ornamentation. Last portion of body whorl with aperture with slightly reflexed peristome, some 447 species forming a cornet detached from rest of shell body whorl with peristome thin and 448 expanded. Body whorl micro sculpture complex, consisting in micro folds forming an irregular 449 net, which in some cases is expanded dorsally over shell cornet. Fourth to five inner apertural 450 teeth forming a complex apertural barrier, except for one species with three teeth. Dorsal portion 451 of shell body whorl with a medial marked notch corresponding to the basal lamella. Columellar 452 lamella undulating, in some species L-shaped. Presence of a short penial sheath overlapping 453 distal portion of the penis. Insertion of penial muscle at proximal penis or distal epiphallus. Vas 454 deferens thin, running freely along penis and attached to penial retractor muscle. 
456 Diagnosis. Clessinia is one of the odontostomid groups showing most complex apertural teeth 457 arrangements. Number of apertural teeth/lamellae ranges from three to five. Together with 458 Plagiodontes $($ type species $=$ Helix dentata Wood, 1828) has a similar protoconch sculpture 459 consisting on axial ribs and transversal grooves between ribs. It differs from Plagiodontes in 460 general shell shape, showing thinner and taller spires and larger numbers of whorls plus strong 461 differences in number of apertural teeth/lamellae. Species here redescribed plus the new species

462 show a shell aperture detached from the body whorl and this character is not observed in the 463 remaining species of Clessinia (former Spixia) and in no other odontostomid genus. Shell 464 aperture shape varies from sub-circular to sub quadrate.

465 Clessinia is found in dry habitats with its distribution area ranging from Argentina, Uruguay to 466 Bolivia and Paraguay. Clessinia differs from Cyclodontina (type species = Clausilia pupoides 467 Spix, 1827) (Cowie, Cazzaniga \& Glaubrecht, 2004) in having more apertural teeth/lamellae, 468 some species of Cyclodontina are even toothless. Shells of Cyclodontina are basally wider, 469 sometimes glossy, without any particular ultrastructural shell sculpture described for this genus.

470 The shell aperture in Cyclodontina is not detached from the body whorl as in some Clessinia 471 species. Cyclodontina is distributed in Bolivia, Paraguay, Argentina, Uruguay and Brazil.

472 Clessinia differs from Pilsbrylia (type species = Pilsbrylia paradoxa Hylton Scott, 1952), in the 473 general shell shape because Pilsbrylia species have a fusiform, broader shell shape, and the 474 presence of only two apertural teeth. On the contrary to Clessinia, Pilsbrylia species inhabit in 475 humid forest.

476 Habitat preferences. Species of Clessinia inhabit dry areas where rocky formations are 477 frequently found among low xerophytic vegetation. Few species occur in Yungas ecoregion, but 478 in transition zones with dryer forests. They usually live below rocks in contact to the ground, in 479 rock crevices, or buried in soil under shrubs. Some species can be found glued to leaves in 480 bushes. Clessinia nattkemperi is usually found attached to the surface of cactuses or under dead 481 cactus in contact with soil.

482 Species distribution (Figs. 5A-D)

483 Clessinia species here treated are distributed in the Pampean Sierras of Central Argentina, in 484 the portion corresponding to the provinces of Córdoba and Catamarca (Fig. 5A). These Sierras 485 form a mountain complex of about $300 \mathrm{~km}^{2}$ in extent with a direction of north to south and 486 consist in a series of parallel mountain ranges. An extended depression of salty surface called 
487 Salinas Grandes, located between northern Córdoba, southeastern Catamarca and La Rioja 488 provinces, and Salinas de Ambargasta between southern Santiago del Estero and northwestern 489 Córdoba, subdivide the Pampean Sierras forming a real ecological barrier for land snail 490 dispersion (Fig. 5B, D). Main mountain systems in Córdoba are the Sierra Chica, Sierra Grande 491 and Sierra de Comechingones, this last is extended to San Luis province. Clessinia is mainly 492 distributed around and to the north of the Sierra Chica, including minor mountains such as 493 Sierras de Ischilin, Higuerita, Copacabana and Massa in Córdoba. Also scatter occurrences have 494 been registered to the southwest in Sierra de Pocho. In Catamarca, occurrences are registered in 495 the Ambato and Esquiu departments, both also corresponding to the Pampean Sierras but to the 496 northwest of the Salinas Grandes (Fig. 5B, C). All the localities of occurrences of Clessinia 497 species here considered are found in different patches areas of Chaco Serrano between 400 to 498 1,500 m above sea level. Remaining Clessinia species (former genus Spixia) have a wider area of

499 distribution in the Dry Chaco, Espinal and Monte ecoregions in Argentina (Salas Oroño, 2007, 500 2010) (Fig. 5 B).

501

502 Species description

503 Clessinia cordovana (Pfeiffer, 1855)

504 Figs. 5-9, Tables 1, 2.

505 Bulimus cordovanus Pfeiffer, 1855: 149; -Pfeiffer, 1856: 34; -Pfeiffer, 1859: 435; -Dohrn, 506 1875: 202; 1877: 157; -Kobelt, 1878: 150;-Martens, 1890-1891: 251;-Breure, 1974: 114.

507 Bulimus “Macrodontes” cordovanus -Doering, 1875 [1877a]: 331; -Doering, 1875 [1877b]: 508250.

509 Odontostomus (Scalarinella) cordovanus -Pilsbry, 1901 [1901-1902]: 66, pl. 13, fig. 100.

510 Odontostomus (Macrodontes) cordovanus -Holmberg, 1912: 152.

511 Odontostomus (Scalarinella) cordovanus -Parodiz, 1939: 732, fig. 1.

512 Cyclodontina (Scalarinella) cordovana-Parodiz, 1944: 5; -1957: 29.

513 Cyclodontina (Clessinia) cordovanus -Hylton Scott, 1966: 31, figs. 1-5, 7.

514 Cyclodontina (Clessinia) gracilis Hylton Scott, 1966: 34, figs. 6, 8.

515 Clessinia cordovana -Fernández, 1973: 142; -Cuezzo, Miranda \& Ovando, 2013: 28.

516 Clessinia gracilis-Fernández, 1973: 144; Breure \& Romero, 2012: 18.

517 Cyclodontina (Clessinia) gracilis-Breure, 1974: 116. 
519 Type Material: Lectotype SMF 10417a (H: 16.3; Dap: 3.7; Dm 4.5; Hap: 4.8); paralectotype 520 SMF 10417b (H: 17; Dap: 3.6; Dm: 4.7; Hap: 4.4); holotype Cyclodontina (Clessinia) gracilis 521 Hylton Scott, 1966, MACN-In 6421.

522 Type locality: Argentina, Córdoba province. "Pendiente Oeste de la Sierra de Aconjigasta, en las 523 quebradas húmedas como la de la Mermela, de Jatan, del Nieve y más al sud cerca de Aguas de 524 los Oscuros" (Doering, 1877a).

\section{Description}

526 External Features (Figs. 6A-C): Body dark to light grey with two blackish pigmented,

527 longitudinal bands extending from the mantle collar to the tentacles. Black tentacles. Foot short, 528 light gray, with a blunt end.

529 Shell (Figs. 6A-L, 7): Turritelliform to sub-fusiform, comprising $8 \frac{1}{2}$ to $9 \frac{1}{2}$ slightly convex 530 whorls. Coloration pale to dark brown, uniform (Figs. 6A-I). Protoconch with axial, regularly 531 arranged strength ribs, and thin spiral parallel bands delimited by spiral grooves between ribs 532 (Figs. 7A, B). Teleoconch with axial, oblique, shallow thin costules separated by regular spaces. 533 Surface of the teleoconch traversed by spiral rows bearing two types of periostracal hairs (Figs. $5347 \mathrm{C}-\mathrm{F})$. Spiral rows bearing long hairs of 200 to $300 \mu \mathrm{m}($ mean $=227, n=8)$ intercalated with 535 two to three spiral rows, one of each bearing hairs wider at base and less tall (Fig. 7E). Departing 536 from each spiral row, interconnected axial micro folds giving the appearance of an irregular net.

537 Suture deeply impressed. Distal portion of body whorl detached from rest of the shell forming a 538 cornet (Figs. 6D, E, G, H, 7C). Aperture sub-oval, round to square with thin, continuous, 539 expanded peristome. Five inner lamellae in the aperture not connecting to the peristome (Figs. 540 6J-L). Upper columellar lamella long, straight, spirally following the columellar axis. Lower 541 columellar lamella running parallel, slightly undulating, spirally following columellar axis (Fig. $5426 \mathrm{M}$ ). Basal teeth straight, short, to the left of the aperture producing a groove on dorsal side of 543 the shell (Fig. 6F). Some specimens with dorsal groove not marked (Fig. 6N). Upper palatal teeth 544 small, generally triangular shaped. Lower palatal teeth short. Both palatal teeth perpendicular to 545 columellar axis, deeply located inside cornet. Dorsal side of the aperture with an inner marked 546 groove (Fig. 6J, K, L). Umbilicus narrow. Shell measurements represented in Table 1. 547 Jaw (Fig. 8A): Wide horseshoe shaped. Ten plaques with a triangular central one subdivided 548 into three subplaques, the middle one more triangular-shaped. Five lateral quadrangular to 
549 rectangular shaped plaques at both sides of the central one. Lateral plaques slightly increasing

550 their size towards the tip of the horseshoe. Each plaque traversed by several thin transversal 551 grooves.

552 Pallial System: Pulmonary roof thin and long traversed by few veins mostly concentrated on 553 distal portion. Kidney triangular, short, of a quarter of the total length of the pulmonary roof.

554 Secondary ureter closed over most of its length, opening slightly before rectum. Pallial gland 555 thin, parallel to mantle collar. Afferent vein parallel to main pulmonary vein.

Reproductive System (Figs. 9A-E): Ovotestis embedded into digestive gland within the fourth and fifth shell whorls. Hermaphroditic duct inserting in distal portion of albumen gland (Fig. 9A). Seminal receptacle swollen. Fertilization pouch-spermathecal complex long, digitiform broaden at its base. Bursa copulatrix with sac rounded, longer than spermoviduct reaching the albumen gland. External limits between epiphallus and penis not evident (Figs. 9A, B). Penis cylindrical, long, with a short penis sheath overlapping in part distal penis. Inner morphology of the penis divided into three areas marked by differential pattern of sculpture (Figs. 9C, D).

563

564

565

566

567

568

569

570

571

572

573

574

575 Distribution (Fig. 5C, D): Disjunct distribution between Córdoba and Catamarca provinces.

576 Northwestern mountain ranges of Córdoba province, in Cruz del Eje, Punilla, Pocho, and

577 Tulumba departments. Clessinia gracilis was described in 1966 from a single shell found in La

578 Puerta, Ambato department, Catamarca province, and was synonymized to C. cordovana

579 (Cuezzo, Miranda \& Ovando, 2013) because the holotype has same size and shape as $C$. Proximal portion with same diameter than resting portions, inner sculpture with tightly appressed pustules (Fig. 9E). Penial papilla absent. Penis medial sector long, cylindrical, inner wall with rhomboidal to hexagonal pustules covering the surface, without pilasters (Figs. 9D, E). Distal penis short, inner sculpture consisting in three to four longitudinal, straight, thin pilasters, parallel to each other (Figs. 9C, D). Penial retractor muscle short and thick, inserting in penis proximal portion. Epiphallus $1 / 4$ of penial length. Flagellum thinner than epiphallus and $1 / 2$ epiphallus length. Vas deferens thin, running freely along penis, attached to penial retractor muscle, then free along epiphallus and inserting between flagellum and epiphallus. Vagina cylindrical, with a distal portion thinner in diameter than the proximal, inner wall with longitudinal pilasters. Vagina about double in length of the distal portion of penis.

Habitat (Figs. 6O, P): Calcareous rocky outcrops on mountain slope, under and between roots of woody shrubs. 
580 cordovana. However, during different collecting trips to the area of La Puerta carried out during

581 summer in different years, specimens were not found. This species inhabits the Dry Chaco

582 ecoregion, Chaco Serrano sub-ecoregion.

583

584 Clessinia stelzneri (Doering, 1875)

585 Figs. 2, 5, 10-12, Tables 1, 2.

586 Bulimus (Clessinia) stelzneri Doering, 1874 [1875]: 201.

587 Bulimus “Macrodontes” cordovanus var. stelzneri-Doering, 1875 [1877a]: 332; -Doering, 1875

588 [1877b]: 251.

589 Odontostomus (Scalarinella) cordovanus var. stelzneri-Pilsbry, 1901 [1901-1902]: 67.

590 Odontostomus (Scalarinella) cordovanus stelzneri-Parodiz, 1939: 732, fig. 2.

591 Scalarinella (Scalarinella) cordovana stelzneri-Zilch, 1959-1960: 508.

592 Cyclodontina (Scalarinella) cordovanus stelzneri-Parodiz, 1957: 29.

593 Scalarinella (Scalarinella) cordovana stelzneri-Zilch, 1971: 198, pl. 12, fig. 14; -Neubert \&

594 Janssen, 2004: 230, pl. 19, fig. 248.

595 Clessinia cordovana stelzneri-Breure, 1974: 110;-Breure \& Schouten, 1985: 9, fig. 3.

596 Clessinia stelzneri-Cuezzo, Miranda \& Ovando, 2013: 29.

597

598 Type Material: Lectotype SMF 10417/3a; paralectotypes SMF 26582 (1), SMF 26583 (2), SMF $599325584(4)$.

600 Type Locality: “... quebrada de Yatan (Serrezuela; Provincia de Córdova)”. According to Hylton

601 Scott (1966) the type locality is located in Argentina, Córdoba Prov., Cruz del Eje Dept., Yatan, 602 Serrezuela.

603 Description

604 External Features (Fig. 10A): Body light brown. Foot short with a blunt end. Some specimens 605 with sole lighter than dorsal body coloration.

606 Shell (Figs. 10B-F, 11A-D): Fusiform, comprising $8 \frac{1}{2}$ to 9 slightly convex whorls.

607 Coloration pale to dark brown, sometimes with longitudinal strips clearer in color, other shells 608 with uniform coloration (Figs. 10B-D). Protoconch with axial, regularly arranged strength ribs, 609 and thin spiral parallel bands delimited by spiral grooves (Fig. 11A). Teleoconch with shallow 610 axial costules separated by regular spaces. Surface of the teleoconch traversed by densely 
611 arranged spiral rows bearing two types of periostracal hairs (Figs. 11B-D). Rows of tall hairs

612 intercalated with three to five spiral rows some of which not bearing hairs while other bearing

613 hairs triangular shaped, less tall, usually in touch with each other through their bases (Figs. 11C,

614 D). Ultrastructural ornamentation of body whorl extending over dorsal portion of the cornet. Last

615 portion of the body whorl detached ending into a cornet. Aperture sub-circular with five inner

616 teeth and lamellae not connecting to the peristome (Figs. 10B, E). Upper columellar lamella

617 long, straight, spirally following the columellar axis. Lower columellar lamella running parallel,

618 slightly undulating, spirally following columellar axis (Fig. 10F). Basal lamella straight, short.

619 Dorsally the body whorl shows a deep groove produced by the basal lamella. Shell

620 measurements represented in Table 1.

$621 J a w$ (Fig. 8B): Markedly horseshoe shaped. Nine plaques with a triangular central one

622 subdivided into three triangular subplaques. Four lateral rectangular shaped plaques at both sides

623 of the central one. Lateral plaques strongly increasing their size towards the tip of the horseshoe.

624 Each plaque traversed by several transversal grooves.

625 Radula (Figs. 8F-I): Radular teeth transversally arranged on a straight line. Central tooth

626 tricuspid, with mesocone triangular to rhomboidal. Lateral tooth bicuspids with a high mesocone

627 and a short ectocone in an opposite position to the central tooth. Marginal tooth tricuspid to

628 multicuspids, broader than laterals.

629 Pallial System: same as in C. cordovana.

630 Reproductive System (Figs. 12A-B): Bursa copulatrix with sac rounded, usually longer than

631 spermoviduct, in some specimens longer than spermoviduct plus albumen gland (Fig. 12A).

632 External limits between epiphallus and penis not evident. Penis cylindrical, long, without penis

633 sheath. Inner morphology of the penis divided into three areas marked by differential pattern of

634 sculpture. Proximal portion globose with higher diameter than restant portions, inner sculpture

635 with pustules. Penial papilla absent. Penis medial sector cylindrical, inner wall with a

636 longitudinal, thick, well-delimited pilaster running from proximal to distal end of the medial

637 zone. Inner sculpture of distal penis portion consisting in three to four longitudinal straight thin

638 pilasters, parallel to each other. Penial sheath absent. Penial retractor muscle short and thick,

639 inserting in penis proximal portion. Epiphallus $1 / 3$ of penial length. Flagellum thinner than

640 epiphallus and $2 / 3$ epiphallus length. Vas deferens thin, running freely along penis, attached to

641 penial retractor muscle (Fig. 12B), then free along epiphallus and inserting between flagellum 
642 and epiphallus. Vagina cylindrical, with inner wall with thick, longitudinal pilasters, as long as 643 distal portion of penis.

644 Habitat (Fig. 10P): calcareous rocky outcrops on mountain slope, under and between roots of 645 woody shrubs.

646 Distribution (Fig. 5D): Cruz del Eje and Tulumba departments, Córdoba province. 647

Clessinia tulumbensis sp. nov.

650 urn:lsid:zoobank.org:act:F565D3BD-03AD-4CC1-8BB1-20D72C5BDF00

Figs. 2, 5, 10-12, Tables 1, 2.

651 Odontostomus (Scalarinella) cordovanus striatus Parodiz, 1939: 733;-Breure, 1974: 124.

652 Clessinia cordovana-Cuezzo, Ovando \& Miranda, 2013: 162 [partim].

653

654 Type Material: Holotype: IBN 883 (preserved in ethanol 96\%) (H: 14.9; Dm: 4.61; dm: 3.97; 655 Dap: 3.36; Hap: 4.66). Paratypes: IBS-Ma 311 (3 specimens); IBN 571 (5 specimens, preserved 656 in ethanol 96\%); IBN 558 (1 specimen, preserved in ethanol 96\%) (H: 17.61; Dm: 3.85; dm: 657 3.53; Hap: 3.79; Dap: 2.73). Holotype Clessinia cordovana striata, MACN-In 9127.

658 Type locality: Holotype: Córdoba, Tulumba department, Route 16, between Villa Tulumba and 659 San Jose de la Dormida (-30.79053, -64.63097; 645 m), October 21, 2017, Cuezzo MG and 660 Dominguez E collectors. Paratypes: IBS-Ma 311, idem to holotype; IBN 571, Córdoba, 661 Tulumba, R 16, (-30,40022 -64,04222; 633m), November 25, 2018, Cuezzo MG collector; IBN 662 558, Córdoba, Tulumba, Route 16 before reaching the town of Tulumba, (-30,40094 -64,04039; $663628 \mathrm{~m}$ ), November 24, 2008, Cuezzo MG collector.

664 Etymology. The specific name, "tulumbensis", is given in reference to Tulumba, the political 665 department of Cordoba Province, Argentina, where the type of the new species was collected.

666 Definition: Shell with marked wide axial ribs narrowly separated at regular spaces, traversed by 667 major periostracal spiral rows with shallow continuous lamellae. Periostracal hairs absent. Lower 668 columellar lamella in shell aperture deeply undulating. Proximal penis inner sculpture with 669 undulating thin folds in a reticulated disposition and a short thick, medium pilaster. Medial 670 portion with a pilaster of $2 / 3$ the length of penis. Vagina almost the same length of the distal 671 portion of penis.

\section{Description}


External Features (Figs. 10A, G): Soft body, including the sole with dark brownish

674

675

676

677

678

679

680

681

682

683

684

685

686

687

688

689

690

691

692

693

694

695

696

697

698

699

700

701

702

703 homogeneous coloration. Foot short with blunt end.

Shell (Figs. 10G-O, 11E-F): Turritelliform to sub-fusiform comprising 9 to 10 slightly convex whorls (Figs. 10H-M). Coloration light brown, with whitish ribs. Protoconch with axial strength ribs regularly arranged, with thin spiral parallel bands between ribs (Fig. 11E). Teleoconch with marked oblique, wide axial ribs narrowly separated at regular spaces (Figs. 10H-M, 11E, F). Surface of the teleoconch traversed by major periostracal spiral rows with shallow continuous lamellae, parallel to each other. Between these major spiral rows, two to three minor spiral, undulating shallow lines (Fig. 11E, F). Periostracal hairs absent. At ultrastructural level, departing from each major spiral row, growth axial ramified micro folds traversed by spiral lines, giving the appearance of an irregular net (Fig. 11F). Suture deeply impressed. Last portion of body whorl detached from rest of the shell ending into a cornet (Fig. 10I, L). Aperture sub-oval with parietal side slightly excavated (Figs. 10H, K, N). Peristome simple, thin, slightly expanded and reflexed. A dorsal groove present in upper parietal-palatal side of aperture formed by the detached suture of body whorl. Peristomal ultrastructural sculpture of body whorl extending over dorsal portion of the cornet. Five lamellae present in the interior of the aperture, not connecting to the peristome. Upper columellar lamella long, straight, spirally following the columellar axis. Lower columellar lamella running parallel, deeply undulating, spirally following columellar axis (Fig. 10O). Basal lamella short, located to the right side of the cornet and making a deep indentation on dorsal side of the shell wall (Fig. 10J, M). Umbilicus narrow. Shell measurements represented in Table 2.

Jaw (Fig. 8C): Horseshoe shaped, less open than in C. cordovana. Twelve plaques with a triangular central one subdivided into three subplaques. Six lateral narrow rectangular shaped plaques at both sides of the central one. Lateral plaques slightly increasing their size towards the tip of the horseshoe. Each plaque traversed by several thin transversal grooves.

Pallial System: idem to C. cordovana.

Reproductive System (Figs. 12C-F): Ovotestis embedded into digestive gland into the fourth or fifth spire whorls. Hermaphroditic duct inserting at distal portion of the albumen gland.

Seminal receptacle swollen. Fertilization pouch-spermathecal complex long, digitiform broaden at its base. Albumen gland spread within the sixth whorl. Bursa copulatrix with sac rounded and folded over proximal section of the duct (Fig. 12C). Bursa copulatrix duct, longer than 
704 spermoviduct, surrounding the spermoviduct and running towards basal portion of the albumen

705 gland. External limits between epiphallus and penis not evident, only differentiated by its inner 706 sculpture. Penis cylindrical, long, with a short, thin penis sheath overlapping distal penis (Figs.

707 12C, D). Inner morphology of the penis divided into three areas marked by differential pattern of

708 sculpture. Proximal portion slightly swollen than remaining portions, inner sculpture with

709 undulating thin folds in a reticulated disposition and a short thick, medium pilaster (Figs. 12D,

710 E). Penial papilla absent. Penis medial portion long, cylindrical, inner wall with rhomboidal to

711 hexagonal pustules on the surface, with a pilaster of $2 / 3$ the length of the medial penis portion.

712 Distal penis short, thinner than medial portion with inner sculpture consisting in three to four

713 longitudinal, straight, thin pilasters, parallel to each other. Penial retractor muscle thin and long,

714 inserting in penis proximal portion (Fig. 12F). Epiphallus $1 / 4$ of penial length, with an inner

715 constriction cutting the longitudinal, thin folds. Flagellum thinner than epiphallus and $1 / 2$

716 epiphallus length. Vas deferens thin, running freely along penis, attached to penial retractor

717 muscle, then free along epiphallus and inserting between flagellum and epiphallus (Fig. 12F).

718 Vagina cylindrical, with a distal portion thinner in diameter than the proximal, inner wall with

719 longitudinal pilasters. Vagina almost the same length of the distal portion of penis. Atrium short.

720 Habitat: Living in rocky outcrops, on and under shrubs. Always dry environments.

721 Distribution (Fig. 5D): This species has a small area of distribution located in northwestern

722 Córdoba within Tulumba, and Totoral departments, Argentina. Western limit for C. tulumbensis

723 sp. nov. area of distribution is in Sierra de Macha, extending to the east towards Villa Tulumba,

724 and to the north towards Cerro Colorado. Localities of occurrences are all below $700 \mathrm{~m}$, in

725 Chaco Serrano sub-ecoregion.

726 DNA sequence data: Partial sequences of mitochondrial COI and $16 S-r R N A$ genes, and the

727 nuclear ITS-2 region from two paratypes (IBN 883, specimens 1 and 2) have been deposited in

728 GenBank with accession numbers: MG963436 and MG963437 for COI; MG963462 and

729 MG963463 for 16S-rRNA, and MH789460 and MH789461 for ITS-2.

730 Remarks: The new species, Clessinia tulumbensis sp. nov. include Clessinia cordovana striata

731 (Parodiz, 1939). The name striata has not been used here to avoid homonymy with Pupa striata

732 Spix, 1827, the type species of Spixia, since in the present study the genera Clessinia and Spixia

733 are proposed as synonymous. The new species with its own holotype and paratypes is defined

734 based on live-collected material from which DNA sequences were obtained and the anatomy 
735 described. In this sense, although the Parodiz name is preoccupied, we are not replacing the

736 name proposed by him in 1939 but creating a new species with its own type series. $C$.

737 tulumbensis sp. nov. has clear differences with the remaining species of the cordovana-group

738 showing shell axial ribs more marked than in C. cordovana and C. stelzneri. The periostracum

739 lacks spines or hairs, only major periostracal spiral rows with shallow continuous lamellae are

740 present. C. tulumbensis sp. nov. has a clear delimited pilaster in the medial penis portion, also

741 present in C. stelzneri, but absent in C. cordovana. The penis shows a short, thin penial sheath

742 overlapping part of the penial distal portion and the vagina is short as in C. stelzneri. C.

743 tulumbensis sp. nov. has a narrow distribution area in northern Córdoba, occurring in sympatry

744 with C. stelzneri in some localities within eastern portion of Tulumba department.

Clessinia pagoda Hylton Scott, 1967

748 Figs. 2, 8, 13-15.

749 Clessinia pagoda Hylton Scott, 1967: 98; -Fernández, 1973: 144; -Breure, 1974: 120; -Neubert

750 \& Janssen, 2004: 221, pl. 19, fig. 247; -Cuezzo, Miranda \& Ovando, 2013: 163, fig. 2 A.

751

752 Type Material: Holotype not found; paratypes MACN-In 27284 (15 specimens, type locality),

753 Córdoba, Quilpo, 2-3/IV/1967. Cichero-Biraben Leg. Hylton Scott det., H: 22.2-19.8 (mean =

754 22.5); Hap: 7.4-6.6 (mean = 7.04); Dap: 5.9-4.4 $($ mean = 5); Dm: 8.4-6.5 $($ mean = 7.3); IFML-

755 Moll 14239, Córdoba, Quilpo, 5/4/1967, Birabén-Cichero leg.; MLP-Ma 11077, Córdoba,

756 Quilpo (paratype); SMF 220916/2a.

757 Type locality: Argentina, Córdoba, Cruz del Eje department, Sierra Chica de Córdoba, Quilpo.

758 Description

759 External Features (Figs. 13A, B): Animal dark brown to black, with light brown ocular

760 tentacles. Homogeneous coloration over the cephalopedial region, same specimens with sole

761 light cream. Usually shells of live snails covered with a coat of sand granules (Fig. 13A).

762 Shell (Figs. 13C-J, 14A-F): Subpyriform with conic spire, solid. Seven to 8 whorls with

763 median keel in each spire whorl (Figs. 13C-E). Body whorl with convex contour. Homogeneous

764 light brown when periostracum is present (Figs. 13A, B, F-H). Protoconch with axial strength

765 ribs regularly arranged, space between axial ribs with thin spiral parallel bands (Fig. 14A). 
766 Teleoconch with oblique shallow ribs slightly marked (Fig. 14B). Each spire whorl with an

767 equatorial and/or lower spiral row bearing rounded lamella of 300 to $400 \mu \mathrm{m}$ tall and 200 to 250

$768 \mu \mathrm{m}$ wide (Figs. 13F-H, 14B, C, E). Each lamella superimposed with the following in a row (Fig.

769 14C). Several major and minor spiral rows parallel to the lamellae medial row. Suture between

770 whorls also with a row of lamellae (Fig. 14E). Lamellae are lost in abraded specimens without

771 periostracum (Figs. 13C-E). Minor, shallower spiral rows regularly spaced between major rows

772 with lamellae. Space between minor rows showing micro axial folds with the appearance of an

773 irregular net (Fig. 14D). Sculpture of body whorl consisting in at least five major spiral rows of

774 smaller lamellae than former described for spire. Variable number of minor spiral rows between

775 major rows of lamellae (Fig. 14E). Aperture detached from body whorl forming a cornet,

776 peristome expanded (Figs. 13D, G). Microsculpture of body whorl prolonged dorsally over

777 peristome (Fig. 14F). Suture of body whorl when detached forming a marked keel that produce a

778 marked dorsal angle of the aperture (Figs. 13C, D). Aperture rounded to oval (Figs. 13I, J).

779 Dorsally, last portion of body whorl with a marked groove (Fig. 14F). Five lamellae obliterating 780 the aperture. Umbilicus narrow.

781 Jaw (Fig. 8D): Horseshoe shaped. Eleven plaques with a triangular central one subdivided

782 into three longitudinal subplaques. Lateral plaques quadrangular to rectangular shaped,

783 increasing their size towards the tip of the horseshoe. Each plaque traversed by several

784 transversal grooves.

785 Pallial System (Figs. 15A, B): Pulmonary roof thin, traversed by few veins mostly

786 concentrated on distal portion. Kidney triangular, short, $1 / 4$ the length of the pulmonary roof.

787 Kidney with several longitudinal folds in its interior (Fig. 15B). Secondary ureter closed over

788 most of its length, opening slightly before rectum. Pallial gland thin, parallel to mantle collar.

789 Afferent vein parallel to main pulmonary vein. Mantle collar deeply marked by shell lamellae.

790 Reproductive System (Figs. 15C-F): Ovotestis formed by a bunch of digitiform, long acini

791 embedded in the digestive gland. Hermaphroditic duct inserting at distal portion of the albumen

792 gland, with its medial portion, corresponding to the seminal vesicle, swollen. Fertilization pouch-

793 spermathecal complex long, digitiform broaden at its base (Figs. 15C, D). Bursa copulatrix with

794 sac rounded and its duct slightly swollen at its base. Bursa copulatrix sac level with distal portion

795 of albumen gland, its duct surrounding the spermoviduct, longer than spermoviduct in total

796 length (Fig. 15C). Phallic complex formed by flagellum, epiphallus and penis. External limits 
797 between epiphallus and penis not evident, only differentiated by its inner sculpture. Flagellum

798 tapering towards its tip, thinner than epiphallus and about as long as epiphallus length (Fig. 15E).

799 Epiphallus about the same length than penis, slightly increasing its diameter towards distal

800 portion, with an inner constriction cutting the inner surface into two portions (Fig. 15E).

801 Proximal portion with thick, pronounced, longitudinal pilasters, while distal portion with thin,

802 scatter folds more separated between each other. Penis cylindrical, long, with a short, thin penis

803 sheath overlapping its distal portion (Figs. 15E, F). Penis also separated from epiphallus by a thin

804 inner constriction. Inner surface of penis wall divided into three areas marked by differential

805 pattern of sculpture. Proximal portion externally slightly swollen than resting portions, with inner

806 sculpture formed by tightly appressed thin folds arranged in a reticular shape. Penial papilla

807 absent. Penis medial portion long, cylindrical, inner wall traversed by thin folds that towards

808 distal penis became diagonally arranged (Figs. 15E, F). Distal penis short, thinner than medial

809 portion with inner sculpture consisting in three to six longitudinal, straight, thin folds, parallel to

810 each other. Penial retractor muscle thick and short inserting in penis proximal portion. Vas

811 deferens thin, running under penis sheath and then freely along penis, attached to penial retractor

812 muscle, then free along epiphallus and inserting between flagellum and epiphallus. Vagina

813 cylindrical, even in diameter, inner wall smooth or with shallow longitudinal pilasters. Vagina

814 longer than distal portion of penis (Fig. 15C). Atrium short.

815 Habitat: Found in mountains with xerophilic vegetation usually under rocks or in crevices in

816 rocks.

817 Distribution (Fig. 5D): Clessinia pagoda is only known from the localities of Quilpo and San

818 Marcos Sierra in Córdoba province, Cruz del Eje department, in the Chaco Serrano. C. pagoda is

819 a narrow range endemic species from northwestern Córdoba. The Cerro de la Cruz is close to

820 Quilpo and to San Marcos Sierra, mountain where the species is easily found from 600 to $900 \mathrm{~m}$

821 of altitude.

822 Remarks: Clessinia pagoda paratypes specimens are completely worn out (Figs. 13C-E) and

823 therefore all the miscrosculpture of the periostracum is lost. Living snails are found under clay or

824 granite rocks. They are usually camouflaged with sand grains of the substrate that adhere to the

825 periostracum (Fig. 13A), but the fragile lamellae and complex structures of the periostracum are

826 not perceived until the shell is clean (Figs. 13F-H). Strikingly, other carinated, rare land snail

827 species, Plagiodontes weyenberghii (Doering, 1877a) of the family Odontostomidae (Pizá \& 
828 Cazzaniga, 2012) also occurred in scatter areas through Córdoba in the Chaco Serrano sub-

829 ecoregion.

830

831 Clessinia nattkemperi (Parodiz, 1944)

832 Figs. 2, 8, 16-18.

833 Cyclodontina (Scalarinella) nattkemperi-Parodiz, 1944: 1-2, figs. A-D; -Parodiz, 1957: 29; -

834 Breure, 1974: 119.

835 Clessinia nattkemperi-Fernández, 1973: 144; -Cuezzo, Miranda \& Ovando, 2013: 163.

836

837 Type Material: Holotype MACN-In 25713; Paratypes MACN-In 25713-1 (13 shells, type

838 locality) (Tablado \& Mantinian, 2004).

839 Type locality: Argentina, Catamarca, Esquiú department, Pomancillo, $23 \mathrm{~km}$ from San Fernando

840 del Valle de Catamarca, F. Nattkemper leg. July 1943.

\section{Description}

842 External Features (Figs. 16A-B): Animal pale brown, homogeneous coloration with ocular

843 tentacles of the same color. A dorsal row of pustules from mantle collar ending between the two

844 ommatophoral tentacles. Foot short with blunt extreme.

845 Shell (Figs. 16C-K, 17): Fusiform with gradual increase of diameter towards body whorl.

846 Eight shell whorls with convex contour. Shell yellowish to pale golden. Holotype completely

847 worn out with no periostracal ornaments (Figs. 16C-E). Protoconch consisting of the first two

848 whorls, with strength axial ribs, space between axial ribs with thin spiral parallel bands.

849 Teleoconch with axial ribs and conspicuous periostracum ornamentation when present (Figs.

850 16F-H). Periostracal sculpture consists of 10 to 20 thin spiral rows bearing triangular spines

851 (Figs. 17A-E) separated at regular spaces. Spines with wide base $(50-60 \mu \mathrm{m})$ and about $100 \mu \mathrm{m}$

852 tall (Figs. 17B, C). Space between spiral rows traversed by axial irregular micro folds cut by

853 spiral or diagonal micro ribs forming an irregular net. Only the major type of spiral row is

854 present, some of them without spines intercalated with the ones bearing spines (Fig. 17B).

855 Aperture slightly detached from body whorl forming a shallow cornet (Figs. 16G, 17D, E), sub-

856 ovate to sub-quadrate, with a marked dorsal groove in upper portion of the aperture. Peristome

857 expanded. Microsculpture of body whorl prolonged dorsally over peristome (Fig. 17D). Five

858 inner teeth or lamellae not touching the peristome (Figs. 16I-K). Upper palatal tooth triangular, 
859 not present in some specimens (Fig. 16J). Lower columellar lamella with rounded or rectangular 860 shape when viewing from outside (Figs. 16I-K).

$861 J a w$ (Fig. 8E): Wide horseshoe shaped formed by fifteen plaques, medial one triangular in

862 shape and subdivided into three narrower plaques. Lateral plaques very narrow and about same

863 size. The three last plaques on each side of the jaw broader than more central plaques.

864 Pallial System: Pulmonary roof thin and long traversed by few veins mostly concentrated on

865 distal portion. Kidney triangular, short, a quarter of the total length of the pulmonary roof.

866 Secondary ureter closed over most of its length, opening slightly before rectum. Pallial gland

867 thin, parallel to mantle collar. Afferent vein parallel to main pulmonary vein.

868 Reproductive System (Figs. 18A-D): Ovotestis formed by a bunch of digitiform, long acini

869 embedded in the digestive gland. Hermaphroditic duct inserting at distal portion of the albumen

870 gland, with a swollen medial portion, corresponding to the seminal vesicle (Fig. 18A).

871 Fertilization pouch-spermathecal complex long, thin, digitiform, broaden at its base. Bursa

872 copulatrix with sac rounded with its duct even in diameter along its length. Bursa copulatrix sac

873 level with distal portion of albumen gland, its duct surrounding the spermoviduct, longer than

874 spermoviduct in total length. Phallic complex formed by flagellum, epiphallus and penis.

875 External limits between epiphallus and penis not evident, only differentiated by its inner

876 sculpture. Flagellum thin, tapering towards its tip, thinner than epiphallus and shorter in length

877 (Figs. 18A, B). Epiphallus slightly shorter than penis, increasing its diameter towards distal

878 portion, with an inner constriction cutting the inner surface into two portions. Proximal portion

879 with thin, straight longitudinal pilasters, distal portion shorter with longitudinal folds less

880 separated between each other and scalloped outline. Both portions internally separated by an

881 inner constriction (Fig. 18C). A cylindrical papilla of the epiphallus with distal digitiform

882 extensions is present. Penis mostly cylindrical, long, with a short, thin, transparent penis sheath

883 overlapping its distal portion. Proximal portion more swollen than remaining portions, globular

884 in some specimens, with inner sculpture formed by tightly appressed thin folds arranged in a

885 reticular shape with a central, short pilaster (Figs. 18B, D). Penial papilla absent. Penis medial

886 portion long, cylindrical, inner wall with thin, parallel folds, with marked festooned outline (Fig.

887 18D). Distal penis short, thinner than medial portion with inner sculpture consisting in three to

888 six longitudinal, straight, thin folds, parallel to each other. Penial retractor muscle thick and short

889 inserting in penis proximal portion (Fig. 18A). Vas deferens thin, running under penis sheath and 
890 then freely along penis, attached to penial retractor muscle, then running parallel and attached to

891 epiphallus by thin tissue and inserting between flagellum and epiphallus. Vagina cylindrical,

892 short, even in diameter, inner wall smooth or with shallow longitudinal pilasters. Vagina shorter

893 than distal portion of penis. Atrium short.

894 Habitat (Figs. 16L-N): Clessinia nattkemperi is found in close association with xerophilic

895 plants, mainly cactuses, in patches of Chaco Serrano sub-ecoregion. Specimens usually are

896 hiding between long spines of cactuses or below dead cactuses branches lying over the ground.

897 Found in sandy, dry substrate. Not found in rock crevices as other species of the genus.

898 Distribution (Fig. 5B): This species is endemic to the Sierra de Graciana mountain system and

899 was only collected around the locality of Pomancillo, in Catamarca province, Northwestern

900 Argentina. Dry Chaco ecoregion, Chaco Serrano sub-ecoregion.

901 Remarks: C. nattkemperi is the species of the genus more similar to the former Spixia in general

902 shell shape morphology. Its shell aperture is only slightly detached from the body whorl. It also

903 shows triangular periostracal lamellae that are similar to the ones present in C. martensii

904 (Doering, 1874) and C. tucumanensis (Parodiz, 1941).

905

906

\section{DISCUSSION}

907

Traditional used characters for taxonomic diagnosis in Odontostomidae, such as the shell

908 morphology, provide important information for species identification, but due to their intraspecific variability they should be carefully considered. When Doering described Clessinia in 1875 , he mentioned that the number of plaques of the jaw would be the best character to

911 differentiate the new created genus from Odontostomus, Plagiodontes and Spixia. However, the

912 number of plaques in Clessinia overlaps with the ones present in species of other genera, so by

913 itself this character is not enough for genera differentiation.

914 Our combined morphological and molecular study allows us to propose that the so called 915 cordovana-group is formed by three species, C. cordovana, C. stelzneri and C. tulumbensis $\mathrm{sp}$.

916 nov. The shell in C. tulumbensis sp. nov. has prominent, well-marked ribs, more raised than in $C$.

917 cordovana and $C$. stelzneri. C. cordovana and C. tulumbensis sp. nov. have thinner shells than

918 the other species. Among the cordovana species complex, the shape of the lower columellar

919 lamella is deeply undulating around the columellar axis in C. tulumbensis sp. nov. and straighter

920 in C. cordovana and C. stelzneri, thus showing to be a good character for species identification. 
921 The periostracum is of special taxonomic interest because it bears distinct microscale

922 architectures. However, where and how these structures are formed is yet unknown for the

923 majority of the species (Allgaier, 2011). Haired shells occur in several species of

924 Stylommatophora, as for example in families Polygyridae, Helicidae, Hygromiidae, Clausiliidae,

925 Vertiginidae and Solaropsidae. These families are distantly related suggesting that these features

926 have evolved several times independently. In some cases, the ornamentation can be a response to

927 structural demands from the environment, including camouflage and defense against predators

928 and parasites. These ornaments can be the support for sand granules, dirt or any other component

929 of the natural habitat that can camouflage the shell. Pfenninger et al. (2005) suggest that hairs on

930 shells of Trochulus Chemnitz, 1786 confer a selective advantage in humid habitats only and that

931 are lost in drier habitats. Strikingly, in Argentina drier habitats hold the species with longer hairs

932 such as C. cordovana from central western mountains in Córdoba. Clessinia pagoda is

933 frequently found covered by a thick layer of sand grains overlapping the shell spiral rows but not

934 completely the lamellae. The coloring of the shells covered by sand is perfectly camouflaged

935 with the rocks where they live. In Clessinia, the type and diversity of periostracal ornamentation

936 needs to be further investigated taking into account not only their ecological niche differentiation

937 but also species reproductive behavior. Anatomical studies show that the reproductive system

938 holds the most useful characters for taxonomic identification as in other stylommatophoran

939 snails. Inner sculpture of the penis in the five species studied show particular characters. The

940 presence of a penial pilaster and a sheath also contributes to species differentiation in the

941 cordovana-species group.

942 The geometric morphometric analyses performed in this study confirmed the distinctiveness

943 among all the species here treated. While C. pagoda and C. nattkemperi are clearly different,

944 there is some degree of overlap in shell shape among the species of the cordovana-group. While

945 C. cordovana has a slim body whorl with a sub oval aperture, C. stelzneri has a body whorl more

946 expanded and voluminous with sub circular aperture and C. tulumbensis sp. nov. has an

947 intermediate shape of body whorl with expansion of the central portion of the aperture. When the

948 cordovana-species complex were analyzed alone, shell differences are more evident but still a

949 degree of overlap exists. Clessinia cordovana from Cerro del la Cruz and surrounding San

950 Marcos Sierra areas shows the typical shapes according to the species description, while

951 specimens from Sierra de Pocho are more closely related in shape to C. stelzneri. In the case of 
952 C. tulumbensis sp. nov., Cerro Colorado is the locality that shows specimens with smaller

953 aperture and spire first whorls more expanded. Even when geometric morphometrics is useful for

954 taxonomic identification, we support the necessity of a comparative analysis using also

955 anatomical studies for a correct taxonomic identification of specimens within the cordovana-

956 group.

957 Molecular studies performed with the nuclear marker, revealed that the ITS-2 region contains

958 much less polymorphism than the mitochondrial genes and does not exhibit enough genetic

959 variation to determine species relationships among Clessinia and Spixia species, which are

960 shown as a polytomy in our phylogenetic reconstructions. These results conform well to Breure

961 \& Romero (2012), who obtained poor resolution at lower taxonomical levels within phylogenetic

962 trees of Orthaliciodea by using the same nuclear region. Because this nuclear region seems to be

963 too conserved to depict specific relationships, further studies with more nuclear markers are

964 required in order to reconstruct fully resolved phylogenetic trees in the genus Clessinia. On the

965 other hand, our analyses performed with $16 S-r R N A$ showed that $C$. cordovana differs from $C$.

966 stelzneri by genetic divergences ranging between $17 \%$ ( $p$ distance) to $19.3 \%$ (K2P distance) and

967 from C. tulumbensis sp. nov. by distances ranging between 17\% ( $p$ distance) to 19.8\% (K2P

968 distance), thus suggesting that C. cordovana is a different species from C. stelzneri and $C$.

969 tulumbensis sp. nov. Regarding pairwise interspecific divergence between $C$. stelzneri and $C$.

970 tulumbensis sp. nov., the greatest genetic distances we found are less than $2 \%(1.1-1.8 \%)$.

971 Similarly, based on the COI locus we found that C. cordovana differs from $C$. stelzneri by

972 genetic distances ranging between 14.3\% ( $p$ distance) to 17\% (K2P distance), and from $C$.

973 tulumbensis sp. nov. by divergences ranging between $14.9 \%$ ( $p$ distance) to $19 \%$ (K2P distance),

974 while distances between $C$. stelzneri and $C$. tulumbensis sp. nov. ranged between 1.3 to $4.1 \%$. As

975 with the ribosomal marker, these COI-based values suggest that $C$. cordovana represent a

976 different species from C. stelzneri and C. tulumbensis sp. nov.

977 Our analyses with two different methods to test if morphological species of Clessinia satisfied

978 the criteria to be considered different evolutionary genetic species, allowed us to recognize $C$.

979 cordovana, C. nattkemperi, and C. pagoda as distinct evolutionary genetic species. However, the

980 results from $\mathrm{ABGD}$ and $K / \theta$ approaches failed to recognize the morphological diversity between

981 C. stelzneri and C. tulumbensis sp. nov., and the phylogenetic trees did not support the presence

982 of separate species for both morphological species. The trees showed C. stelzneri as paraphyletic 
983 with respect to $C$. tulumbensis sp. nov., with DNA sequences of $C$. tulumbensis sp. nov. nested

984 among those of $C$. stelzneri. Furthermore, the distance values obtained between $C$. stelzneri and

985 C. tulumbensis sp. nov. are relatively low. This low genetic divergence suggest that the two

986 species have evolved relatively recently, with $C$. tulumbensis sp. nov. having evolved within $C$.

987 stelzneri, and would explain the reduced resolution of species boundaries detection using genetic

988 data, as both $\mathrm{ABGD}$ and $K / \theta$ approaches are known to fail in cases of very recent speciation

989 (Puillandre et al., 2012; Birky, 2013). Thus, based on the molecular markers analyzed, is not

990 possible to assess to which extent intrinsic factors (e.g., hybridization, introgression) or adaptive

991 evolution are implicated in speciation, and further research involving more populations across

992 the distribution area of both species, crossbreeding experiments, and more suitable molecular

993 markers accounting for low divergence times are needed to testing hypotheses of speciation on

994 these Clessinia species. In addition, when the COI sequences of Breure \& Romero (2012) were

995 included together with the sequences obtained here, some interesting situations occur. Based

996 only on the partial COI gene, the phylogenetic trees of Clessinia and Spixia species again

997 showed $C$. stelzneri as paraphyletic when including the sequences provided by Breure \& Romero

998 (2012). At this point, we revised the taxonomic identity of the material from IML BD575

999 currently deposited at IBN, on which Breure \& Romero (2012) based their findings and found

1000 that this material corresponds in morphology to C. tulumbensis sp. nov. and not to C. cordovana,

1001 as stated by these authors. In addition, we observed that $S$. popana was included within the $C$.

1002 stelzneri plus $C$. tulumbensis sp. nov. group, a finding which needs further research based on

1003 new material of this Spixia species in order to rule out a misidentification.

1004 Clessinia gracilis was created by Hylton Scott in 1966 on the base of a single shell from the

1005 locality of "La Puerta", Ambato, in Catamarca, Argentina. Hylton Scott (1966) mentioned that

1006 the shell of $C$. gracilis had "teeth towards the interior of the opening while in the other species

1007 they are mounted on the reflection of the lip". This description of the shell aperture can,

1008 however, be referred to the aperture morphology of all the species of the genus, where the

1009 position of the teeth is always located in the interior of the shell aperture. The holotype of $C$.

1010 gracilis [MACN 6421] has a distinctive arrange of the teleoconch axial ribs, thick and more

1011 separated than the ones present in both C. cordovana and C. tulumbensis sp. nov. During

1012 successive fieldwork carried out the past last years, no specimen corresponding to C. gracilis

1013 was found in or around the type locality in Catamarca. Clessinia gracilis had been previously 
1014 synonymized with $C$. cordovana due to its similar general shape and size (Cuezzo, Miranda \&

1015 Ovando, 2013). Nonetheless, Breure \& Romero (2012) treated C. gracilis and C. cordovana as

1016 different species, but the species identification of the material used in that molecular study raised

1017 our suspicions because its locality (Córdoba: Quilpo) is where C. cordovana is very abundant.

1018 Moreover, Quilpo is distant by a few kilometers from San Marcos Sierra where we have found

1019 specimens with more marked axial ribs. Based on COI sequence, C. gracilis groups together

1020 with $C$. cordovana in our phylogenetic trees, with genetic distances ranging between $7,1 \%(p$

1021 distance) to $8.9 \%$ (K2P distance) from our C. cordovana specimens, and recognized as a

1022 different species by the ABGD analysis. Therefore, the identity of what Breure \& Romero (2012)

1023 consider as $C$. gracilis should be tested using morphological information to confirm the correct

1024 taxonomic identification, whose morphological differentiation might imply the recognition of $C$.

1025 gracilis as a valid species. Regarding C. nattkemperi and C. pagoda, we found genetic distances

1026 greater than $10 \%$ in relation to the other Clessinia species, and both are recognized as different

1027 genetic species according to ABGD and $K / \theta$ approaches. However, a finding in need of further

1028 investigation is the close relationship we obtained in our phylogenetic analyses between $C$.

1029 pagoda and S. cuezzoae, which exhibits very different morphologic features (Salas Oroño, 2010),

1030 but whose genetic distance was about 3.5\% for the $16 S$-rRNA locus and ranged from $4.8 \%(p$

1031 distance) to $5.4 \%$ for the COI marker.

1032 The results obtained here have taxonomic implications at the genus level for Clessinia and

1033 Spixia. On the basis of morphological evidence Spixia and Clessinia are easily externally

1034 distinguished because former Clessinia species have the aperture detached from the body whorl

1035 forming a cornet, periostracal microsculpture extended over dorsal portion of the peristome,

1036 presence of five inner teeth on the shell aperture instead of the three-four in Spixia. However,

1037 there are several other morphological similarities among species of both genera in general shell

1038 shape, type of periostracum microsculpture, reproductive anatomy, presence of a pallial gland,

1039 besides the overlap in geographic ranges. Molecular evidence suggest that taxa placed in former

1040 genera Spixia and Clessinia belong to the same group, and both genera as currently known until

1041 now would be paraphyletic (Breure \& Romero, 2012). Molecular results obtained here support

1042 this previous finding. Nonetheless, previous phylogenies based on molecular data, only included

1043 few representatives' species of the genus Spixia. Moreover, its type species Spixia striata (Spix,

1044 1827), is still only known by its shell description with no information on its internal anatomy and 
1045 molecular identity. Nonetheless, based on the available evidence, Clessinia and Spixia are 1046 synonymous, and according to the principle of priority (ICZN Code, Art.23.1) the valid name of 1047 the taxon should be Clessinia Doering, 1875 which has priority over Spixia Pilsbry \& Vanatta, 10481894.

\section{CONCLUSIONS}

1051 1. Studied species of Clessinia are endemic to the Chaco Serrano sub-ecoregion, restricted to small patches between the Semiarid Chaco and Yungas ecoregion in north-central Argentina.

2. The shell in Clessinia provided useful information for species identification. The aperture, with a continuous peristome, is detached from the body whorl. The apertural teeth are five, always located in the interior of the cornet mostly with no relation to the peristome. The periostracum, a layer that produces a conspicuous ornamentation in Clessinia species has taxonomic importance for the identification of the species. Each species has a particular periostracal structure of hairs of different length and densities and lamellas of different shape and sizes.

3. Morphological and molecular evidence support the composition of Clessinia cordovanacomplex by three species, Clessinia cordovana, Clessinia stelzneri and Clessinia tulumbensis sp. nov. Shell geometric morphometrics support our results on the species composition of the cordovana-complex but cannot be used alone as a single source of information for species identification.

4. The genitalia and jaw are also useful sources of characters for species identification. Inner penial sculpture, comparative length of flagellum, proportion of epiphallus respect to penis, the attachment of the vas deferens to a thick penis muscular retractor are the most conspicuous characters.

5. Based on our current analyses, and on previous findings (Breure \& Romero, 2012) Clessinia and Spixia are synonymous, and according to the principle of priority (ICZN Code,

1071 Art.23.1) the valid name of the taxon should be Clessinia Doering, 1875 which has priority over 1072 Spixia Pilsbry \& Vanatta, 1894.

1073

1074

\section{ACKNOWLEDGEMENTS}


1075 MGC would like to thank E. Dominguez and D. Dos Santos for companion and support in 1076 collecting land snails during field work. Thanks are also extended to the staff of the Centro 1077 Integral de Microscopia Electronica (CIME) for help in preparation of specimens and use of the 1078 SEM and to L. Cristobal for her assistance with GIS analysis. We also would like to thank the 1079 detailed suggestions and corrections made by Gary Rosenberg and an anonymous reviewer as 1080 well as the editor, Rudiger Bieler that improved our manuscript. 


\section{REFERENCES}

1083 Allgaier C. 2011. A hairy business_-periostracal hair formation in two species of helicoid snails 1084 (Gastropoda, Stylommatophora, Helicoidea). Journal of Morphology 272:1131-1143 DOI $108510.1002 /$ jmor.10969.

1086 Beltramino AA, Vogler RE, Rumi A, Guzmán LB, Martín SM, Peso JG. 2018. The exotic 1087 jumping snail Ovachlamys fulgens (Gude, 1900) (Gastropoda: Helicarionidae) in urban areas 1088 of the Upper-Paraná Atlantic Forest. Anais da Academia Brasileira de Ciências 90(2):159110891603 DOI 10.1590/0001-3765201820170766.

1090 Birky CW Jr. 2013. Species detection and identification in sexual organisms using population 1091 genetic theory and DNA sequences. PLoS ONE 8:e52544 DOI

1092 10.1371/journal.pone.0052544.

1093 Birky CW Jr, Adams J, Gemmel M, Perry J. 2010. Using population genetic theory and DNA 1094 sequences for species detection and identification in asexual organisms. PLoS ONE 5:e10609 1095 DOI 10.1371/journal.pone.0010609.

1096 Bookstein FL. 1991. Morphometric tools for landmark data: geometry and biology. Cambridge: 1097 Cambridge University Press. 435 p.

1098 Bouchet P, Rocroi JP, Hausdorf B, Kaim A, Kano Y, Nützel A, Parkhaev P, Schrödl M, 1099 Strong EE. 2017. Revised classification, nomenclator and typification of Gastropod and 1100 Monoplacophoran families. Malacologia 61(1-2):1-526 DOI 10.4002/040.061.0201.

1101 Breure ASH. 1974. Catalogue of Bulimulidae (Gastropoda, Euthyneura), II. Odontostominae. 1102 Basteria 38:109-127.

1103 Breure ASH, Schouten JR. 1985. Notes on and descriptions of Bulimulidae (Mollusca, 1104 Gastropoda), III. Zoologische Verhandelingen 216:1-98.

1105 Breure ASH, Groenenberg DSJ, Schilthuizen M. 2010. New insights in the phylogenetic 1106 relations within Orthalicoidea (Gastropoda, Stylommatophora) based on 28S sequence data. 1107 Basteria 74:25-31.

1108 Breure ASH, Ablett JD. 2012. Annotated type catalogue of the Bothriembryontidae and 1109 Odontostomidae (Mollusca, Gastropoda, Orthalicoidea) in the Natural History Museum, 1110 London. ZooKeys 182:1-70 DOI 10.3897/zookeys.182.2720.

1111 Breure ASH, Romero PE. 2012. Support and surprises: molecular phylogeny of the land snail 1112 superfamily Orthalicoidea using three-locus gene analysis with a divergence time analysis and 
1113 ancestral area reconstruction. Archive fur Molluskenkunden 141(1):1-20 DOI

1114 10.1127/arch.moll/1869-0963/141/001-020.

1115 Carvajal-Rodriguez A, Conde-Padin P, Rolan-Alvarez E. 2005. Decomposing shell form into

1116 size and shape by geometric morphometric methods in two sympatric ecotypes of Littorina

1117 saxatilis. Journal of Molluscan Studies 71:313-318 DOI 10.1093/mollus/eyi037.

1118 Cowie RH, Cazzaniga NJ, Glaubrecht M. 2004. The South American Mollusca of Johann

1119 Baptist Ritter von Spix and their publication by Johann Andreas Wagner. The Nautilus $1120 \quad$ 118(2):71-87.

1121 Cruz RA, Pante MJ, Rohlf FJ. 2012. Geometric morphometric analysis of shell shape variation

1122 in Conus (Gastropoda: Conidae). Zoological Journal of the Linnean Society 165:296-310

1123 DOI 10.1111/j.1096-3642.2011.00806.x.

1124 Cuezzo MG. 1997. Comparative anatomy of three species of Epiphragmophora Doering, 1874

1125 (Pulmonata: Xantonychidae) from Argentina. The Veliger 40(3):216-227.

1126 Cuezzo MG. 2003. Phylogenetic analysis of the Camaenidae (Mollusca: Stylommatophora) with

1127 special emphasis on the American taxa. Zoological Journal of the Linnean Society 138:449-

$1128 \quad 476$ DOI 10.1046/j.1096-3642.2003.00061.x.

1129 Cuezzo MG. 2006. Systematic revision and cladistic analysis of Epiphragmophora Doering

1130 from Argentina and Southern Bolivia (Gastropoda: Stylommatophora: Xanthonychidae).

1131 Malacologia 49(1):121 188 DOI 10.4002/1543-8120-49.1.121.

1132 Cuezzo MG, Miranda MJ, Ovando XMC. 2013. Species catalogue of Orthalicoidea in

1133 Argentina (Gastropoda: Stylommatophora). Malacologia 56(1-2):135-191 DOI

$1134 \quad 10.4002 / 040.056 .0210$.

1135 Darriba D, Taboada GL, Doallo R, Posada D. 2012. jModelTest 2: more models, new

1136 heuristics and parallel computing. Nature Methods 9:772 DOI 10.1038/nmeth.2109.

1137 Davison A, Blackie RLE, Scothern GP. 2009. DNA barcoding of Stylommatophoran land

1138 snails: a test of existing sequences. Molecular Ecology Resources 9:1092-1101 DOI

$1139 \quad 10.1111 / \mathrm{j} .1755-0998.2009 .02559 . x$.

1140 Doering A. 1874 [1875]. Estudios sistemáticos y anatómicos sobre los moluscos pulmoníferos

1141 de los países del Plata. Periódico Zoológico 1(3):129-204.

1142 Doering A. 1875 [1877a]. Apuntes sobre la fauna de moluscos de la República Argentina

1143 (Tercera Parte). Boletín de la Academia de Ciencias Exactas en Córdoba 2(3):300-339. 
1144 Doering A. 1875 [1877b]. Apuntes sobre la fauna de moluscos de la República Argentina 1145 (continuación). Periódico Zoológico 2(4):219-258.

1146 Dohrn H. 1875. Miscellen. Malakozoologische Blätter 22:202-203.

1147 Dohrn H. 1877. Conchyliologische Miscellen. Malakozoologische Blätter 24:157-159.

1148 Dubois A. 2007. Phylogeny, taxonomy and nomenclature: the problem of taxonomic categories

1149 and of nomenclatural ranks. Zootaxa 1519:27-68 DOI 10.11646/zootaxa.1519.1.3.

1150 Dubois A. 2010. Editorial. Taxonomy in the century of extinctions: taxonomic gap, taxonomic 1151 impediment, taxonomic urgency. Taprobanica 2(1):1-5 DOI 10.4038/tapro.v2i1.2702.

1152 Dubois A. 2017. The need for reference specimens in zoological taxonomy and nomenclature.

1153 Bionomina 12:4-38 DOI 10.11646/bionomina.12.1.2.

1154 Felsenstein J. 1985. Confidence limits on phylogenies: an approach using the bootstrap.

1155 Evolution 39:783-791 DOI 10.2307/2408678.

1156 Fernández D. 1973. Catálogo de la malacofauna terrestre Argentina. Comisión de

1157 Investigaciones Científicas de la Provincia de Buenos Aires 4:1-197.

1158 Folmer O, Black M, Hoeh W, Lutz R, Vrijenhoek R. 1994. DNA primers for amplification of

1159 mitochondrial cytochrome c oxidase subunit I from diverse metazoan invertebrates.

1160 Molecular Marine Biology and Biotechnology 3:294-299.

1161 Fontaneto D, Flot JF, Tang CQ. 2015. Guidelines for DNA taxonomy, with a focus on the 1162 meiofauna. Marine Biodiversity 45:433-451 DOI 10.1007/s12526-015-0319-7.

1163 Gasparri NI, Grau HR. 2009. Deforestation and fragmentation of Chaco dry forest in NW 1164 Argentina (1972-2007). Forest Ecology and Management 258:913-921 DOI

$1165 \quad$ 10.1016/j.foreco.2009.02.024.

1166 González VL, Kayal E, Halloran M, Shrestha Y, Harasewych MG. 2016. The complete 1167 mitochondrial genome of the land snail Cerion incanum (Gastropoda: Stylommatophora) and 1168 the phylogenetic relationships of Cerionidae within Panpulmonata. Journal of Molluscan 1169 Studies 82:525-533 DOI 10.1093/mollus/eyw017.

1170 Grau HR, Torres R, Gasparri NI, Blendinger PG, Marinaro S, Macchi L. 2015. Natural

1171 grasslands in the Chaco. A neglected ecosystem under threat by agriculture expansion and

1172 forest-oriented conservation policies. Journal of Arid Environments 123:40-46 DOI

$1173 \quad$ 10.1016/j.jaridenv.2014.12.006. 
1174 Greve C, Gimnich F, Hutterer R, Misof B, Haase M. 2012. Radiating on oceanic islands:

1175

1176

1177

1178

1179

1180

1181

1182

1183

1184

1185

1186

1187

1188

1189

1190

1191

1192

1193

1194

1195

1196

1197

1198

1199

1200

1201

1202

1203

1204 patterns and processes of speciation in the land snail genus Theba (Risso 1826). PLoS ONE 7(4):e34339 DOI 10.1371/journal.pone.0034339.

Guindon S, Dufayard JF, Lefort V, Anisimova M, Hordijk W, Gascuel O. 2010. New algorithms and methods to estimate maximum-likelihood phylogenies: assessing the performance of PhyML 3.0. Systematic Biology 59:307-321 DOI 10.1093/sysbio/syq010.

Hall TA. 1999. BioEdit: a user-friendly biological sequence alignment editor and analysis program for Windows 95/98/NT. Nucleic Acids Symposium Series 41:95-98.

Holmberg EL. 1912. Bulimuli et Odontostomi Argentini adhuc indescipti, necnon species ad subgenus nondum relatae. Anales del Museo Nacional de Historia Natural de Buenos Aires 23:147-153.

Hylton Scott MI. 1966. Nueva Cyclodontina y revaloración del subgénero Clessinia Doering, 1874. Neotropica 12:30-35.

Hylton Scott MI. 1967. Nuevos Odontostomidos de Córdoba. Neotropica 13(42):97-103.

Izquierdo AE, Grau HR. 2009. Agriculture adjustment, land-use transition and protected areas in Northwestern Argentina. Journal of Environment Management 90:858-865 DOI 10.1016/j.jenvman.2008.02.013.

Katoh K, Rozewicki J, Yamada KD. 2017. MAFFT online service: multiple sequence alignment, interactive sequence choice and visualization. Briefings in Bioinformatics bbx108 DOI $10.1093 /$ bib/bbx108.

Kerney MP, Cameron RAD. 1979. A field guide to the land snail of Britain and North-West Europe. London: Collins. 288 p.

Klingenberg CP. 2011. Morpho J. Faculty of Life Sciences, University of Manchester, United Kingdom. Available at: www.flywings.org.uk/MorphoJ guide/frameset.htm?index.htm.

Kobelt W. 1878. Argentinische Landconchylien von W. Kobelt. Jahrbücher der Deutschen Malakozoologischen Gessellschaft 5:143-150.

Kumar S, Stecher G, Li M, Knyaz C, Tamura K. 2018. MEGA X: molecular evolutionary genetics analysis across computing platforms. Molecular Biology and Evolution 35:15471549 DOI 10.1093/molbev/msy096.

Larkin MA, Blackshields G, Brown NP, Chenna R, McGettigan PA, McWilliam H, Valentin F, Wallace IM, Wilm A, Lopez R, Thompson JD, Gibson TJ, Higgins DG. 2007. 
1205 Clustal W and Clustal X version 2.0. Bioinformatics 23:2947-2948 DOI

1206 10.1093/bioinformatics/btm404.

1207 Lefort V, Longueville JE, Gascuel O. 2017. SMS: Smart Model Selection in PhyML.

1208 Molecular Biology and Evolution 34:2422-2424 DOI 10.1093/molbev/msx149.

1209 Martens KE von. 1890-1891. Land and freshwater Mollusca. In: Goldman FD, Salvin O, eds.

1210 Biologia Centrali-Americana. London: Taylor \& Francis, 1-706.

1211 Morello J, Matteucci SD, Rodriguez AF, Silva ME. 2012. Ecoregiones y complejos

1212 ecosistémico argentinos. Facultad de Arquitectura, diseño y urbanismo, GEPAMA. Buenos

1213 Aires: Universidad Nacional de Buenos Aires, 719 p.

1214 Neubert E, Janssen R. 2004. Die Typen und Typoide des Natur-Museums Senckenberg, 84:

1215 Mollusca: Gastropoda: Pulmonata: Orthalicoidea: Bulimulidae (2), Orthalicidae,

1216 Placostylidae. Archiv für Molluskenkunde 133:193-297.

1217 Olson DM, Dinerstein E, Wikramanayake ED, Burgess ND, Powell GVN, Underwood EC, 1218 D'Amico JA, Itoua I, Strand HE, Morrison JC, Loucks CJ, Allnutt TF, Ricketts TH, 1219 Kura Y, Lamoreux JF, Wettengel WW, Hedao P, Kassem KR. 2001. Terrestrial

1220 ecoregions of the world: a new map of life on Earth. BioScience 51:933-938 DOI

$1221 \quad$ 10.1641/0006-3568(2001)051[0933:TEOTWA]2.0.CO;2.

1222 Parodiz JJ. 1939. Revisión de Plagiodontes y Scalarinella (Odontostominae). Physis 17:7111223734.

1224 Parodiz JJ. 1944. Contribuciones al conocimiento de los Moluscos terrestres Sudamericanos, II.

1225 Una nueva especie de Scalarinella de Catamarca. Comunicaciones Zoológicas del Museo de

1226 Historia Natural de Montevideo 1:1-6.

1227 Parodiz JJ. 1957. Catalogue of the land Mollusca of Argentina. The Nautilus 71(1):22-30.

1228 Pfeiffer L. 1855. Versuch einer Anordnung der Heliceen nach natürlichen Gruppen.

1229 Malakozoologische Blätter 2:112-188.

1230 Pfeiffer L. 1856. Description of twenty five new species of land shells, from the collection of

1231 Hugh Cuming, Esq. Proceedings of the Zoological Society of London, for 1856[24]:32-36.

1232 Pfeiffer L. 1859. Monographia heliceorum viventium: sistens descriptiones systematicas et

1233 criticas omnium huius familiae generum et specierum hodie cognitarum. Brockhaus: Lipsiae.

1234 ix $+920 p$. 
1235 Pfenninger M, Hrabáková M, Steinke D, Depraz A. 2005. Why do snails have hair? A

1236

1237

1238

1239

1240

1241

1242

1243

1244

1245

1246

1247

1248

1249

1250

1251

1252

1253

1254

1255

1256

1257

1258

1259

1260

1261

1262

1263

1264

1265

Bayesian inference of character evolution. BMC Evolutionary Biology 5:59-70 DOI 10.1186/1471-2148-5-59.

Pilsbry HA. 1901 [1901-1902]. Oriental bulimulid Helicidae. Odontostominae, Cerionidae. Volume XIV. Manual of Conchology, Second Series: Pulmonata. Conchological Section. Academy of Natural Sciences of Philadelphia $302+$ xcix pp., 62 pls.

Pizá J, Cazzaniga N. 2012. Barrels and pagodas: clarifying the identity and variability of two nominal taxa of carinated land snails in the genus Plagiodontes (Gastropoda: Orthalicidae: Odontostominae). Journal of Natural History 46:383-410 DOI 10.1080/00222933.2011.640440.

Puillandre N, Lambert A, Brouillet S, Achaz G. 2012. ABGD, automatic barcode gap discovery for primary species delimitation. Molecular Ecology 21:1864-1877 DOI 10.1111/j.1365-294X.2011.05239.x.

Quantum GIS Development Team. 2009. Quantum GIS Geographic Information System. Open Source Geospatial Foundation Project. Available at: http://qgis.osgeo.org.

Ramírez J, Ramírez R. 2010. Analysis of the secondary structure of mitochondrial LSU rRNA of Peruvian land snails (Orthalicidae: Gastropoda). Revista Peruana de Biología 17:53-57 DOI 10.15381/rpb.v17i1.51.

Restrepo S, Tabima JF, Mideros MF, Grünwald NJ, Matute DR. 2014. Speciation in fungal and oomycete plant pathogens. Annual Review of Phytopathology 52:289-316 DOI 10.1146/annurev-phyto-102313-050056.

Rohlf FJ. 2016a. TpsUtil, Digitize Landmarks and Outlines. Stony Brook, Department of Ecology and Evolution, State University of New York at Stony Brook. Available at: $\underline{\text { http://life.bio.sunysb.edu/morph/. }}$

Rohlf FJ. 2016b. TpsDig, Digitize Landmarks and Outlines. Stony Brook, Department of Ecology and Evolution, State University of New York at Stony Brook. Available at: http://life.bio.sunysb.edu/morph/.

Ronquist F, Teslenko M, van der Mark P, Ayres DL, Darling A, Höhna S, Larget B, Liu L, Suchard MA, Huelsenbeck JP. 2012. MrBayes 3.2: efficient bayesian phylogenetic inference and model choice across a large model space. Systematic Biology 61:539-542 DOI $10.1093 /$ sysbio/sys029. 
1266 Rumi A, Vogler RE, Beltramino AA. 2017. The South-American distribution and southernmost record of Biomphalaria peregrina - a potential intermediate host of schistosomiasis. PeerJ 5:e3401 DOI 10.7717/peerj.3401.

Salas Oroño E. 2007. Taxonomic review of the Spixia pyriformis species complex (Gastropoda: Pulmonata: Odontostominae). Zootaxa 1498:1-25.

Salas Oroño E. 2010. A new species of Spixia from Argentina (Gastropoda: Pulmonata: Odontostominae). Journal of Conchology 40(3):1-9.

Schneider CA, Rasband WS, Eliceiri KW. 2012. NIH Image to ImageJ: 25 years of image analysis. Nature Methods 9(7):671-675 DOI 10.1038/nmeth.2089.

Schön I, Pinto RL, Halse S, Smith AJ, Martens K, Birky CW Jr. 2012. Cryptic species in putative ancient asexual darwinulids (Crustacea, Ostracoda). PLoS ONE 7:e39844 DOI 10.1371/journal.pone.0039844.

Simone LRL. 2006. Land and freshwater Molluscs of Brazil. São Paulo: EGB, Fapesp. 390 p.

Solem A. 1966. The Neotropical land snail genera Labyrinthus and Isomeria (Pulmonata: Camaenidae). Fieldiana, Zoology 50:1-226.

Tablado A, Mantinian, J. 2004. Catálogo de ejemplares tipo de la División Invertebrados del Museo Argentino de Ciencias Naturales. II. Mollusca. Revista del Museo Argentino de Ciencias Naturales 6(2):363-384.

Tompa AS. 1984. Land Snails (Stylommatophora). In: Tompa AS, Verdonk HH, Van Den Biggelar JA, eds. The Mollusca. New York: Academic Press, 47-140. DOI 10.1016/B978-008-092659-9.50009-0.

Valdecasas AG, Williams D, Wheeler QD. 2008. 'Integrative taxonomy' then and now: a response to Dayrat (2005). Biological Journal of the Linnean Society 93: 211-216 DOI 10.1111/j.1095-8312.2007.00919.x.

Vogler RE, Beltramino AA, Peso JG, Rumi A. 2014. Threatened gastropods under the evolutionary genetic species concept: redescription and new species of the genus Aylacostoma (Gastropoda: Thiaridae) from High Paraná River (Argentina-Paraguay). Zoological Journal of the Linnean Society 172:501-520 DOI 10.1111/zoj.12179. evolutionary history of an extinct South American freshwater snail based on historical DNA. PLoS ONE 11:e0169191 DOI 10.1371/journal.pone.0169191. 
1297 Wade CM, Mordan PB. 2000. Evolution within the gastropod molluscs: using the ribosomal

1298 RNA gene cluster as an indicator of phylogenetic relationships. Journal of Molluscan Studies 1299 66:565-570 DOI 10.1093/mollus/66.4.565.

1300 Wheeler QD. 2004. Taxonomic triage and the poverty of phylogeny. Philosophical Transactions 1301 of the Royal Society of London 359:571-583 DOI 10.1098/rstb.2003.1452.

1302 Wheeler QD, Raven PH, Wilson EO. 2004. Taxonomy: impediment or expedient? Science 1303 303(5656):285 DOI 10.1126/science.303.5656.285.

1304 Zilch A. 1959-1960. Gastropoda: Euthyneura. In: Schindewolf OH, ed. Handbuch der

1305 Paläozoologie. Bornträger, Berlin, xii +834 pp.

1306 Zilch A. 1971. Die Typen und Typoide des Natur-Museums Senckenberg, 47: Mollusca-

1307 Euthyneura von A. Döring aus Argentinien. Archiv für Molluskenkunde, 101:195-213. 
Figure 1

Line drawings of Clessinia showing the placement of shells to obtain the linear measurements $(\mathrm{mm})$. 

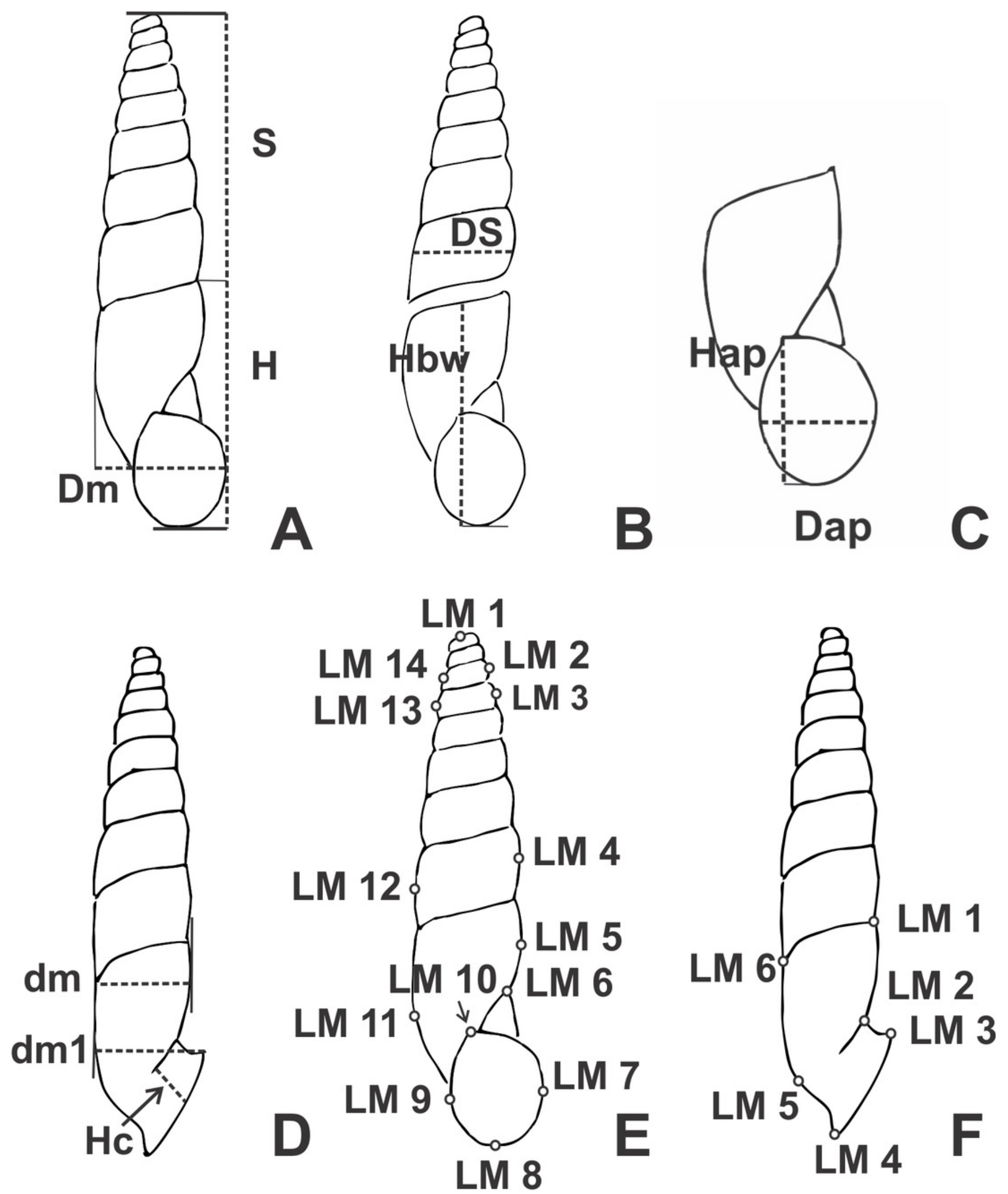


\section{Figure 2}

Geometric morphometric analyses

Canonical Variate Analyses (CVA) of shell shape variation (ventral view) along the first two canonical axes. Wireframe diagrams show shape changes associated with variation along each axis. (A) Based on all Clessinia species. (B) based on Clessinia cordovana species group from different localities of ocurrences. 


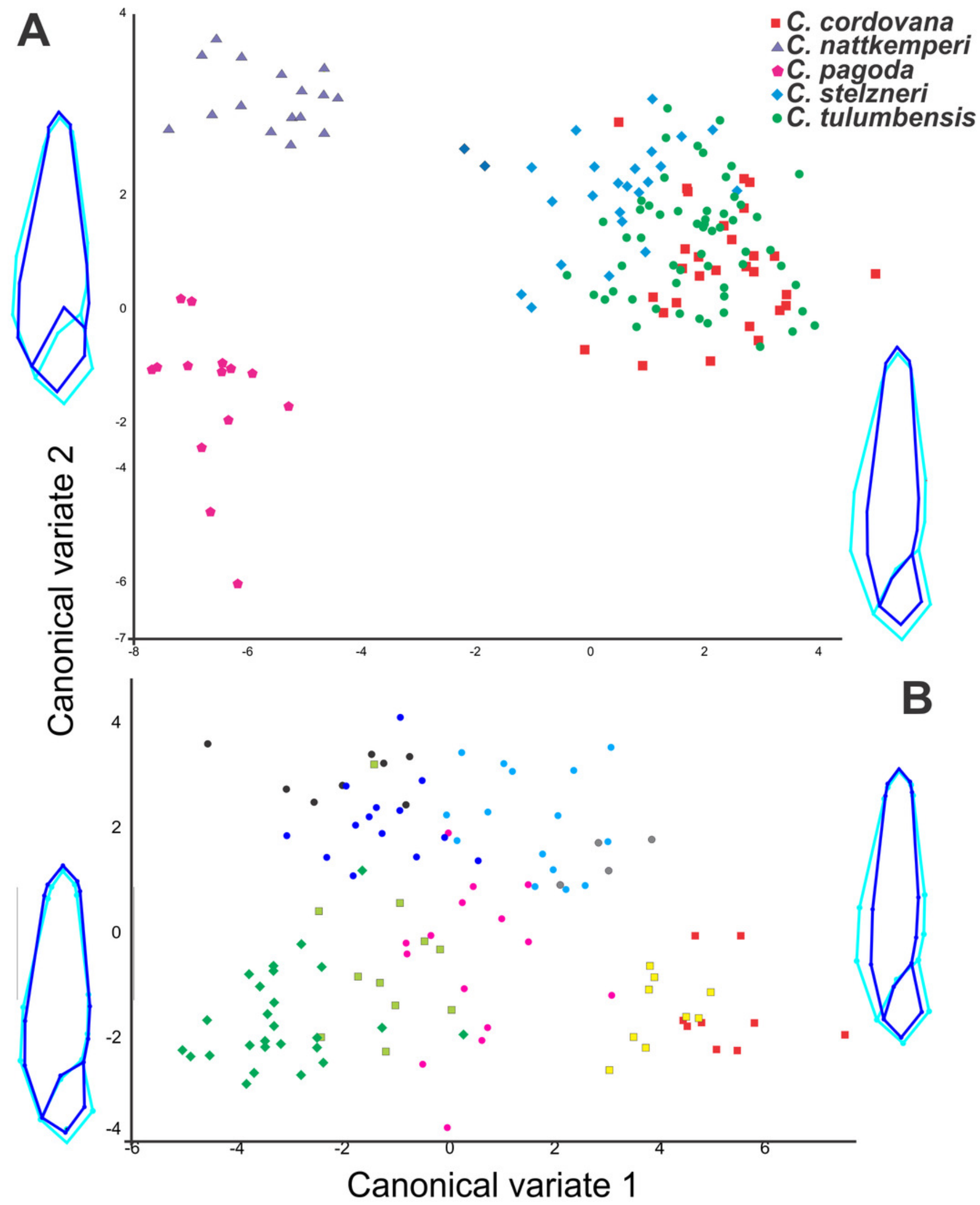

- C. cordovana C Cruz

- C. cordovana SIMS - C. cordovana SPo
- C. stelzneri CSV

- C. tulumbensis DF-Tu

- C. tulumbensis R16
- C. tulumbensis T-SJD

-C. tulumbensis ViFa

-C. tulumbensis CC 
Figure 3

Bayesian tree of Clessinia and Spixia species based on a 992 bp multi-locus dataset (COI and 16S-rRNA).

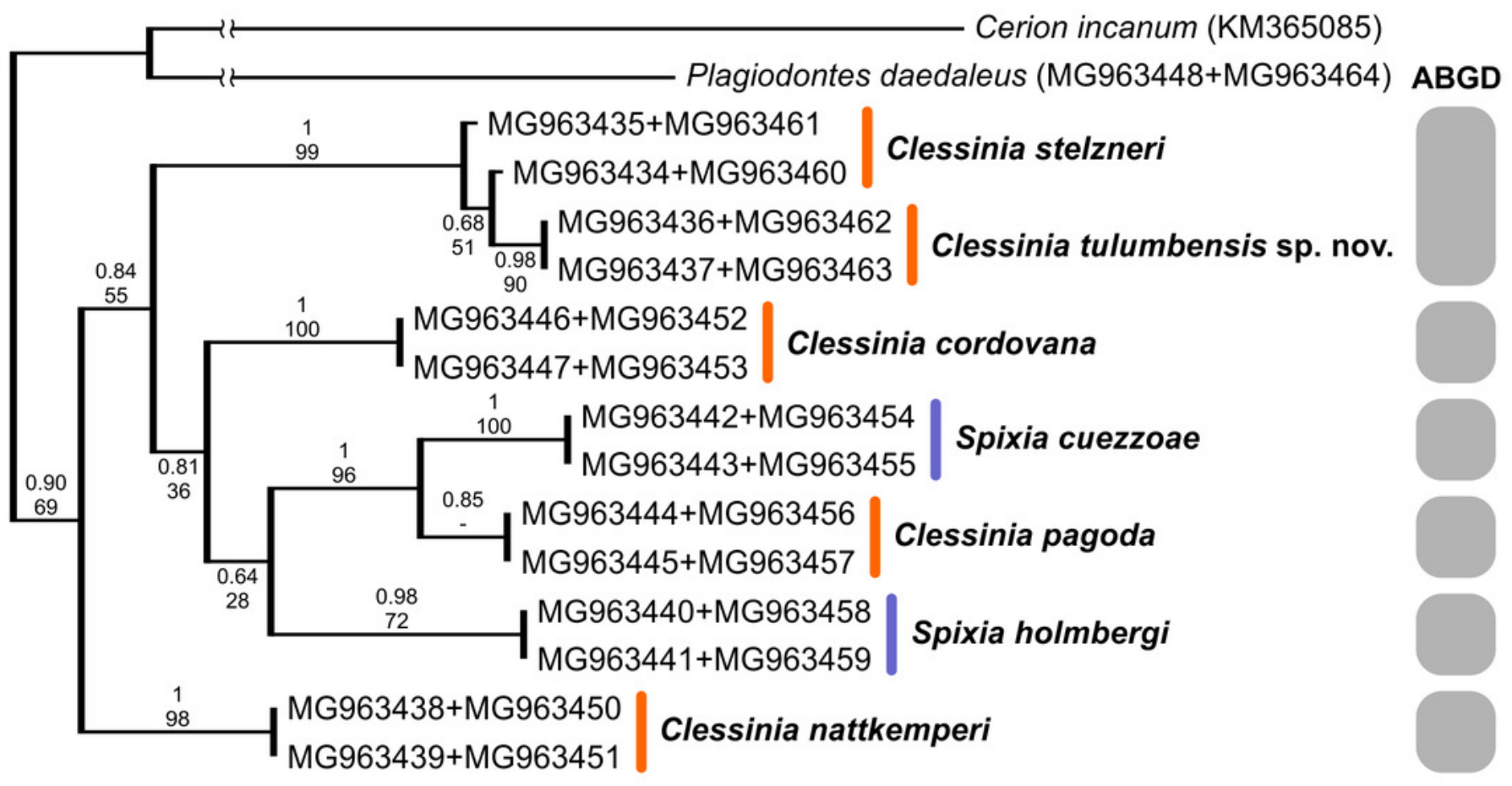




\section{Figure 4}

Bayesian tree of Clessinia and Spixia species based on the partial COI gene.

The posterior-probability values for $\mathrm{BI}$ and bootstrap values for the ML tree are shown above and below the branches. Numbers within groups are GenBank accession numbers. Gray bars indicate putative species identified by the ABGD analysis.

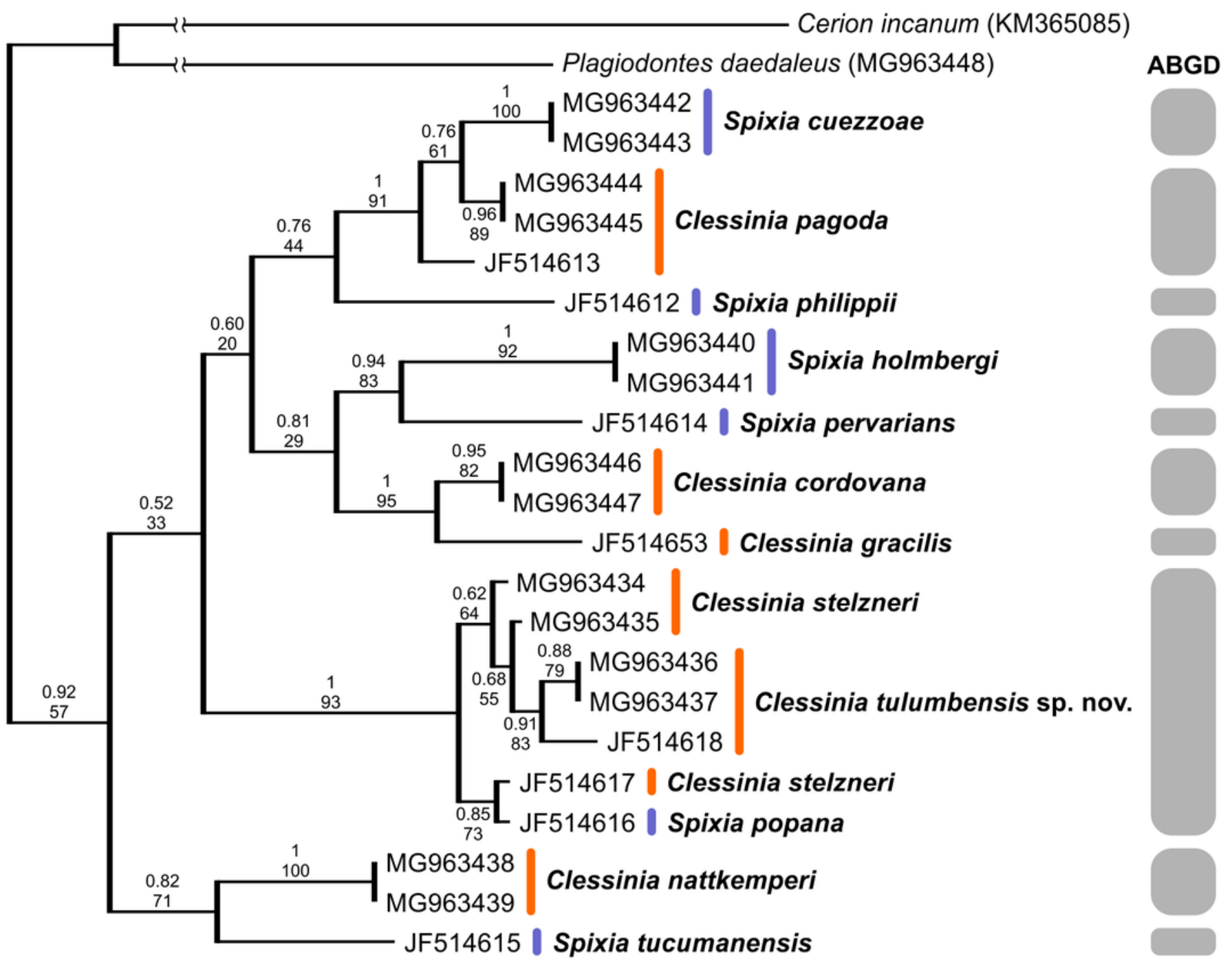




\section{Figure 5}

Distribution of Clessinia species.

(A) Position of Argentina in South America. (B) Ecoregions in north-central Argentina, note that the Dry Chaco ecoregion area is highlighted with a brown line limits. Quadrate areas correspond to $\mathrm{C}$ and $\mathrm{D}$ figures; (C) Catamarca province with localities of occurrences for C.nattkemperi and C. cordovana, ecoregions colors as in B; (D) Northern Cordoba province with localities of occurences of resting Clessinia species, ecoregions colors as in B. 

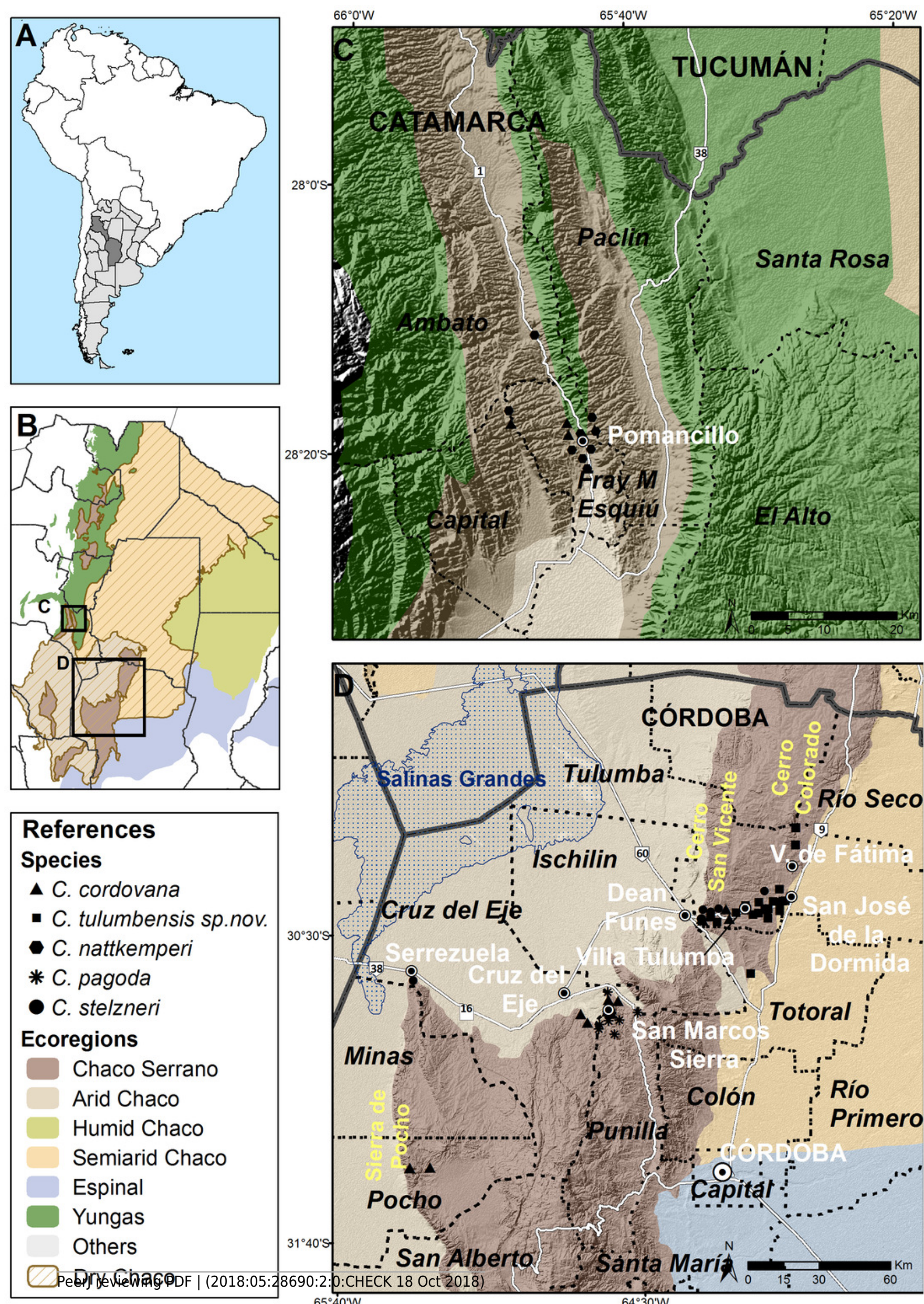

\section{References \\ Species \\ A C. cordovana \\ - C. tulumbensis sp.nov. \\ - C. nattkemperi \\ * C. pagoda \\ - C. stelzneri}

\section{Ecoregions}

Chaco Serrano Arid Chaco

Humid Chaco Semiarid Chaco

Espinal

Yungas

Others 


\section{Figure 6}

Clessinia cordovana, general shell morphology and habitat.

(A, B) Live specimen from Sierra de Pocho, central Córdoba. (C) Live specimen from San Marcos Sierra, northwestern Córdoba. (D) Ventral, (E) lateral, and (F) dorsal views of a shell from Sierra de Pocho, note the length of the periostral hairs, scale bar $=4 \mathrm{~mm}$ (IFML-Moll 15415). (G) Ventral, (H) lateral, and (I) dorsal views of a shell from San Marcos Sierra, note that the length of the periostracal hairs is shorter than in the previous locality, scale bar $=5$ $\mathrm{mm}$ (IBN 563. (J) Oval-shaped shell aperture of $C$. cordovana. (K) Square-shaped shell aperture. (L) Semicircular shaped shell aperture. (M) Part of the body whorl and aperture showing inner portion of lower columellar lamella. (N) Detail of dorsal view of the body whorl. (O) View of the species habitat in San Marcos Sierra, Córdoba. (P) View of the species habitat in Sierra de Pocho, Córdoba. Photographs by M.G. Cuezzo. 


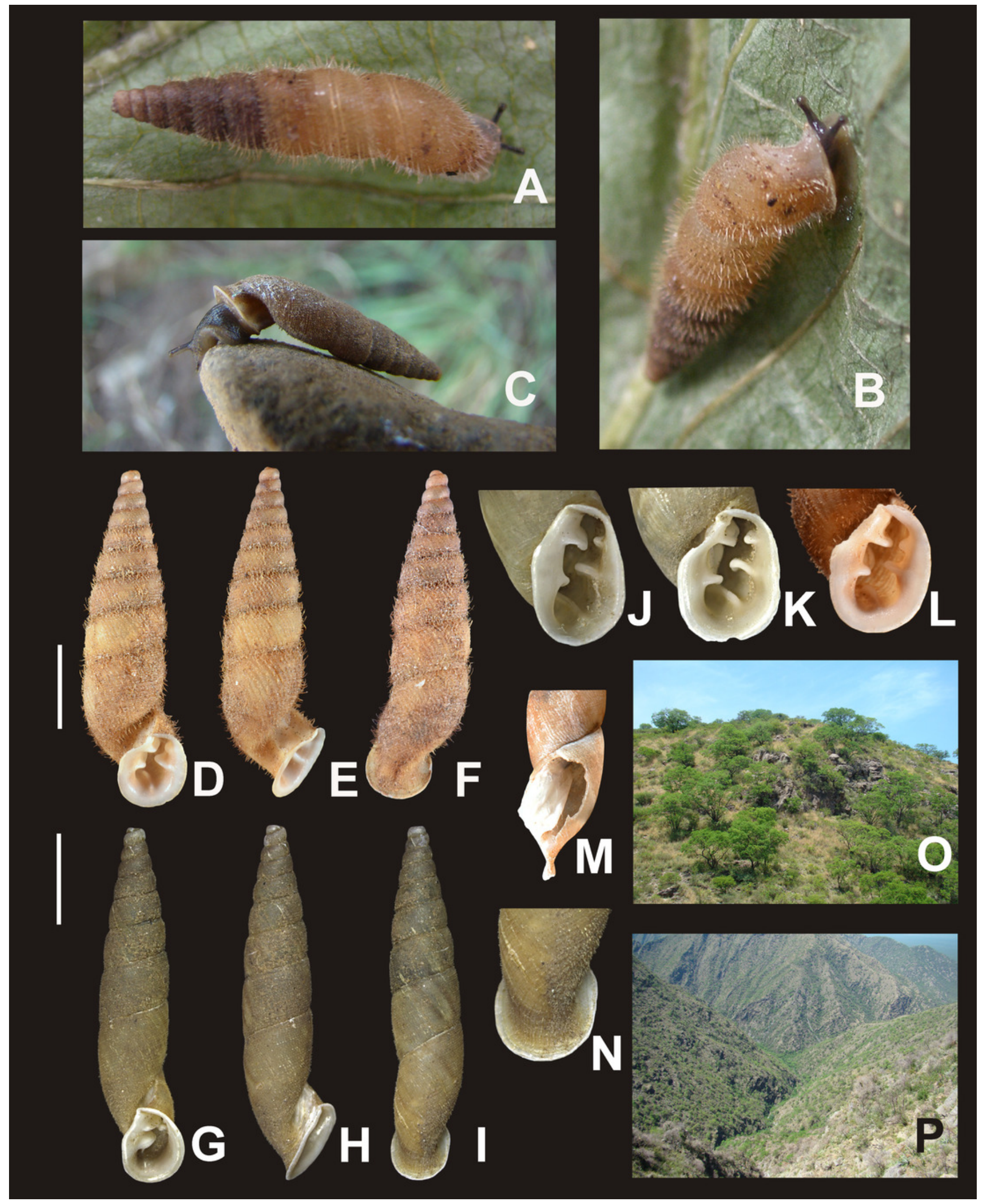




\section{Figure 7}

Clessinia cordovana, shell ultrastructure.

(A) Protoconch sculpture with axial, regularly arranged strength ribs, scale bar $=100 \mu \mathrm{m}$. (B)

Detail of protoconch showing thin spiral parallel bands delimited by spiral grooves between ribs, scale bar $=10 \mu \mathrm{m}$. (C) Body whorl and aperture detached from the rest of the shell, showing the long periostracal hairs, scale bar $=1000 \mu \mathrm{m}$. (D) Conic spire with spiral lines bearing hears, scale bar $=1000 \mu \mathrm{m}$. (E) Detail of periostracal hairs with triangular base, scale bar $=100 \mu \mathrm{m}$. (F) Detail of the interconnected axial micro folds giving the appearance of an irregular net, scale bar $=100 \mu \mathrm{m}$. Photographs by M.G. Cuezzo.

*Note: Auto Gamma Correction was used for the image. This only affects the reviewing manuscript. See original source image if needed for review. 

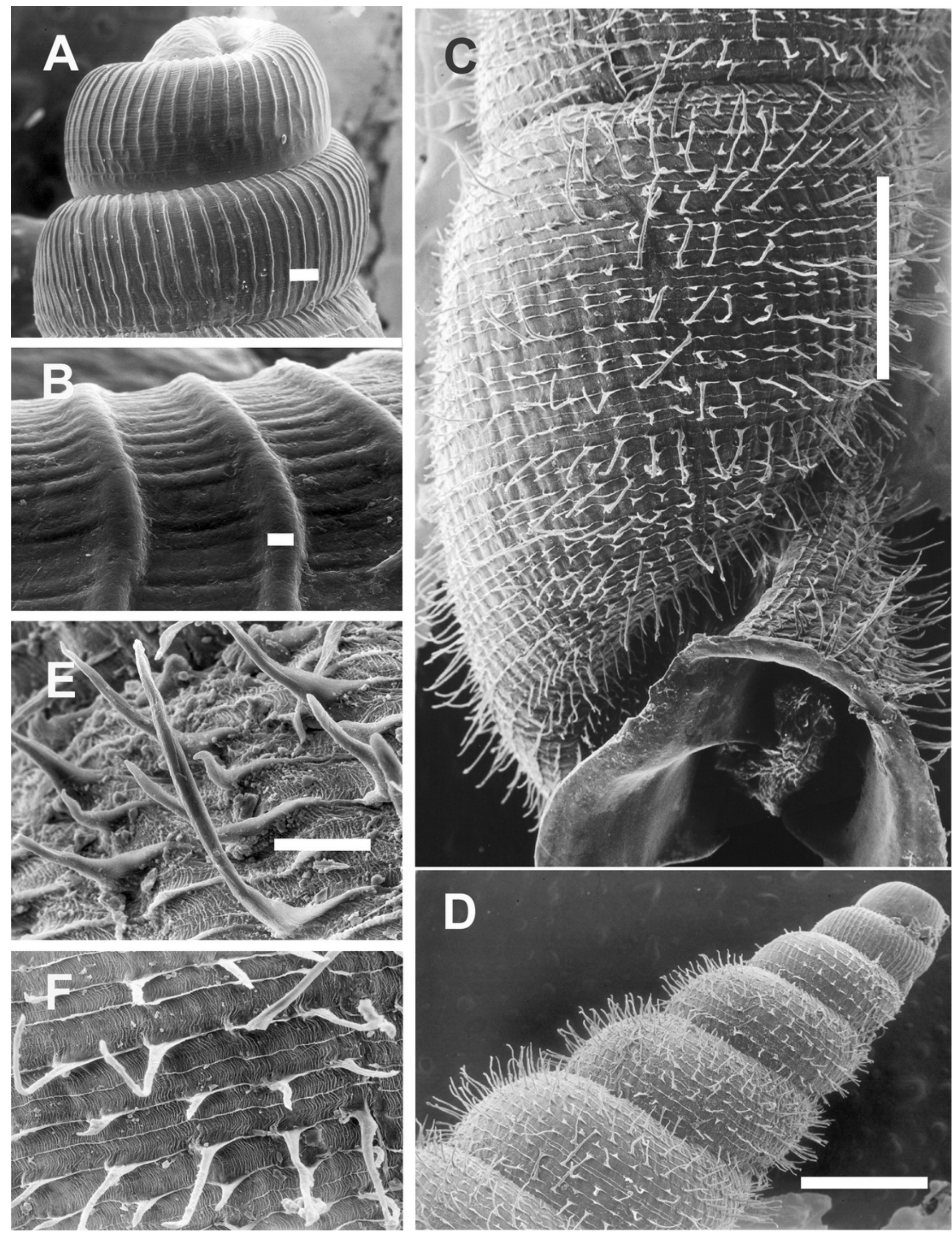

D

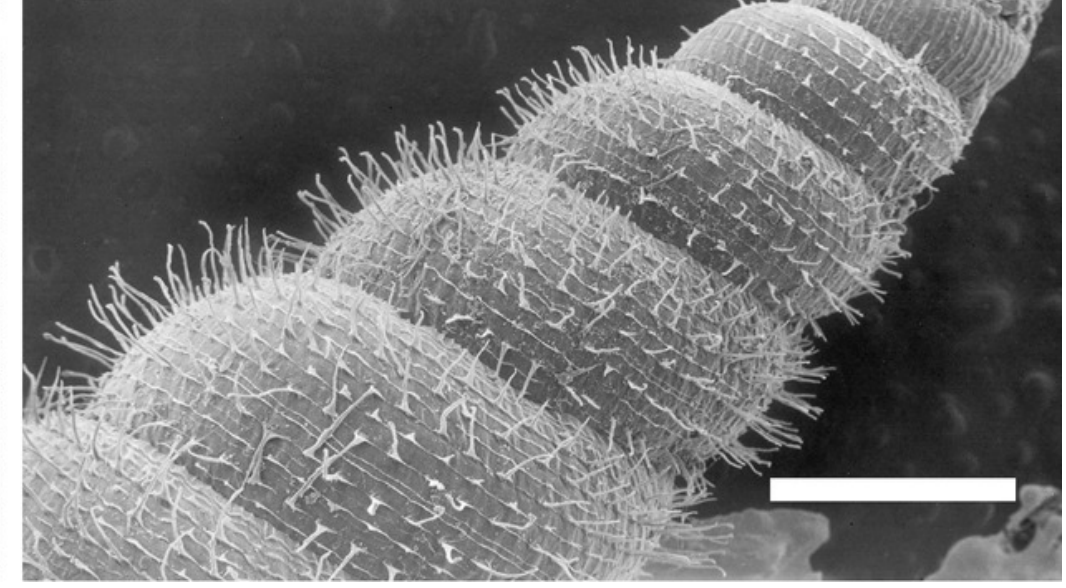




\section{Figure 8}

Radula and jaw in Clessinia.

(A) Jaw of $C$. cordovana, scale bar $=100 \mu \mathrm{m}$. (B) Jaw of $C$. stelzneri, scale bar $=100 \mu \mathrm{m}$. (C) Jaw of $C$. tulumbensis sp.nov., scale bar $=100 \mu \mathrm{m}$. (D) Jaw of $C$. pagoda, scale bar $=100 \mu \mathrm{m}$. (E) Jaw of $C$. nattkemperi, scale bar $=100 \mu \mathrm{m}$. (F-I) C. stelzneri: (F) General view of the radula, scale bar $=10 \mu \mathrm{m}$. $(\mathrm{G})$ Central and first lateral teeth, scale bar $=10 \mu \mathrm{m}$. (H) Lateral and marginal teeth in general view, scale bar $=10 \mu \mathrm{m}$. (I) Detail of lateral teeth, scale bar $=$ $10 \mu \mathrm{m}$. 


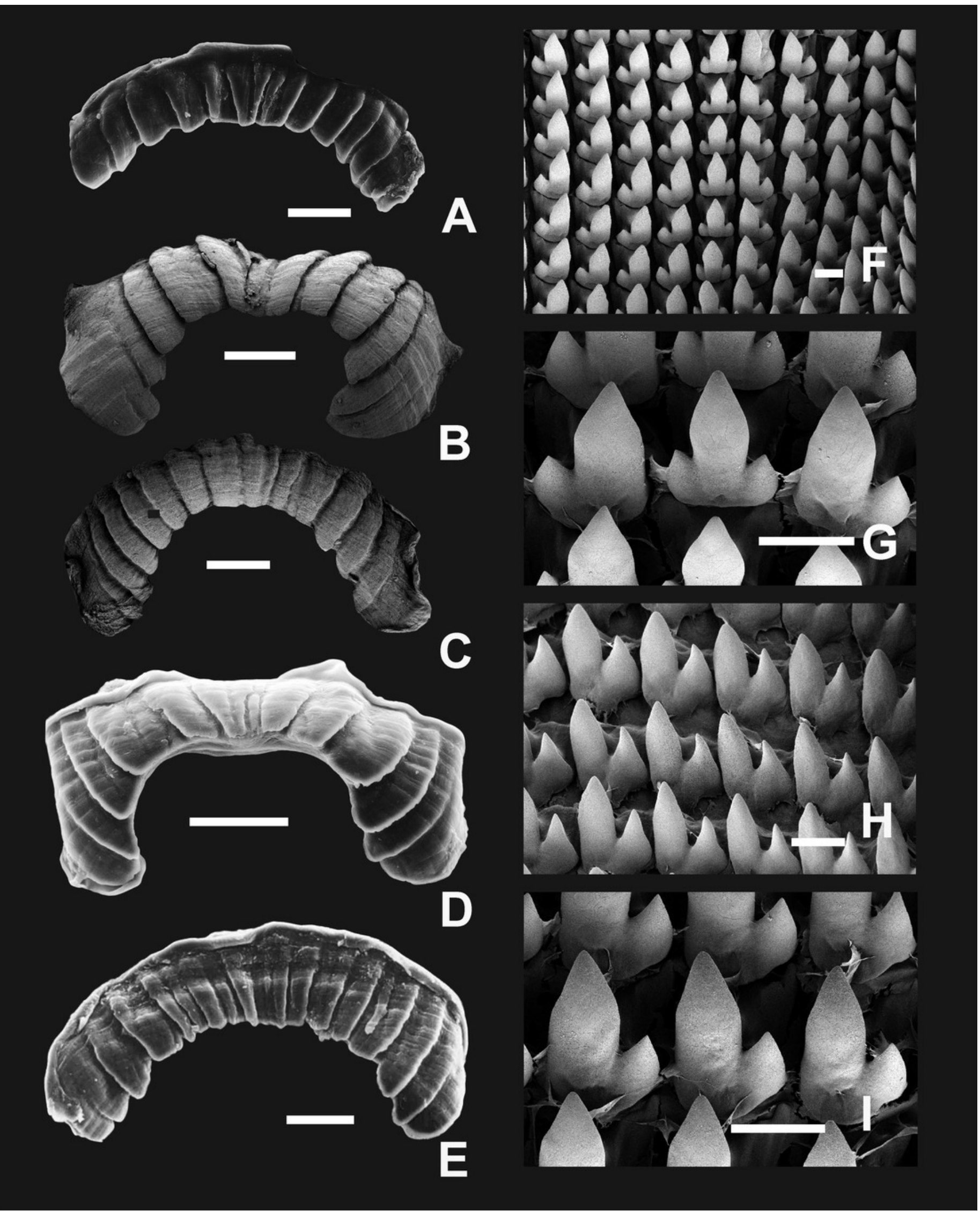




\section{Figure 9}

Clessinia cordovana, anatomy.

(A) General view of the reproductive system dissected out, limits penis/epiphallus is indicated, scale bar $=2 \mathrm{~mm}$. (B) Detail of the proximal portion of the penis complex showing the vas deferens attached to the penis muscular retractor, scale bar $=2 \mathrm{~mm}$. (C) Inner sculpture of penis showing the limits of three areas of the penial complex, note the position of the vas deferens, scale bar $=2 \mathrm{~mm}$. (D) Photograph of the inner sculpture of penis, same scale bar equal to figure $C$. (E) Detail of the rhomboidal pustules located in the medial inner portion of the penis wall. Abbreviations: ag, albumen gland; bc, bursa copulatrix; dp, penis distal portion; e, epiphallus; f, flagellum; hd, hermaphroditic duct; mp, penis medial portion; $\mathrm{mr}$, penial retractor muscle; $\mathrm{p}$, penis; ppr, penis proximal portion; ps, penis sheath; $v$, vagina; vd, vas deferens. 

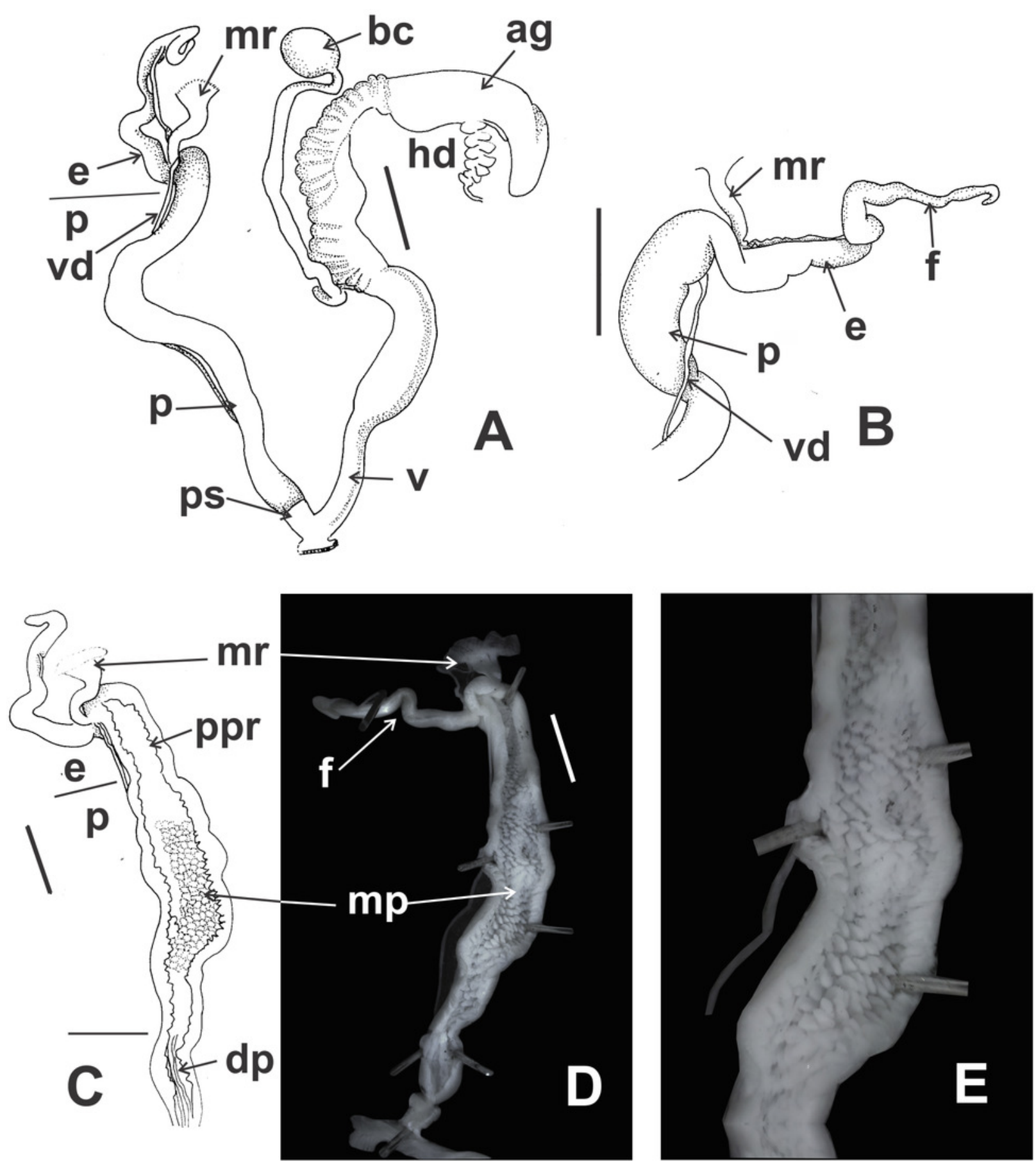


\section{Figure 10}

Clessinia stelzneri (A, B-F) and C. tulumbensis sp. nov. (A, G-M), general shell morphology and habitat (P).

(A) Live specimens of $C$. stelzneri (left) and C. tulumbensis sp. nov. (right). (B) Ventral, (C) lateral, (D) dorsal shell of Clessinia stelzneri, scale bar $=5 \mathrm{~mm}$. (E) Detail of the aperture, note the inner position of the obstructing teeth and lamellae. (F) Detail of the shell cornet of C. stelzneri with the palatal wall removed to show the undulating lower columellar lamella. (G) Live specimen of $C$. tulumbensis sp. nov., note axial ribs well marked especially in the body whorl and the lack of periostracal hairs. (H) Ventral, (I) lateral, (J) dorsal shell of the holotype of Clessinia tulumbensis sp. nov. (IBN 883), scale bar $=4 \mathrm{~mm}$. (K) Ventral, (L) lateral, (M) dorsal shell of a paratype of $C$. tulumbensis sp. nov. (IBN 571), scale bar $=2 \mathrm{~mm}$. (N) Shell aperture in C. tulumbensis sp. nov. (O) Detail of the shell cornet of $C$. tulumbensis sp. nov. with the palatal wall removed to show the deeply undulating lower columellar lamella. (P) Natural micro-habitat of Clessinia tulumbensis sp. nov. Photographs by M.G. Cuezzo. 


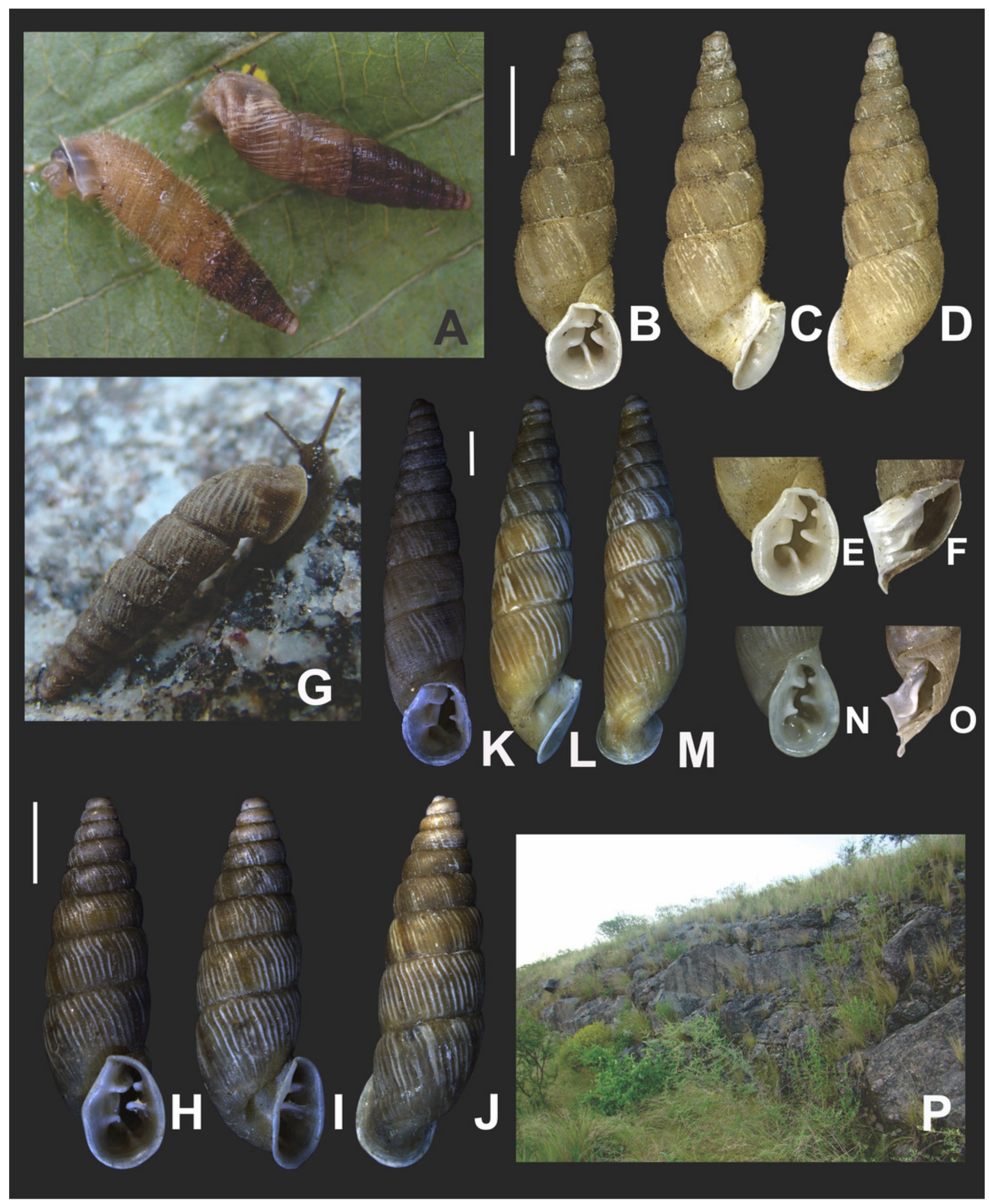




\section{Figure 11}

Clessinia stelzneri and C. tulumbensis sp. nov., shell ultrastructure.

C. stelzneri: (A) Protoconch and first whorl of the spire, scale bar $=100 \mu \mathrm{m}$. (B) Detail of the periostracal ultrastructure of following whorls, scale bar $=1000 \mu \mathrm{m}$. (C) Detail of periostracal hairs, scale bar $=100 \mu \mathrm{m}$. (D) Detail of body whorl close to aperture showing periostracal hairs and marked axial costules, scale bar $=100 \mu \mathrm{m}$. Clessinia tulumbensis sp.nov.: (E) second and third spire shell whorls with spiral rows without periostracal hairs, scale bar = $300 \mu \mathrm{m}$. (F) Contour of body whorl in C. tulumbensis sp. nov. with dense arrange of periostracal spiral rows, scale bar $=100 \mu \mathrm{m}$. Photographs by M.G. Cuezzo.

*Note: Auto Gamma Correction was used for the image. This only affects the reviewing manuscript. See original source image if needed for review. 

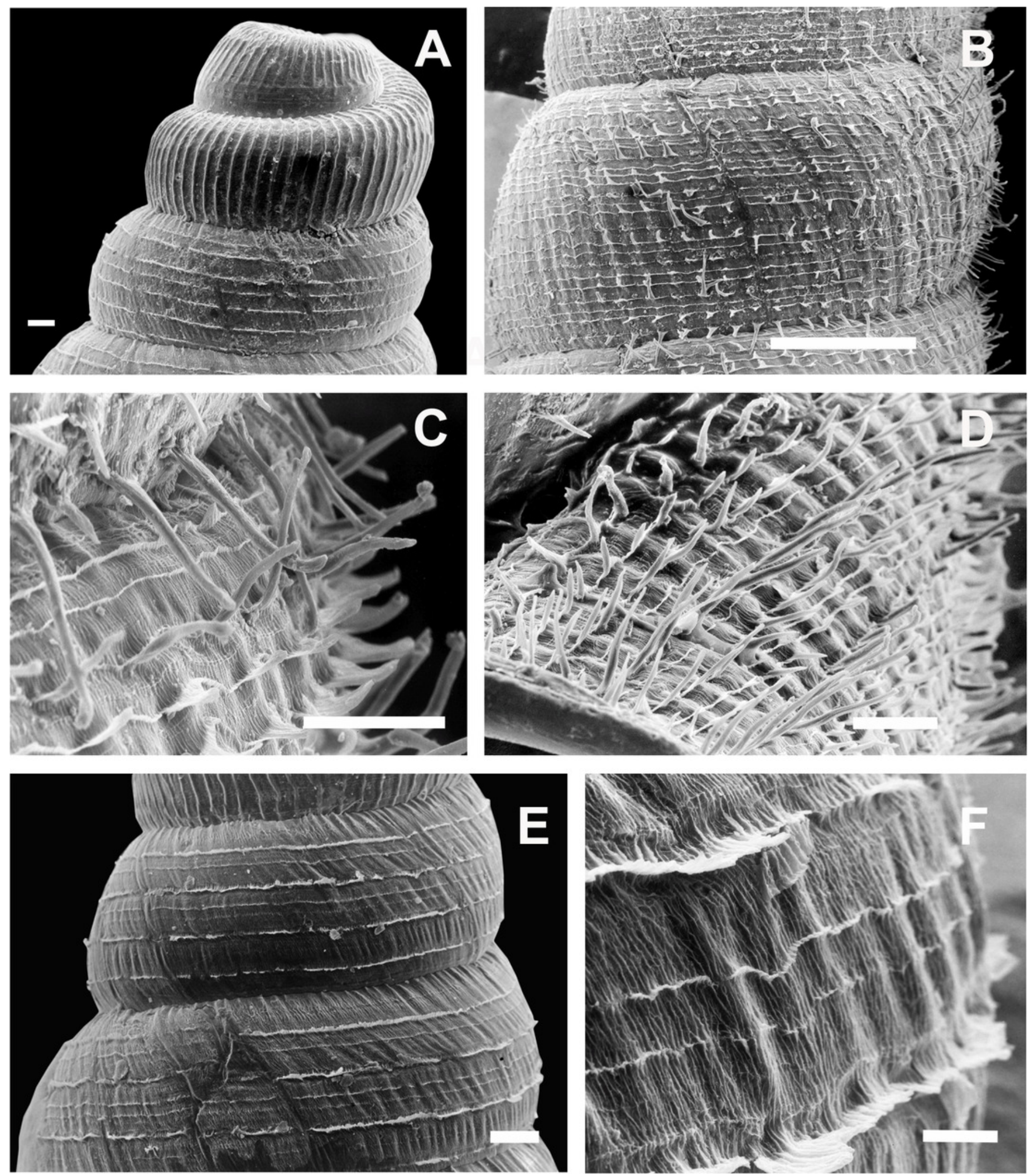


\section{Figure 12}

Clessinia stelzneri (A, B) and Clessinia tulumbensis sp. nov. (C-F), reproductive system.

Clessinia stelzneri: (A) General view, limits penis/epiphallus are indicated, scale bar $=2 \mathrm{~mm}$.

(B) Photograph showing the path of the vas deferens through the proximal penis, epiphallus, then it is attached to the retractor muscle, and later inserts between the epiphallus and flagellum. Clessinia tulumbensis sp. nov.: (C) general view of the reproductive system, scale bar $=2 \mathrm{~mm}$. (D) Inner sculpture of epiphallus-penis wall, scale bar $=3 \mathrm{~mm}$. (E) Photograph showing inner sculpture of penis. (F) Relation of the vas deferens and the penis muscular retractor, scale bar $=1 \mathrm{~mm}$. Abbreviations: ag, albumen gland; bc, bursa copulatrix; e, epiphallus; ec, epiphallus inner constriction; f, flagellum; mr, penial retractor muscle; $p$, penis; ppi, penial pilaster; ps, penis sheath; s, spermoviduct; v, vagina; vd, vas deferens. 

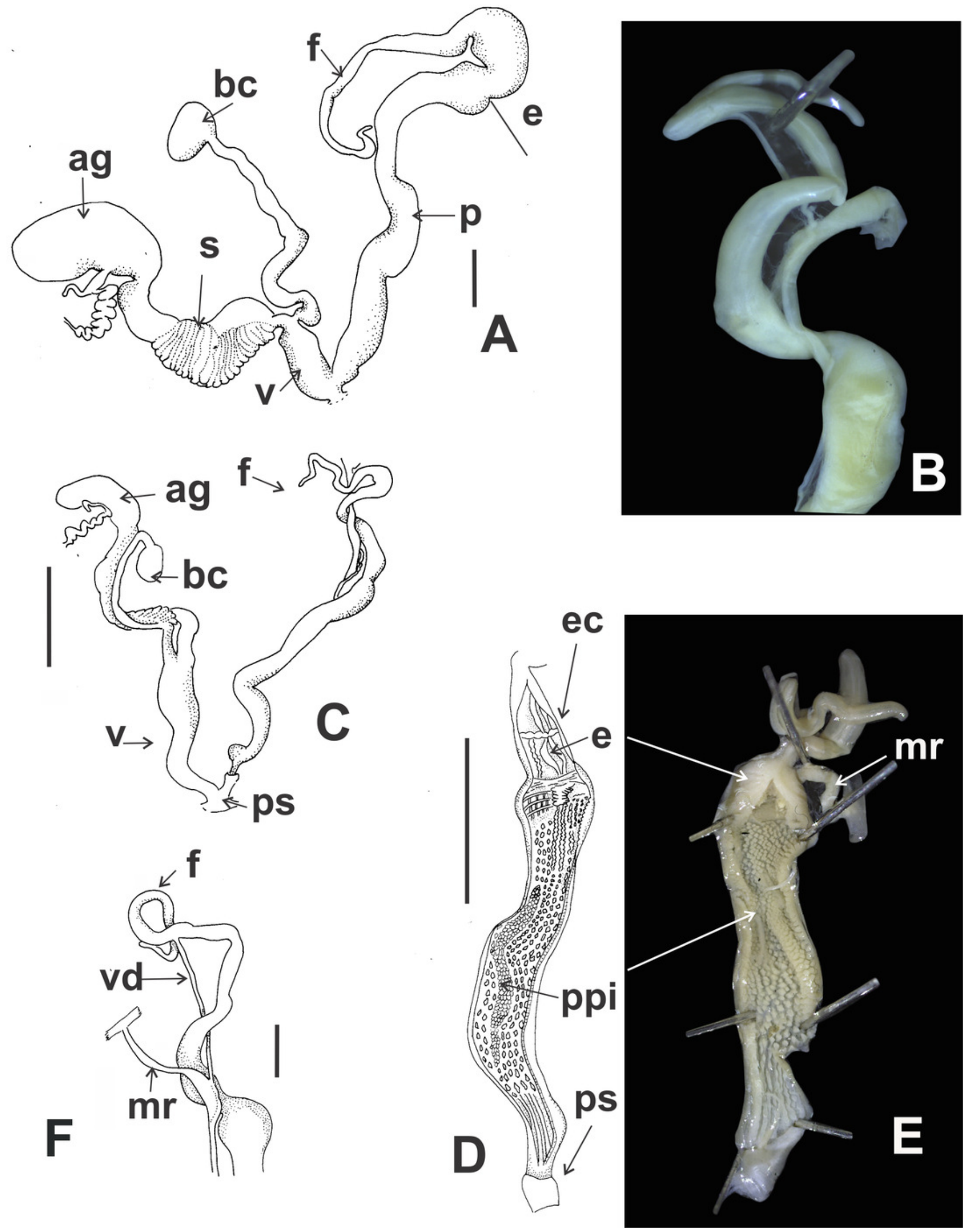


\section{Figure 13}

Clessinia pagoda, general shell morphology and habitat.

(A) Live specimen with a thick layer of sand granules covering periostracal sculpture. (B) Live specimen partially cleaned, crawling on granitic rock. (C-E) Paratype (MACN-In 27284) eroded shell without periostracal complex sculpture on ventral (C), lateral (D) and dorsal (E) views. $(F-H)$ Ventral $(F)$, lateral $(G)$ and dorsal $(H)$ views of a cleaned shell showing periostracal structures typical of the species, scale bar $=5 \mathrm{~mm}$. (I, J) Shape variability of the aperture, scale bar $=5 \mathrm{~mm}$. (K) View of the habitat in San Marcos Sierra on the road to Quilpo, type locality. (L) Typical microhabitat of C. pagoda. Photographs by M.G. Cuezzo. 

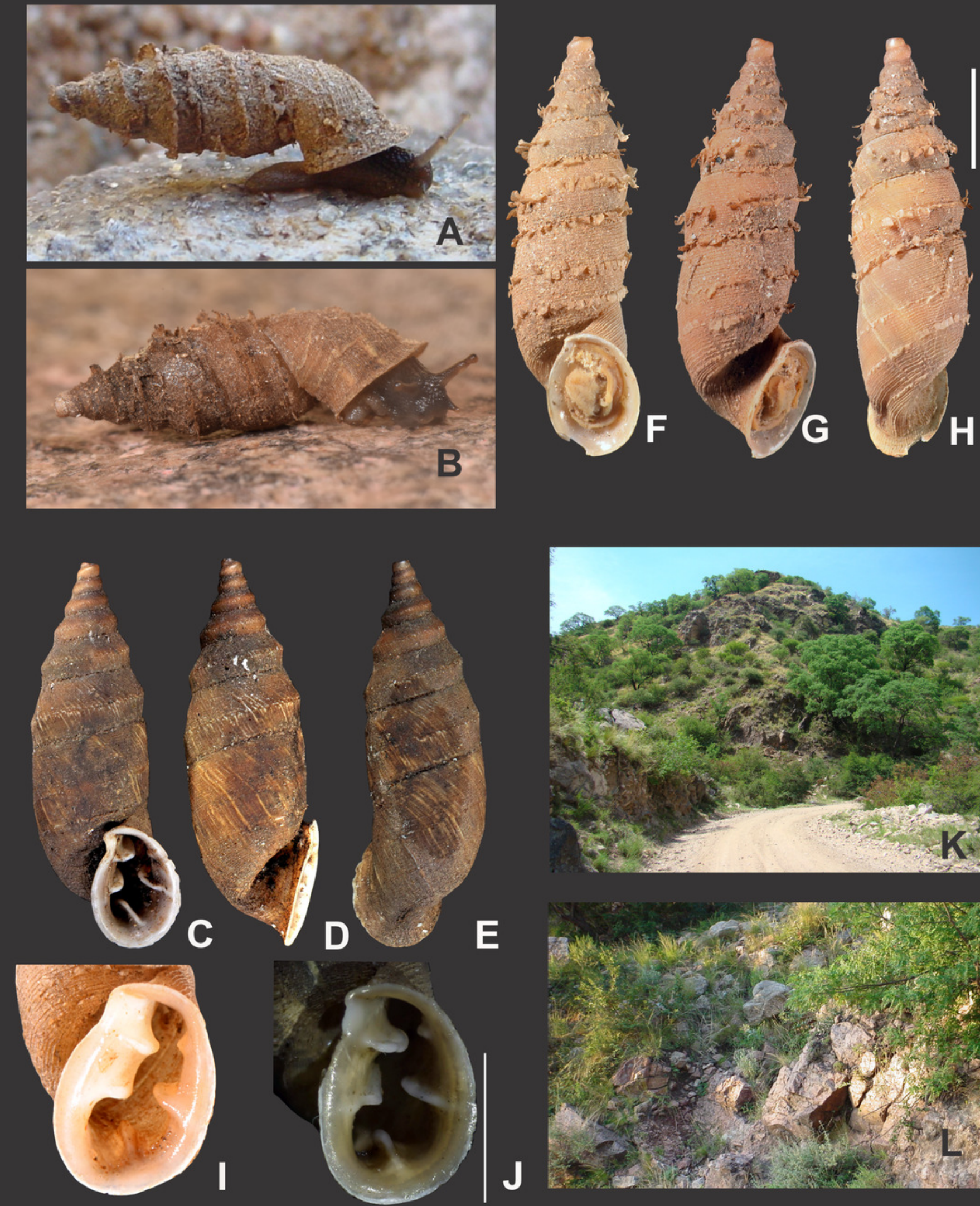

E
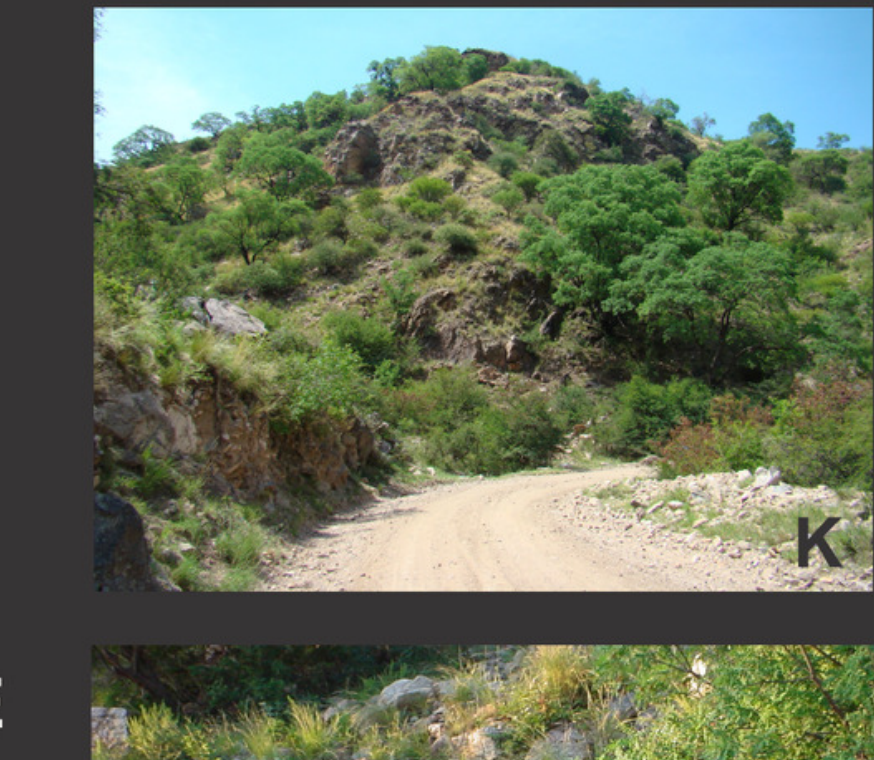

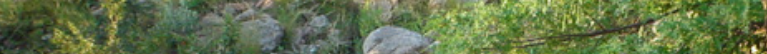
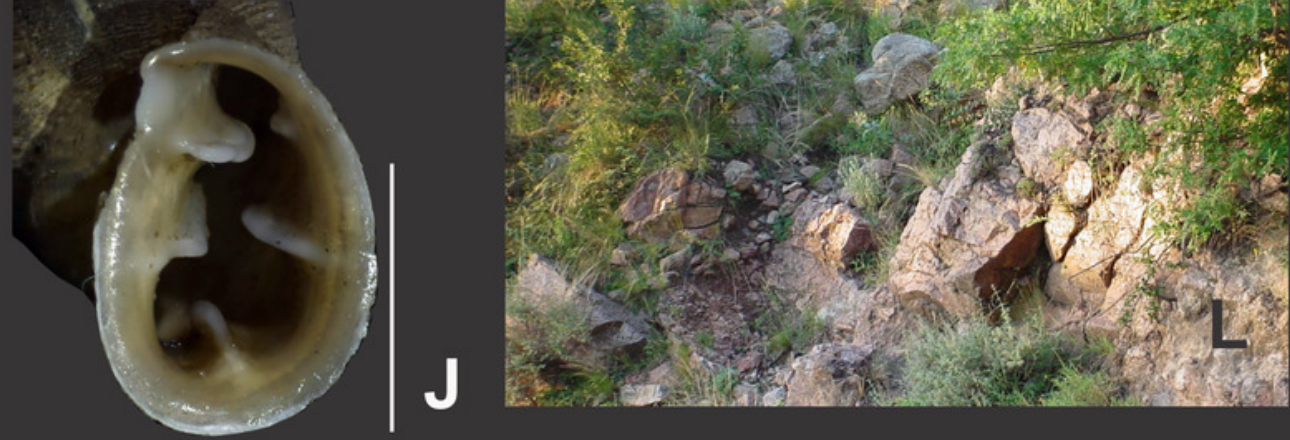


\section{Figure 14}

Clessinia pagoda, shell ultrastructure.

(A) Protoconch and following whorls of the spire, note the change of periostracal sculpture between protoconch and other whorls, scale bar $=100 \mu \mathrm{m}$. (B) Fourth and fifth shell whorls, note the spire line bearing lamellae located in the low portion of each teleoconch whorl, scale bar $=100 \mu \mathrm{m}$. (C) Lamellae superimposed with the following in a spiral row in the shell whorl, scale bar $=10 \mu \mathrm{m}$. (D) Detail of micro axial folds with the appearance of an irregular net in the space between minor rows, scale bar $=10 \mu \mathrm{m}$. (E) Lateral view of a teleoconch whorl with spiral major and minor rows, and the row bearing lamellas, scale bar $=200 \mu \mathrm{m}$. (F) Dorsal view of the body whorl showing the microsculpture prolonged over the expanded peristome, scale bar $=1000 \mu \mathrm{m}$. Photographs by M.G. Cuezzo. 

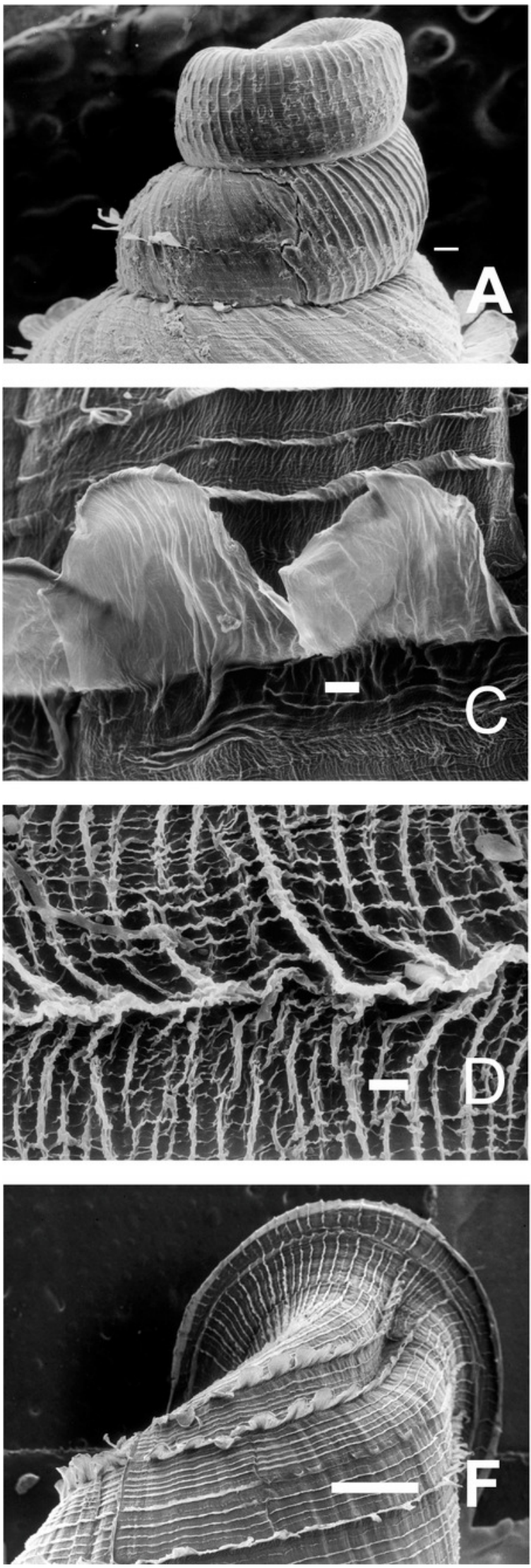
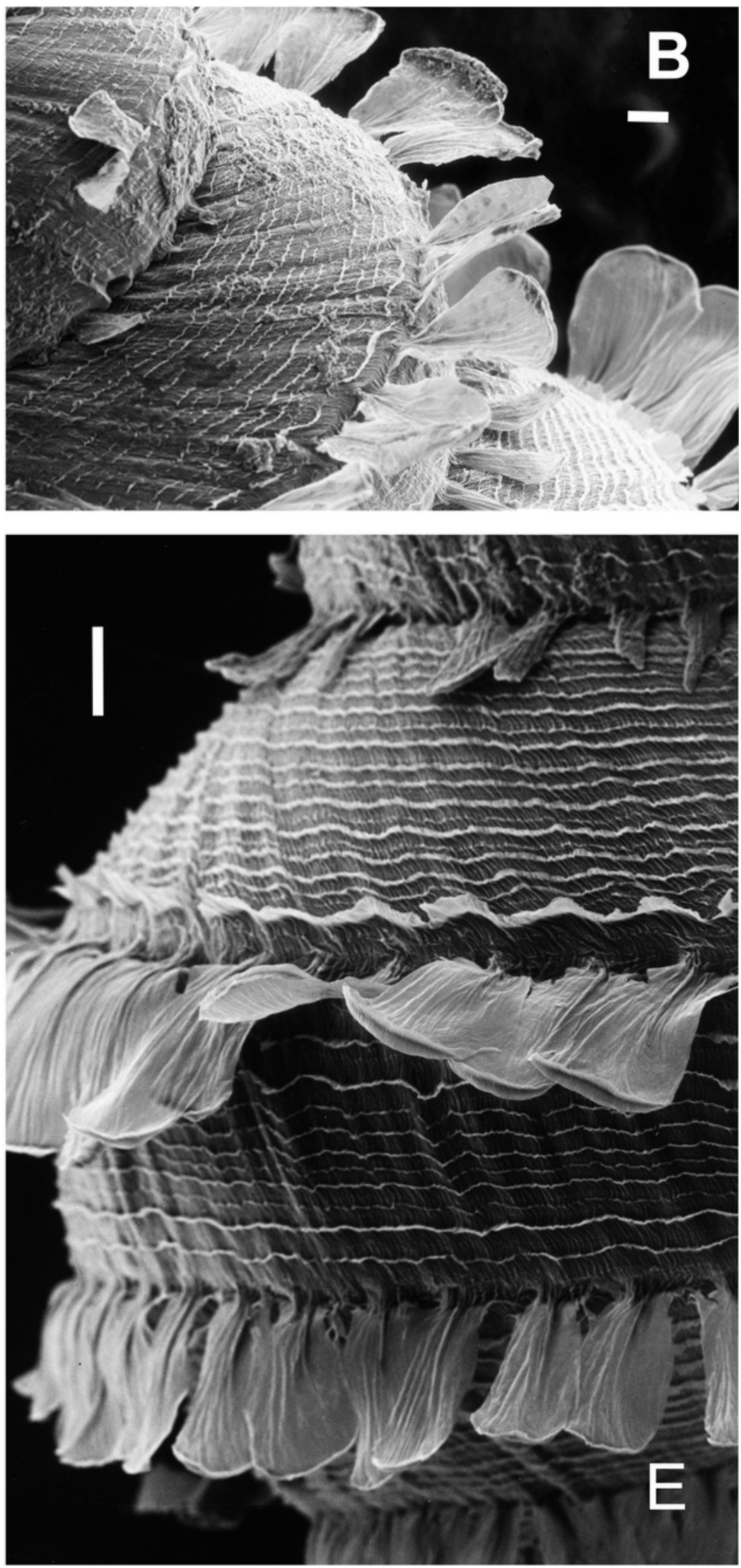


\section{Figure 15}

Clessinia pagoda, anatomy.

(A) General view of the ventral side of the pulmonary cavity, scale bar $=5 \mathrm{~mm}$. (B) Detail of the kidney, scale bar $=5 \mathrm{~mm}$. (C) General view of the reproductive system, limits penis/epiphallus and epiphallus/flagellum are indicated, scale bar $=5 \mathrm{~mm}$. (D) Detail of the fertilization pouch-spermathecal complex, scale bar $=2 \mathrm{~mm}$. (E) External view of the phallic complex, scale bar $=5 \mathrm{~mm}$. (F) Inner view showing the sculpture of epiphallus-penis wall, scale bar = $1 \mathrm{~mm}$. Abbreviations: ag, albumen gland; bc, bursa copulatrix; e, epiphallus; ec, epiphallus inner constriction; f, flagellum; fp, fertilization pouch-spermathecal complex; hd, hermaphroditic duct; k, kidney; mc, mantle collar; p, penis; pc, pericardium; pf, pulmonary fold; ps, penis sheath; r, rectum; s, spermoviduct; v, vagina. 


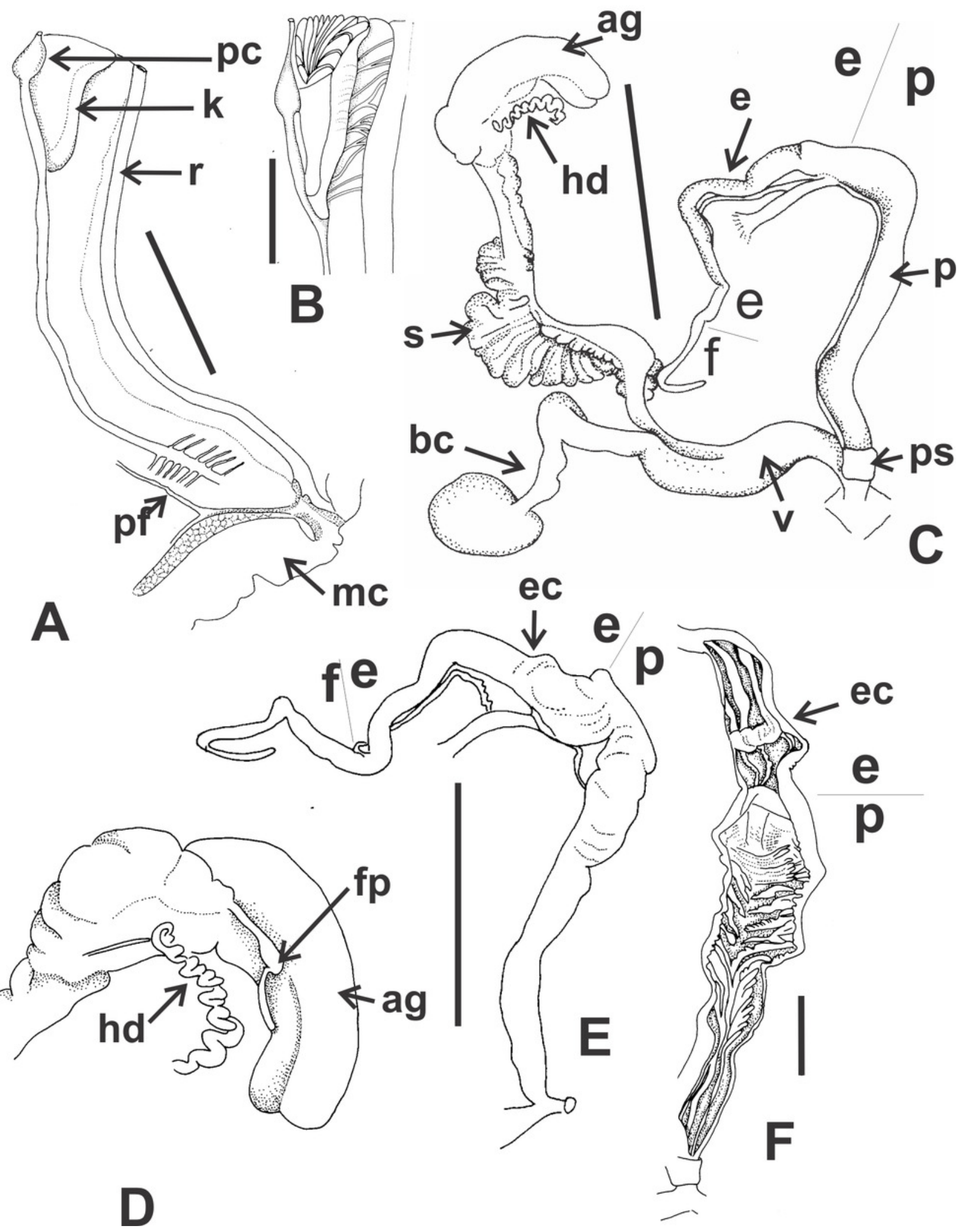




\section{Figure 16}

Clessinia nattkemperi, general shell morphology and habitat.

(A, B) Live specimens of Clessinia nattkemperi. (C) Ventral, (D) lateral and (E) dorsal views of the Holotype specimen (MACN-In 25713), note the eroded shell surface lacking all the periostracal ornamentation. (F) Ventral, $(G)$ lateral and $(H)$ dorsal views of a shell with periostracal ornamentation, scale bar $=3 \mathrm{~mm}$. (I-K) Detail of the teeth in a sub-oval (I), subquadrate (J), and narrower sub-oval (K) shell aperture, scale bar $=2 \mathrm{~mm}$. (L) View of the Chaco Serrano habitat of Clessinia nattkemperi in Catamarca. (M) View of the microhabitat of C. nattkemperi. (N) Live specimens between spines in cactuses. Photographs by M.G. Cuezzo. 

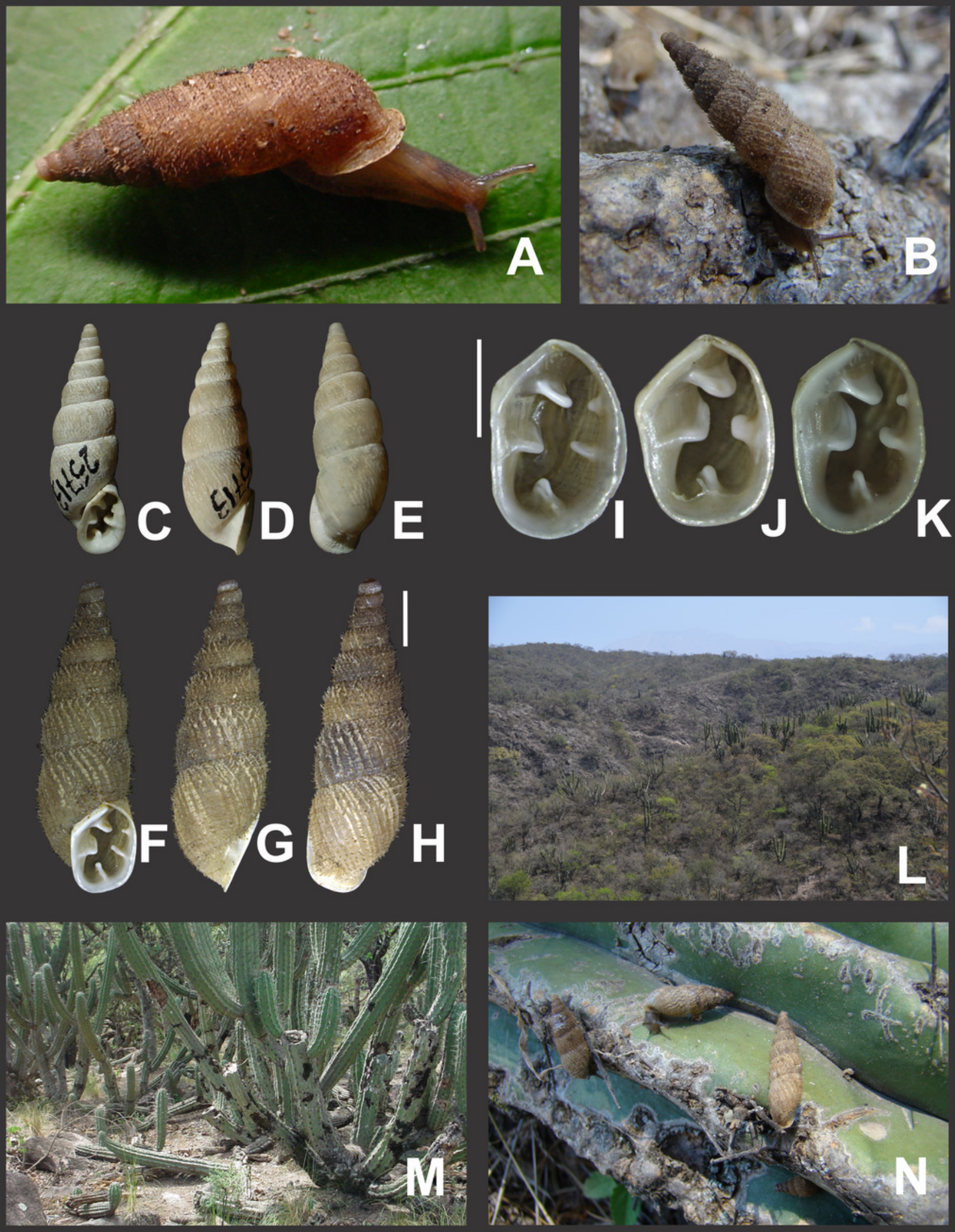


\section{Figure 17}

Clessinia nattkemperi, shell ultrastructure.

(A) Second and third whorls of the teleoconch showing general aspect of the sculpture, scale bar $=200 \mu \mathrm{m}$. (B) Spiral rows bearing triangular spines, scale bar $=100 \mu \mathrm{m}$. (C) Detail of the spines triangular shaped with wide base, scale bar $=10 \mu \mathrm{m}$. (D) Dorsal view of the body whorl at the level of the aperture showing microsculpture prolonged over peristome, scale bar $=1000 \mu \mathrm{m}$. (E) Lateral view of the body whorl with the detached aperture, scale bar $=$ $1000 \mu \mathrm{m}$. Photographs by M.G. Cuezzo.

*Note: Auto Gamma Correction was used for the image. This only affects the reviewing manuscript. See original source image if needed for review. 

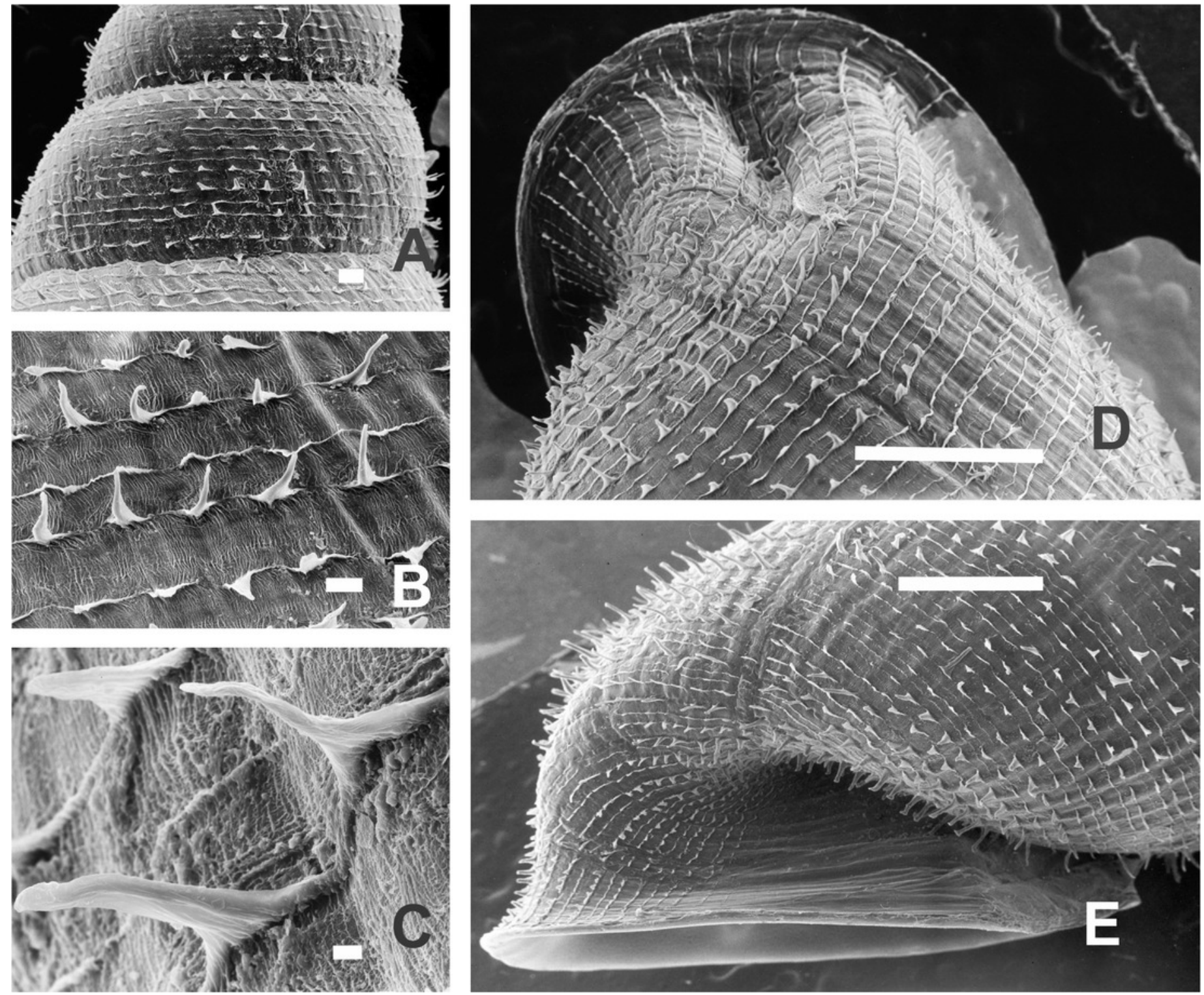


\section{Figure 18}

Clessinia nattkemperi, anatomy.

(A) General view of the reproductive system, scale bar $=5 \mathrm{~mm}$. (B) Exterior view of the phallic complex, limits penis/epiphallus and epiphallus/flagellum are indicated, scale bar $=5$

$\mathrm{mm}$. (C) Detail of inner wall sculpture of the epiphallus, scale bar $=1 \mathrm{~mm}$. (D) Detail of the inner sculpture of the penis wall, scale bar $=1 \mathrm{~mm}$. Abbreviations: ag, albumen gland; bc, bursa copulatrix; dp, penis distal portion; e, epiphallus; ef, epiphallic folds; ep, epiphallic papilla; f, flagellum; hd, hermaphroditic duct; $\mathrm{mp}$, penis medial portion; $\mathrm{mr}$, penis retractor muscle; p, penis, pp, proximal penis; ps, penis sheath; s, spermoviduct. 


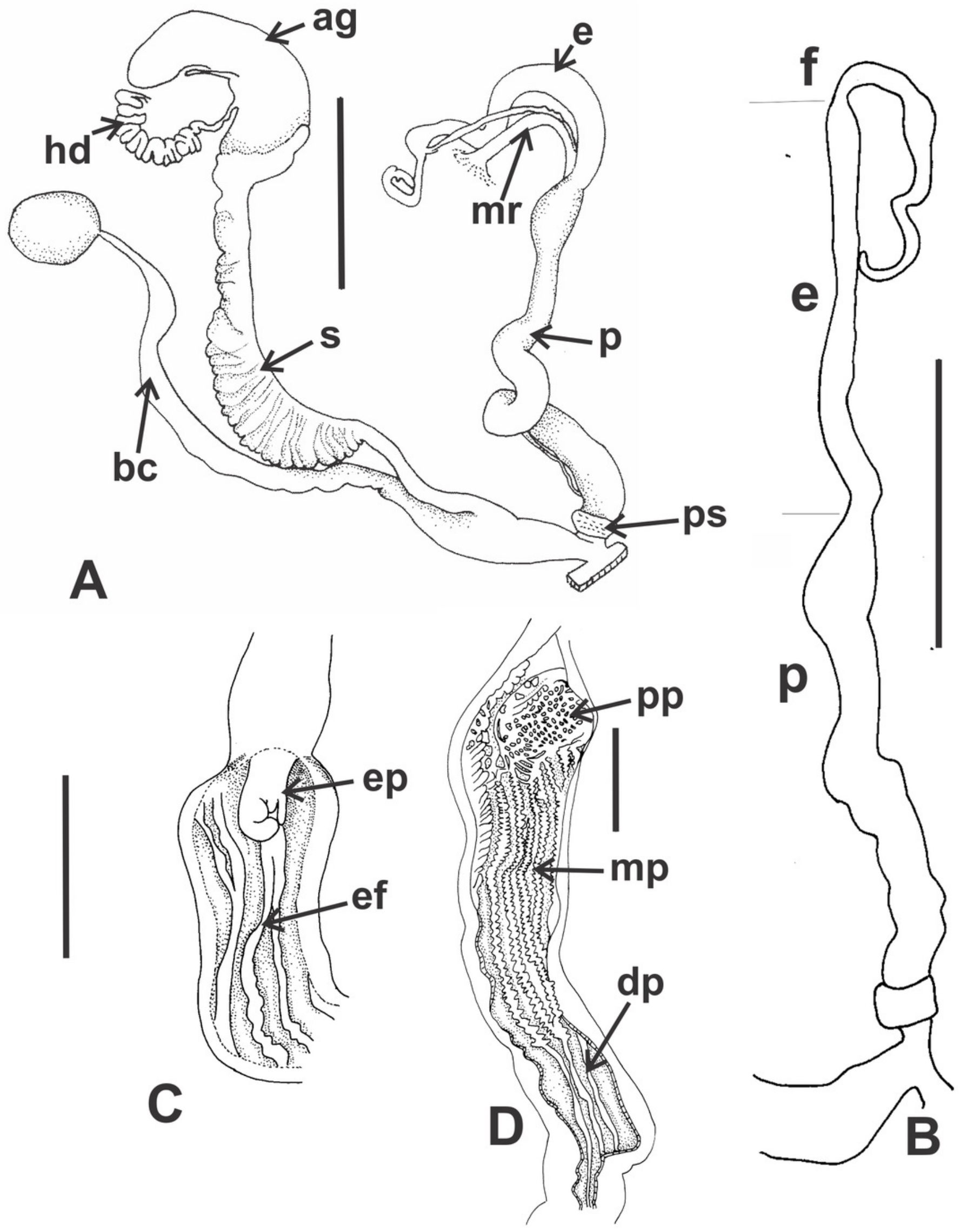




\section{Table $\mathbf{1}$ (on next page)}

Shell measurements among Clessinia species.

Abbreviations: body whorl height (Hbw), apertural height (Hap), total shell height $(\mathrm{H})$, apertural diameter (Dap), major diameter (Dm), and spire width (DS). Other variables measured on lateral view, were: shell minor diameter $(\mathrm{dm})$, shell minor diameter with peristome (dm1), and detached length $(\mathrm{Hc})$. 


\begin{tabular}{|c|c|c|c|c|c|c|c|c|c|c|c|c|c|c|c|c|c|c|c|c|}
\hline & \multicolumn{4}{|c|}{$\begin{array}{c}\text { Clessinia cordovana } \\
(\mathrm{n}=28)\end{array}$} & \multicolumn{4}{|c|}{$\begin{array}{c}\text { Clessinia stelzneri } \\
(\mathrm{n}=25)\end{array}$} & \multicolumn{4}{|c|}{$\begin{array}{c}\text { Clessinia tulumbensis } \\
(\mathrm{n}=61)\end{array}$} & \multicolumn{4}{|c|}{$\begin{array}{c}\text { Clessinia pagoda } \\
(\mathrm{n}=15)\end{array}$} & \multicolumn{4}{|c|}{$\begin{array}{c}\text { Clessinia nattkemperi } \\
(\mathrm{n}=15)\end{array}$} \\
\hline & $\begin{array}{l}\text { Mea } \\
\mathrm{n}\end{array}$ & SD & Min & Max & $\begin{array}{l}\text { Mea } \\
\mathrm{n}\end{array}$ & SD & Min & Max & \begin{tabular}{|l|} 
Mea \\
$\mathrm{n}$
\end{tabular} & SD & Min & Max & $\begin{array}{l}\text { Mea } \\
n\end{array}$ & SD & Min & Max & $\begin{array}{l}\text { Mea } \\
n\end{array}$ & SD & Min & $\operatorname{Max}$ \\
\hline $\mathrm{H}$ & $\begin{array}{l}17.3 \\
6 \\
\end{array}$ & 1.1 & \begin{tabular}{|l|}
15.5 \\
2 \\
\end{tabular} & $\begin{array}{l}19.8 \\
9\end{array}$ & $\begin{array}{l}18.1 \\
1\end{array}$ & $\begin{array}{l}0.8 \\
6 \\
\end{array}$ & $\begin{array}{l}16.8 \\
8\end{array}$ & $\begin{array}{l}20.4 \\
7\end{array}$ & \begin{tabular}{|l|}
16.7 \\
1 \\
\end{tabular} & $\begin{array}{l}1.1 \\
8\end{array}$ & $\begin{array}{l}10.5 \\
3\end{array}$ & $\begin{array}{l}18.9 \\
1\end{array}$ & $\begin{array}{l}18.6 \\
1 \\
\end{array}$ & $\begin{array}{l}0.8 \\
4 \\
\end{array}$ & $\begin{array}{l}16.9 \\
5\end{array}$ & $\begin{array}{l}20.2 \\
2\end{array}$ & $\begin{array}{l}16.7 \\
6 \\
\end{array}$ & $\begin{array}{l}0.9 \\
7 \\
\end{array}$ & $\begin{array}{l}15.3 \\
9\end{array}$ & $\begin{array}{l}18.7 \\
7 \\
\end{array}$ \\
\hline $\mathrm{Dm}$ & 3.84 & $\begin{array}{l}0.3 \\
8\end{array}$ & \begin{tabular}{|l}
3.29 \\
\end{tabular} & 4.63 & 4.67 & $\begin{array}{l}0.2 \\
8\end{array}$ & 4.01 & 5.20 & 4.03 & $\begin{array}{l}0.2 \\
4\end{array}$ & 3.48 & 4.56 & 5.6 & $\begin{array}{l}0.2 \\
5\end{array}$ & 5.17 & 5.98 & 4.81 & $\begin{array}{l}0.2 \\
1\end{array}$ & 4.51 & 5.27 \\
\hline DS & 4.83 & $\begin{array}{l}0.7 \\
3 \\
\end{array}$ & 3.8 & 6.2 & 3.86 & $\begin{array}{l}0.3 \\
2 \\
\end{array}$ & 3.4 & 4.4 & 4.48 & $\begin{array}{l}0.4 \\
8 \\
\end{array}$ & 3.7 & 5.9 & 4.15 & $\begin{array}{l}0.4 \\
6 \\
\end{array}$ & 3.5 & 5.1 & 4.75 & $\begin{array}{l}0.2 \\
2\end{array}$ & 4.3 & 5.1 \\
\hline $\begin{array}{l}\mathrm{Hb} \\
\mathrm{W}\end{array}$ & 7.97 & $\begin{array}{l}0.4 \\
9\end{array}$ & \begin{tabular}{|l|l}
7.24 \\
\end{tabular} & 9.34 & 8.59 & 0.4 & 7.89 & 9.39 & \begin{tabular}{|l|}
7.52 \\
\end{tabular} & $\begin{array}{l}0.3 \\
4\end{array}$ & 6.67 & 8.34 & $\begin{array}{l}10.7 \\
5\end{array}$ & $\begin{array}{l}0.5 \\
2\end{array}$ & 9.98 & $\begin{array}{l}11.7 \\
5\end{array}$ & 8.35 & $\begin{array}{l}0.4 \\
3\end{array}$ & 7.74 & 8.93 \\
\hline Dap & 3.35 & $\begin{array}{l}0.2 \\
9\end{array}$ & 2.71 & 3.77 & 3.84 & $\begin{array}{l}0.2 \\
3\end{array}$ & 3.33 & 4.35 & 3.25 & $\begin{array}{l}0.2 \\
7\end{array}$ & 2.69 & 3.83 & 4.37 & $\begin{array}{l}0.3 \\
3\end{array}$ & 3.58 & 4.91 & 3.88 & $\begin{array}{l}0.2 \\
2\end{array}$ & 3.54 & 4.32 \\
\hline Hap & 4.46 & $\begin{array}{l}0.2 \\
6\end{array}$ & 3.88 & 4.87 & 4.85 & $\begin{array}{l}0.3 \\
5\end{array}$ & 4.13 & 5.7 & 4.25 & $\begin{array}{l}0.2 \\
7\end{array}$ & 3.6 & 4.75 & 6.13 & 0.4 & 5.62 & 6.93 & 5.28 & $\begin{array}{l}0.2 \\
2\end{array}$ & 4.81 & 5.64 \\
\hline $\mathrm{Hc}$ & 1.95 & $\begin{array}{l}0.4 \\
5\end{array}$ & 1.24 & 2.84 & 2.22 & $\begin{array}{l}0.3 \\
1\end{array}$ & 1.65 & 2.72 & 1.73 & $\begin{array}{l}0.3 \\
8\end{array}$ & 0.84 & 2.66 & 2.53 & 0.4 & 1.74 & 3.06 & 1.34 & $\begin{array}{l}0.2 \\
5\end{array}$ & 0.92 & 1.64 \\
\hline $\mathrm{dm}$ & 3.87 & $\begin{array}{l}0.4 \\
3\end{array}$ & 3.3 & 4.62 & 4.67 & $\begin{array}{l}0.2 \\
8\end{array}$ & 4.01 & 5.2 & \begin{tabular}{|l|}
4.04 \\
\end{tabular} & $\begin{array}{l}0.2 \\
5\end{array}$ & 3.42 & 4.56 & 5.75 & $\begin{array}{l}0.3 \\
1\end{array}$ & 5.2 & 6.27 & 4.84 & $\begin{array}{l}0.1 \\
9\end{array}$ & 4.62 & 5.14 \\
\hline $\mathrm{dm} 1$ & 3.96 & $\begin{array}{l}0.4 \\
8\end{array}$ & 3.31 & 4.76 & 4.39 & $\begin{array}{l}0.4 \\
5\end{array}$ & 3.46 & 4.86 & \begin{tabular}{|l}
3.77 \\
\end{tabular} & $\begin{array}{l}0.3 \\
1\end{array}$ & 3.02 & 4.38 & 5.78 & $\begin{array}{l}0.4 \\
2\end{array}$ & 5.04 & 6.65 & 4.3 & $\begin{array}{l}0.3 \\
5\end{array}$ & 3.75 & 4.94 \\
\hline
\end{tabular}




\section{Table 2 (on next page)}

Collection information and GenBank accession numbers for the samples used herein for the molecular studies. 


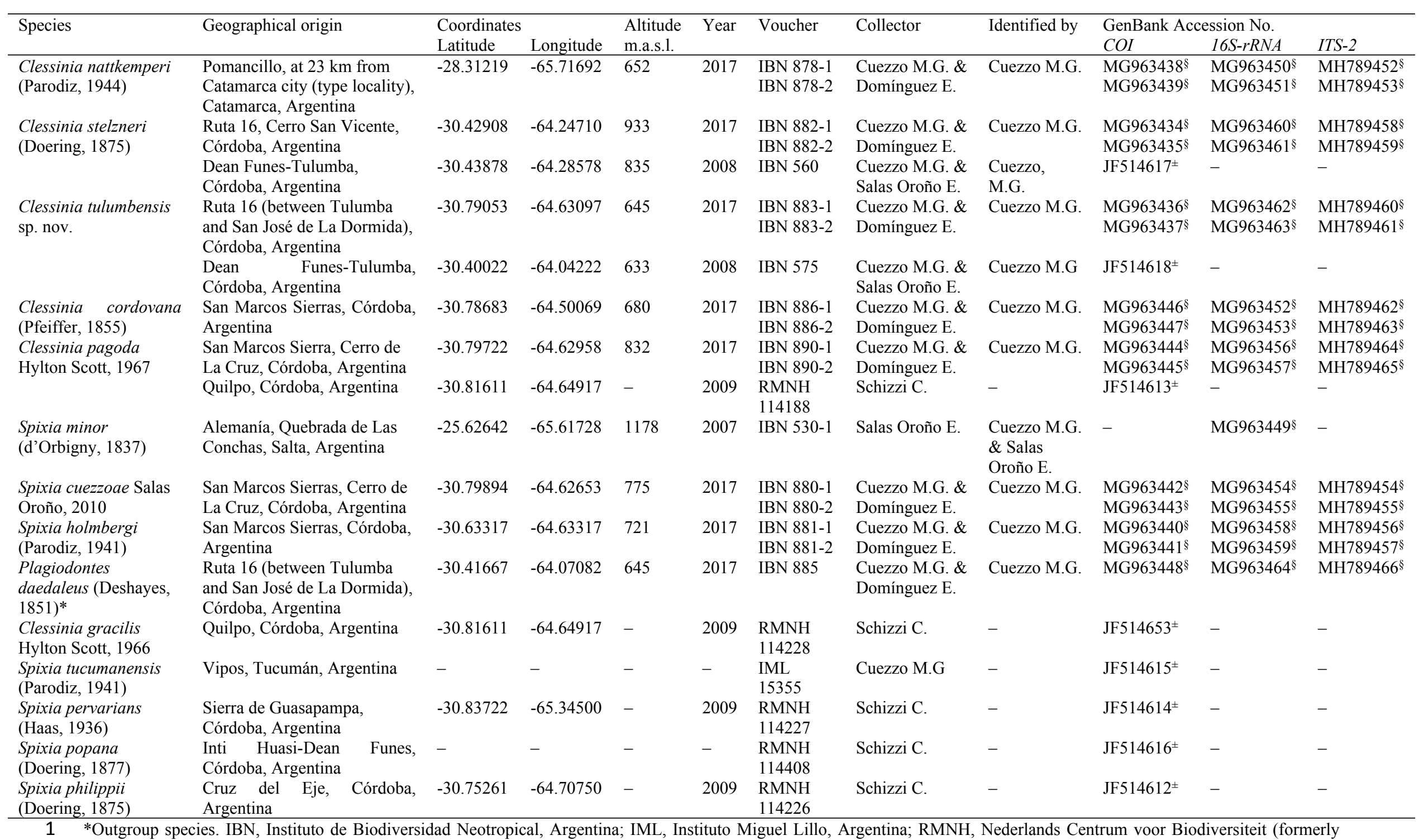

2 Rijksmuseum van Natuurlijke Historie), The Netherlands. Reference to sequences: ${ }^{\S}$ This work; ${ }^{ \pm}$Breure \& Romero (2012). 


\section{Table 3(on next page)}

Polymorphic positions based on a 822 bp DNA fragment of the 5.8S-ITS2-28S region for Clessinia and Spixia species. 


\begin{tabular}{|c|c|c|c|c|c|c|c|c|c|c|}
\hline & 113 & 117 & 140 & 233 & 310 & 311 & 361 & 469 & 516 & 712 \\
\hline C. tulumbensis sp. nov. & $\mathrm{C}$ & $\mathrm{C}$ & $\mathrm{A}$ & $\mathrm{G}$ & A & $\mathrm{G}$ & $\mathrm{C}$ & A & $\mathrm{A}$ & $\mathrm{C}$ \\
\hline C. stelzneri & . & . & . & . & . & . & . & . & . & . \\
\hline C. cordovana & A & A & . & . & G & . & . & . & $\cdot$ & . \\
\hline C. nattkemperi & $\mathrm{A}$ & . & . & . & . & $\mathrm{T}$ & $\mathrm{T}$ & G & . & . \\
\hline C. pagoda & $\mathrm{A}$ & . & . & . & . & . & $\cdot$ & $\cdot$ & . & . \\
\hline S. сиеzzoae & $\mathrm{A}$ & · & $\mathrm{C}$ & · & . & · & . & $\cdot$ & · & · \\
\hline S. holmbergi & A & . & . & $\mathrm{T}$ & . & . & . & . & $\mathrm{T}$ & $\mathrm{T}$ \\
\hline
\end{tabular}

1 Numbers indicate the position of variable sites. C. tulumbensis sp. nov. is shown as reference sequence; dot indicates identity 2 with the reference sequence. 


\section{Table 4 (on next page)}

Genetic distances in ITS-2 sequences among Clessinia and Spixia species.

Uncorrected (below the diagonal) and corrected (K2P; above the diagonal) distances are shown. 


\section{1}

\begin{tabular}{|c|c|c|c|c|c|c|c|c|c|c|c|c|c|c|c|c|}
\hline Species & $\begin{array}{l}\text { GenBank } \\
\text { No.* }\end{array}$ & ID & 1 & 2 & 3 & 4 & 5 & 6 & 7 & 8 & 9 & 10 & 11 & 12 & 13 & 14 \\
\hline \multirow[t]{2}{*}{ C. nattkemperi } & MH789452 & 1 & - & 0.000 & 0.006 & 0.006 & 0.005 & 0.005 & 0.004 & 0.004 & 0.007 & 0.007 & 0.005 & 0.005 & 0.005 & 0.005 \\
\hline & MH789453 & 2 & 0.000 & - & 0.006 & 0.006 & 0.005 & 0.005 & 0.004 & 0.004 & 0.007 & 0.007 & 0.005 & 0.005 & 0.005 & 0.005 \\
\hline \multirow[t]{2}{*}{ C. cordovana } & MH789462 & 3 & 0.006 & 0.006 & - & 0.000 & 0.004 & 0.004 & 0.002 & 0.002 & 0.006 & 0.006 & 0.004 & 0.004 & 0.004 & 0.004 \\
\hline & MH789463 & 4 & 0.006 & 0.006 & 0.000 & - & 0.004 & 0.004 & 0.002 & 0.002 & 0.006 & 0.006 & 0.004 & 0.004 & 0.004 & 0.004 \\
\hline \multirow[t]{2}{*}{ S. сиеzzoae } & MH789454 & 5 & 0.005 & 0.005 & 0.004 & 0.004 & - & 0.000 & 0.001 & 0.001 & 0.005 & 0.005 & 0.002 & 0.002 & 0.002 & 0.002 \\
\hline & MH789455 & 6 & 0.005 & 0.005 & 0.004 & 0.004 & 0.000 & - & 0.001 & 0.001 & 0.005 & 0.005 & 0.002 & 0.002 & 0.002 & 0.002 \\
\hline \multirow[t]{2}{*}{ C. pagoda } & MH789464 & 7 & 0.004 & 0.004 & 0.002 & 0.002 & 0.001 & 0.001 & - & 0.000 & 0.004 & 0.004 & 0.001 & 0.001 & 0.001 & 0.001 \\
\hline & MH789465 & 8 & 0.004 & 0.004 & 0.002 & 0.002 & 0.001 & 0.001 & 0.000 & - & 0.004 & 0.004 & 0.001 & 0.001 & 0.001 & 0.001 \\
\hline \multirow[t]{2}{*}{ S. holmbergi } & MH789456 & 9 & 0.007 & 0.007 & 0.006 & 0.006 & 0.005 & 0.005 & 0.004 & 0.004 & - & 0.000 & 0.005 & 0.005 & 0.005 & 0.005 \\
\hline & MH789467 & 10 & 0.007 & 0.007 & 0.006 & 0.006 & 0.005 & 0.005 & 0.004 & 0.004 & 0.000 & - & 0.005 & 0.005 & 0.005 & 0.005 \\
\hline \multirow[t]{2}{*}{ C. stelzneri } & MH789458 & 11 & 0.005 & 0.005 & 0.004 & 0.004 & 0.002 & 0.002 & 0.001 & 0.001 & 0.005 & 0.005 & - & 0.000 & 0.000 & 0.000 \\
\hline & MH789459 & 12 & 0.005 & 0.006 & 0.004 & 0.004 & 0.002 & 0.002 & 0.001 & 0.001 & 0.005 & 0.005 & 0.000 & - & 0.000 & 0.000 \\
\hline \multirow[t]{2}{*}{ C. tulumbensis sp. nov. } & MH789460 & 13 & 0.005 & 0.005 & 0.004 & 0.004 & 0.002 & 0.002 & 0.001 & 0.001 & 0.005 & 0.005 & 0.000 & 0.000 & - & 0.000 \\
\hline & MH789461 & 14 & 0.005 & 0.005 & 0.004 & 0.004 & 0.002 & 0.002 & 0.001 & 0.001 & 0.005 & 0.005 & 0.000 & 0.000 & 0.000 & - \\
\hline
\end{tabular}

*References to the sequences are provided in Table 1. 


\section{Table 5 (on next page)}

Genetic distances in 16S-rRNA sequences among Clessinia and Spixia species.

Uncorrected (below the diagonal) and corrected (K2P; above the diagonal) distances are shown. 


\begin{tabular}{|c|c|c|c|c|c|c|c|c|c|c|c|c|c|c|c|c|c|}
\hline Species & $\begin{array}{l}\text { GenBank } \\
\text { No.* }\end{array}$ & ID & 1 & 2 & 3 & 4 & 5 & 6 & 7 & 8 & 9 & 10 & 11 & 12 & 13 & 14 & 15 \\
\hline S. minor & MG963449 & 1 & - & 0.163 & 0.163 & 0.167 & 0.159 & 0.176 & 0.176 & 0.162 & 0.162 & 0.166 & 0.171 & 0.221 & 0.221 & 0.226 & 0.221 \\
\hline \multirow[t]{2}{*}{ C. nattkemperi } & MG963450 & 2 & 0.145 & - & 0.018 & 0.162 & 0.166 & 0.157 & 0.157 & 0.153 & 0.153 & 0.175 & 0.179 & 0.198 & 0.198 & 0.198 & 0.193 \\
\hline & MG963451 & 3 & 0.145 & 0.018 & - & 0.149 & 0.153 & 0.157 & 0.157 & 0.153 & 0.153 & 0.184 & 0.188 & 0.198 & 0.198 & 0.198 & 0.193 \\
\hline \multirow[t]{2}{*}{ C. cordovana } & MG963452 & 4 & 0.149 & 0.145 & 0.135 & - & 0.007 & 0.158 & 0.158 & 0.149 & 0.149 & 0.180 & 0.184 & 0.193 & 0.193 & 0.198 & 0.193 \\
\hline & MG963453 & 5 & 0.142 & 0.149 & 0.138 & 0.007 & - & 0.158 & 0.158 & 0.149 & 0.149 & 0.180 & 0.184 & 0.193 & 0.193 & 0.198 & 0.193 \\
\hline \multirow[t]{2}{*}{ S. cuezzoae } & MG963454 & 6 & 0.156 & 0.142 & 0.142 & 0.142 & 0.142 & - & 0.000 & 0.036 & 0.036 & 0.131 & 0.136 & 0.202 & 0.207 & 0.207 & 0.202 \\
\hline & MG963455 & 7 & 0.156 & 0.142 & 0.142 & 0.142 & 0.142 & 0.000 & - & 0.036 & 0.036 & 0.131 & 0.136 & 0.202 & 0.207 & 0.207 & 0.202 \\
\hline \multirow[t]{2}{*}{ C. pagoda } & MG963456 & 8 & 0.145 & 0.138 & 0.138 & 0.135 & 0.135 & 0.035 & 0.035 & - & 0.000 & 0.136 & 0.140 & 0.189 & 0.193 & 0.193 & 0.189 \\
\hline & MG963457 & 9 & 0.145 & 0.138 & 0.138 & 0.135 & 0.135 & 0.035 & 0.035 & 0.000 & - & 0.136 & 0.140 & 0.189 & 0.193 & 0.193 & 0.189 \\
\hline \multirow[t]{2}{*}{ S. holmbergi } & MG963458 & 10 & 0.149 & 0.156 & 0.163 & 0.160 & 0.160 & 0.121 & 0.121 & 0.124 & 0.124 & - & 0.007 & 0.193 & 0.198 & 0.198 & 0.193 \\
\hline & MG963459 & 11 & 0.152 & 0.160 & 0.167 & 0.163 & 0.163 & 0.124 & 0.124 & 0.128 & 0.128 & 0.007 & - & 0.193 & 0.198 & 0.198 & 0.193 \\
\hline \multirow[t]{2}{*}{ C. stelzneri } & MG963460 & 12 & 0.191 & 0.174 & 0.174 & 0.170 & 0.170 & 0.177 & 0.177 & 0.167 & 0.167 & 0.170 & 0.170 & - & 0.011 & 0.014 & 0.011 \\
\hline & MG963461 & 13 & 0.191 & 0.174 & 0.174 & 0.170 & 0.170 & 0.181 & 0.181 & 0.170 & 0.170 & 0.174 & 0.174 & 0.011 & - & 0.018 & 0.014 \\
\hline \multirow[t]{2}{*}{ C. tulumbensis sp. nov. } & MG963462 & 14 & 0.195 & 0.174 & 0.174 & 0.174 & 0.174 & 0.181 & 0.181 & 0.170 & 0.170 & 0.174 & 0.174 & 0.014 & 0.018 & - & 0.004 \\
\hline & MG963463 & 15 & 0.191 & 0.170 & 0.170 & 0.170 & 0.170 & 0.177 & 0.177 & 0.167 & 0.167 & 0.170 & 0.170 & 0.011 & 0.014 & 0.004 & - \\
\hline
\end{tabular}

*References to the sequences are provided in Table 1. 


\section{Table 6(on next page)}

Genetic distances in COI sequences among Clessinia and Spixia species.

Uncorrected (below the diagonal) and corrected (K2P; above the diagonal) distances are shown. 
1

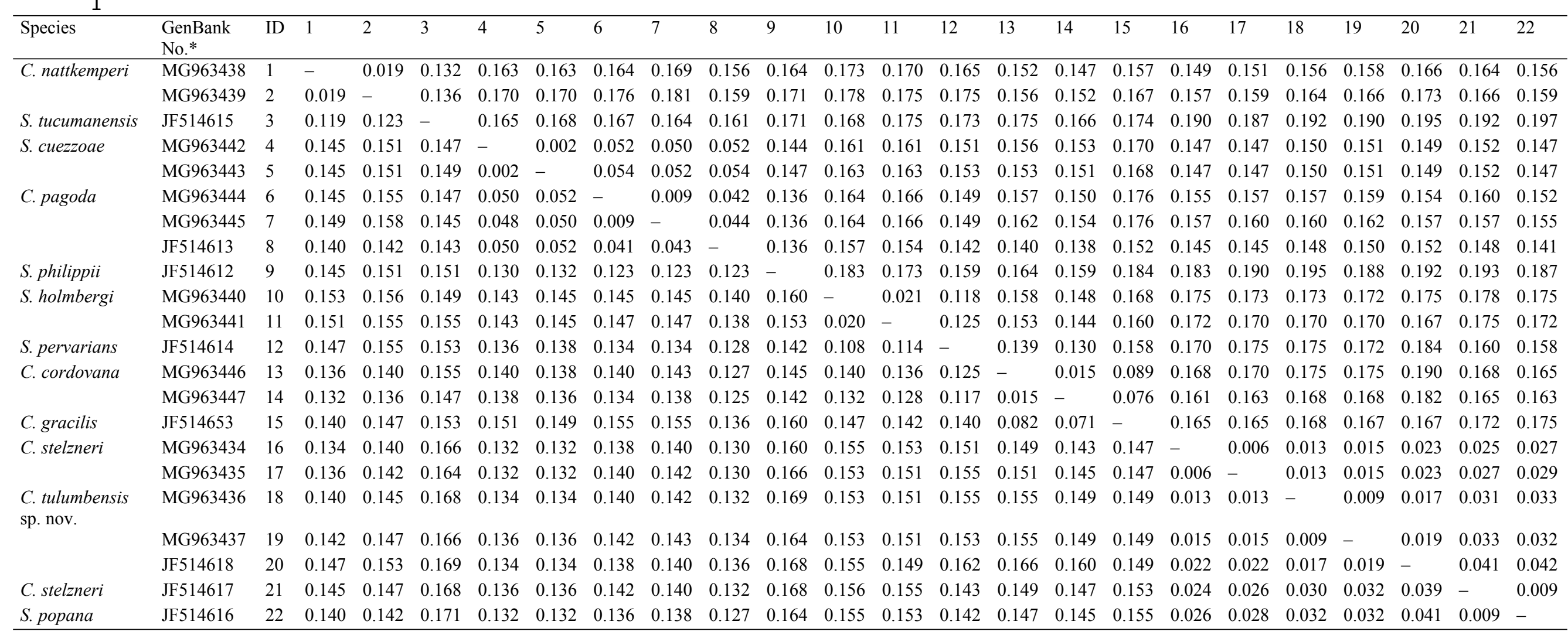

2 *References to the sequences are provided in Table 1. 


\section{Table 7 (on next page)}

Summary of results of $\mathrm{K} / \theta$ tests for Clessinia and Spixia species based on a multi-locus dataset (COI and 16S-rRNA). 


\begin{tabular}{|c|c|c|c|c|}
\hline Groups tested & $\theta_{1} \& \theta_{2}$ & $\boldsymbol{K}$ & $K / \theta$ ratio & n1, n2 \\
\hline \multirow[t]{2}{*}{ C. stelzneri-C. tulumbensis sp. nov. } & 0.01945946 & 0.017108882 & 0.88 & 2,2 \\
\hline & 0.01286174 & & 1.33 & \\
\hline \multirow{2}{*}{ C. pagoda-S. cuezzoae } & 0.01082642 & 0.0464957308 & 4.29 & 2,2 \\
\hline & 0.00214056 & & 21.72 & \\
\hline \multirow[t]{2}{*}{ C. pagoda $-S$. holmbergi } & 0.01082642 & 0.1481874665 & 13.69 & 2,2 \\
\hline & 0.03578084 & & 4.14 & \\
\hline \multirow[t]{2}{*}{ S. holmbergi-S. cuezzoae } & 0.03578084 & 0.1502558675 & 4.20 & 2,2 \\
\hline & 0.00214056 & & 70.19 & \\
\hline \multirow[t]{2}{*}{ C. cordovana -S. cuezzoae } & 0.03344482 & 0.1532695330 & 4.58 & 2,2 \\
\hline & 0.00214056 & & 71.60 & \\
\hline \multirow[t]{2}{*}{ C. cordovana -S. holmbergi } & 0.03344482 & 0.1648849724 & 4.93 & 2,2 \\
\hline & 0.03578084 & & 4.61 & \\
\hline \multirow{2}{*}{ C. cordovana - C. pagoda } & 0.03344482 & 0.1502652394 & 4.49 & 2,2 \\
\hline & 0.01082642 & & 13.88 & \\
\hline \multirow[t]{2}{*}{ C. nattkemperi-C. cordovana } & 0.04049494 & 0.1573729569 & 3.89 & 2,2 \\
\hline & 0.03344482 & & 4.70 & \\
\hline \multirow{2}{*}{ C. nattkemperi-S. cuezzoae } & 0.04049494 & 0.1649819496 & 4.07 & 2,2 \\
\hline & 0.00214056 & & 77.07 & \\
\hline \multirow[t]{2}{*}{ C. nattkemperi $-S$. holmbergi } & 0.04049494 & 0.1733817044 & 4.28 & 2,2 \\
\hline & 0.03578084 & & 4.85 & \\
\hline \multirow[t]{2}{*}{ C. nattkemperi-C. pagoda } & 0.04049494 & 0.1616734496 & 3.99 & 2,2 \\
\hline & 0.01082642 & & 14.93 & \\
\hline \multirow[t]{2}{*}{ C. stelzneri \& C. tulumbensis sp. nov. - C. nattkemperi } & 0.01921596 & 0.1739526225 & 9.05 & 4,2 \\
\hline & 0.04049494 & & 4.30 & \\
\hline \multirow[t]{2}{*}{ C. stelzneri \& C. tulumbensis sp. nov. - C. cordovana } & 0.01921596 & 0.1776448056 & 9.24 & 4,2 \\
\hline & 0.03344482 & & 5.31 & \\
\hline \multirow[t]{2}{*}{ C. stelzneri \& C. tulumbensis sp. nov. - S. cuezzoae } & 0.01921596 & 0.1687162889 & 8.78 & 4,2 \\
\hline & 0.00214056 & & 78.82 & \\
\hline \multirow[t]{2}{*}{ C. stelzneri \& C. tulumbensis sp. nov. - S. holmbergi } & 0.01921596 & 0.1810391204 & 9.42 & 4,2 \\
\hline & 0.03578084 & & 5.06 & \\
\hline \multirow[t]{2}{*}{ C. stelzneri \& C. tulumbensis sp. nov. - C. pagoda } & 0.01921596 & 0.1706482546 & 8.88 & 4,2 \\
\hline & 0.01082642 & & 15.76 & \\
\hline
\end{tabular}

1

$\theta$, mean pairwise sequence difference within a clade; $K$, mean pairwise sequence difference between clades; $\mathrm{n} 1, \mathrm{n} 2, \mathrm{number}$ of sequences within each of the clades compared. 